\title{
The Piccolo in the 21st Century: History, Construction, and Modern Pedagogical Resources
}

\author{
Keith D. Hanlon
}

Follow this and additional works at: https://researchrepository.wvu.edu/etd

\section{Recommended Citation}

Hanlon, Keith D., "The Piccolo in the 21st Century: History, Construction, and Modern Pedagogical Resources" (2017). Graduate Theses, Dissertations, and Problem Reports. 5756.

https://researchrepository.wvu.edu/etd/5756

This Dissertation is protected by copyright and/or related rights. It has been brought to you by the The Research Repository @ WVU with permission from the rights-holder(s). You are free to use this Dissertation in any way that is permitted by the copyright and related rights legislation that applies to your use. For other uses you must obtain permission from the rights-holder(s) directly, unless additional rights are indicated by a Creative Commons license in the record and/ or on the work itself. This Dissertation has been accepted for inclusion in WVU Graduate Theses, Dissertations, and Problem Reports collection by an authorized administrator of The Research Repository @ WVU.

For more information, please contact researchrepository@mail.wvu.edu. 
THE PICCOLO IN THE $21^{\text {ST }}$ CENTURY: HISTORY, CONSTRUCTION, AND MODERN PEDAGOGICAL RESOURCES

\author{
Keith D. Hanlon \\ Dissertation submitted \\ to The College of Creative Arts \\ at West Virginia University \\ in partial fulfillment of the requirements for the degree of \\ Doctor of Musical Arts \\ in Flute Performance

\begin{abstract}
Committee
Lynn Hileman, DMA, Committee Chair

Nina Assimakopoulos, MM, Primary Research Advisor

Beth Royall, MLIS, MM, Secondary Research Advisor

Keith Jackson, DMA

Mary Ferer, $\mathrm{PhD}$
\end{abstract}

School of Music

Morgantown, West Virginia

2017

Keywords: piccolo, piccolo pedagogy, piccolo history, piccolo resources, piccolo construction, piccolo manufacture

Copyright 2017 Keith D. Hanlon 


\begin{abstract}
The Piccolo in the $21^{\text {st }}$ Century: History, Construction, and Modern Pedagogical Resources
\end{abstract}

Keith D. Hanlon

The piccolo and the flute have the same origin and share similar historical developments; however, they require different approaches to attain high levels of proficiency. The flute benefits from a well-documented history of construction, a lineage of pedagogy, and a vast repertoire while the piccolo has not shared the same prestige. Initially utilized as military instrument and seen as an auxiliary instrument by many, the piccolo has become an integral part of the modern orchestra. Unfortunately, the piccolo did not receive the same pedagogical attention as the flute until more recently. With the limited availability of piccolo teachers and reliable method books, most players have had to learn to play the piccolo on their own. It is only in the last few decades that the piccolo has become a respected solo and chamber instrument prompting the development of method books and teachers specializing in the piccolo.

In the early 1970s, growth in the solo repertoire for the piccolo and the desire of performers to specialize on the instrument produced master piccolo teachers who are now publishing methods for the instrument. These specialists have been promoting the piccolo's prominence in the new millennium and inspiring the next generation of piccolo players to specialize. The purpose of this document is to provide both teachers and students with a reference that includes a broad understanding of the historical use and mechanical development of the piccolo as well as an annotated bibliography of piccolo articles and research. 


\section{Acknowledgments}

Thank you to my committee for seeing me through this adventure. It was several years in the making. Thank you for setting professional goals for me and being examples of collegiality, and mostly, for not losing faith in me.

Thank you to Nicola Mazzanti for your friendship and wonderful guidance. I have enjoyed our chats and your fire for the piccolo was the spark that set me on to my research.

Therese Wacker, your friendship and ear have been constants along my journey and I appreciate your continued support of my career and the initial push that helped me get started on this path.

A special thank you to Michael Lynn and Robert Bigio for your puzzle solving skills, knowledge, and friendship. It is nice to know that you both are only an email away.

Thank you, Liz Woolfolk, for your continued support. You always have my back and never let me down. Serving with you and being your friend was, and still is, an honor. Love you!

Carl Adams and Francile Bilyeu, whose friendship and guidance over the years along with the good swift kicks when I needed them were most appreciated. I cherish your musical guidance and remember our weekly lessons fondly. Without you both, I would not be where I am today.

Thank you, Mom, for all that you have done raising three children on your own. You have always managed to find the energy to be a loving and supportive parent. I am your biggest fan and you are my most supportive critic. Thank you for the gift of music. I love you.

Most of all, thank you to my husband Dustin. Who has been a constant support throughout this process and cheered me on from the start. We have survived several moves for school and work, and our family has grown. You have always been very patient with me during my most stressful times. I could not imagine having done this without the support and love that you have given me. I love you. 
Table of Contents

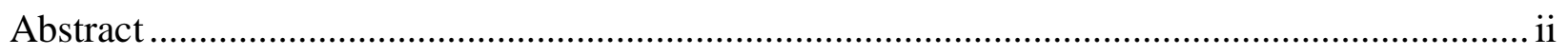

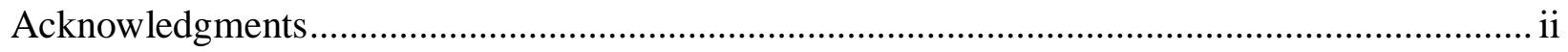

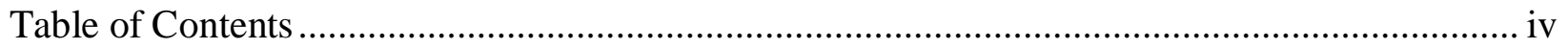

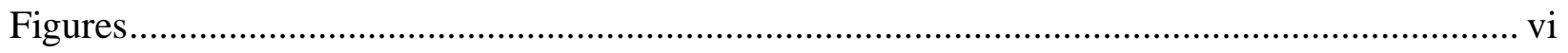

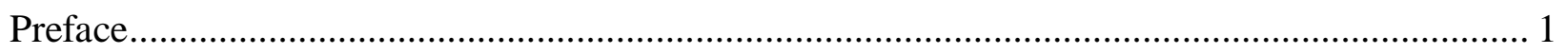

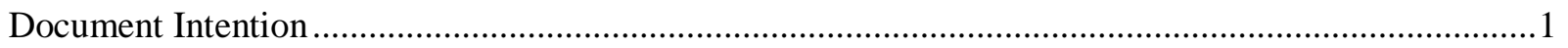

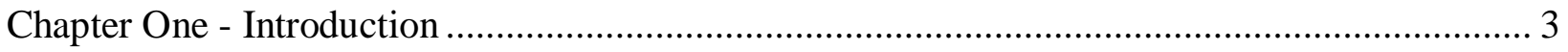

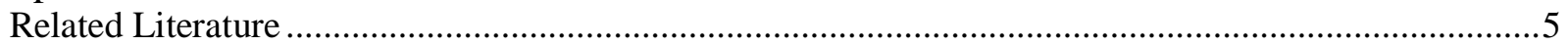

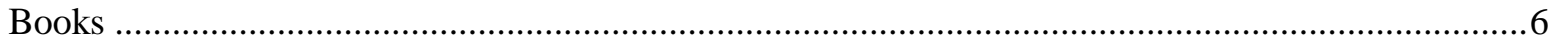

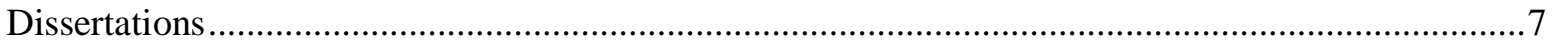

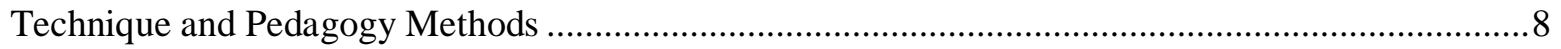

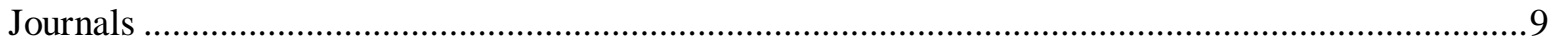

Procedure …

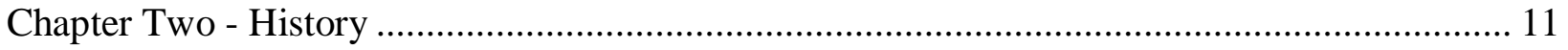

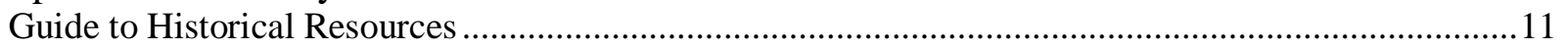

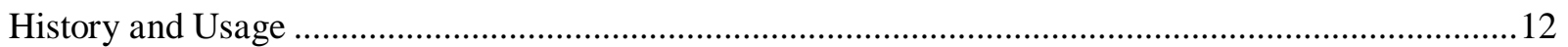

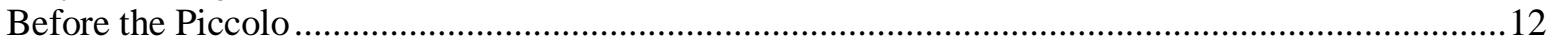

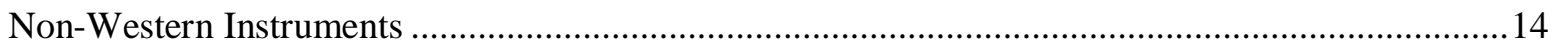

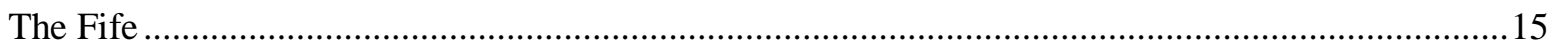

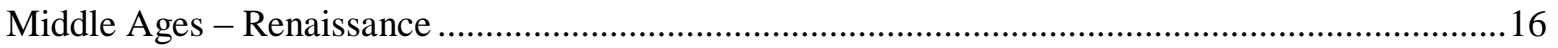

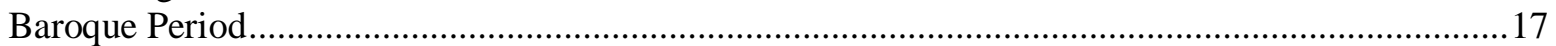

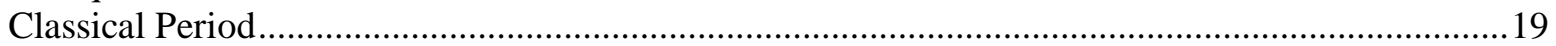

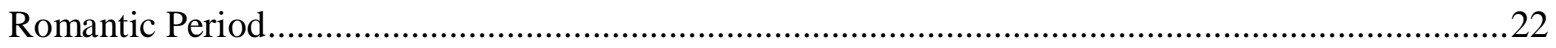

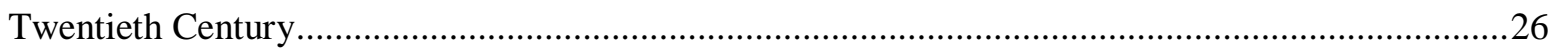

Chapter Three - Mechanical Development ..................................................................... 31

Chronological Mechanical Development by Period ...........................................................................

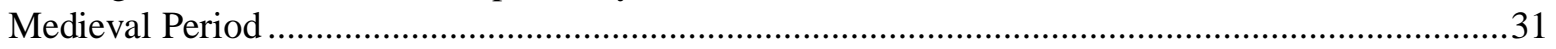

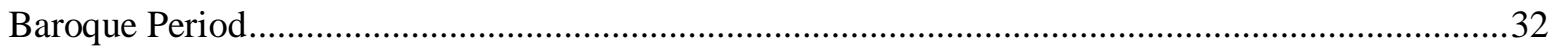

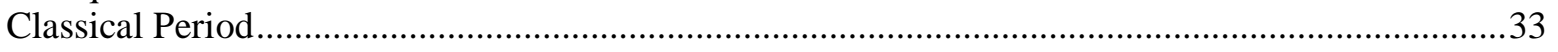

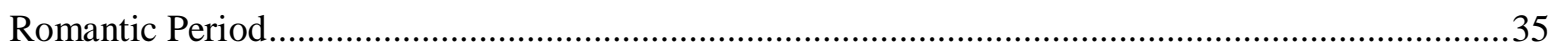

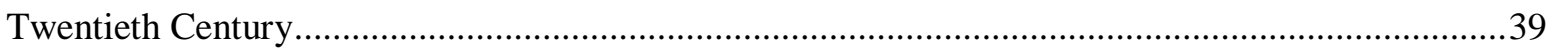

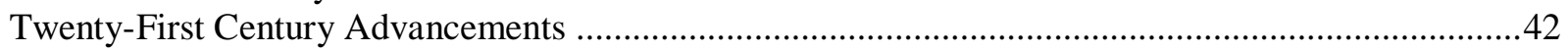

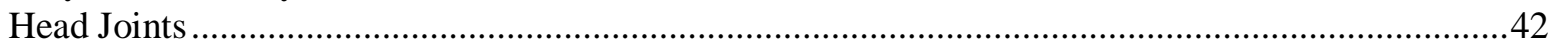

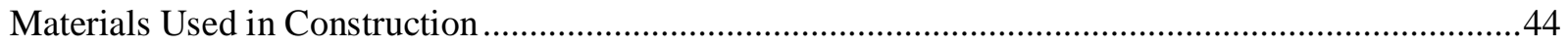

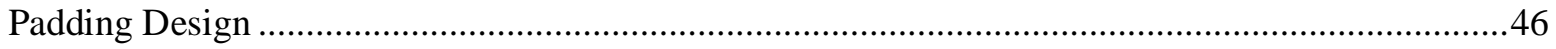

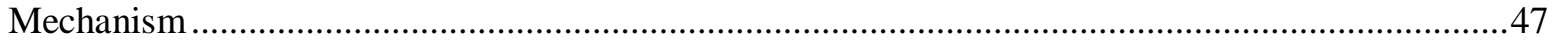

Chapter Four - Problematic Pedagogy ...................................................................... 54

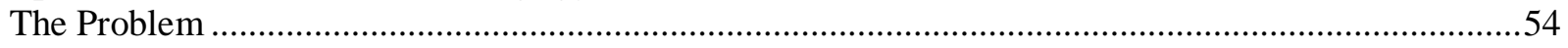

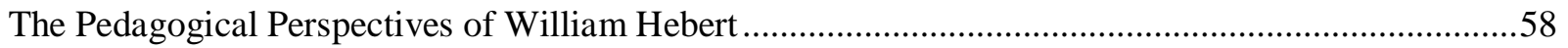




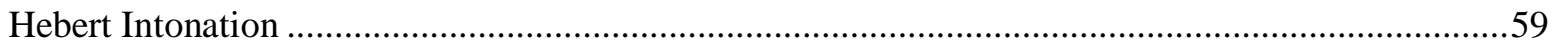

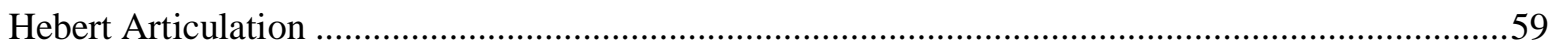

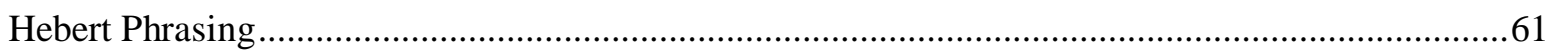

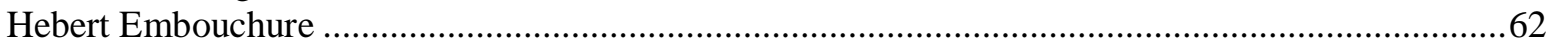

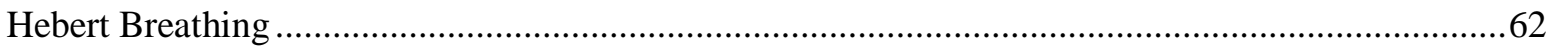

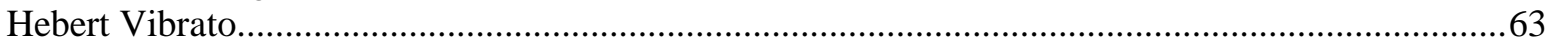

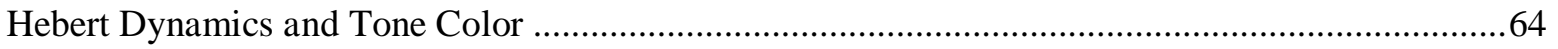

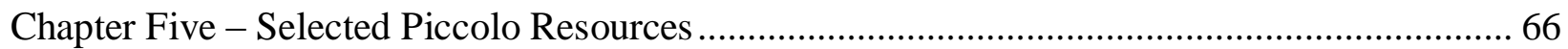

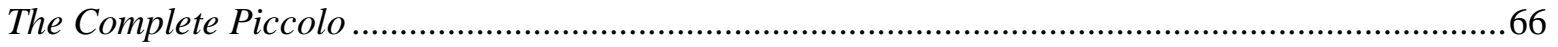

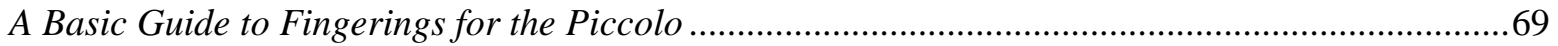

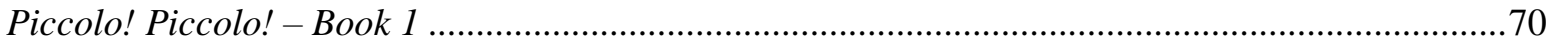

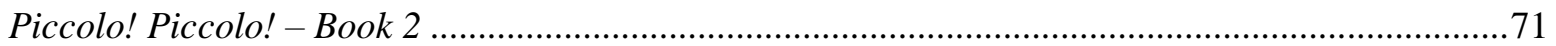

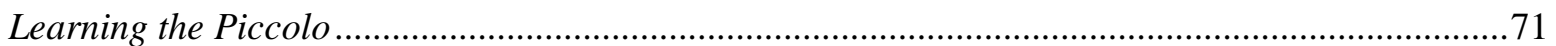

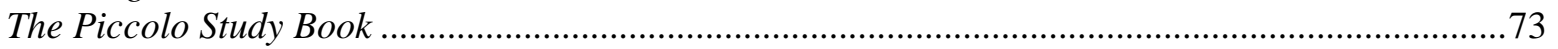

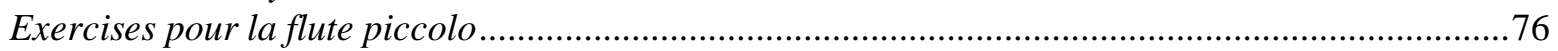

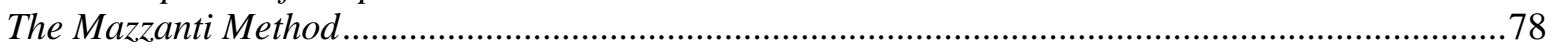

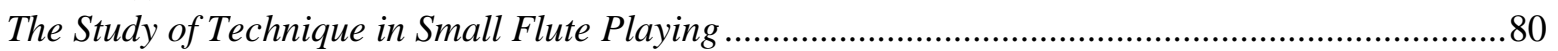

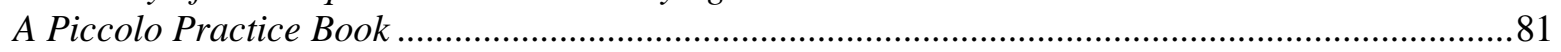

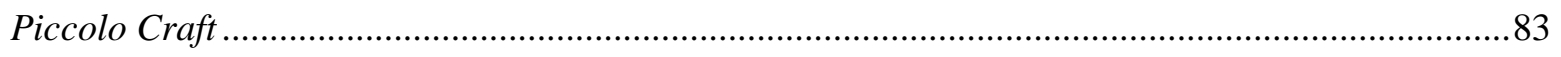

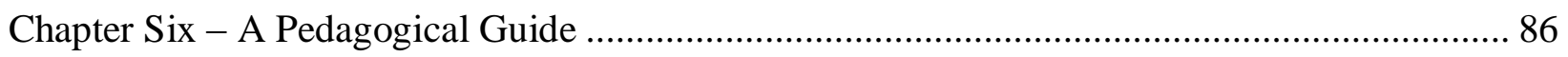

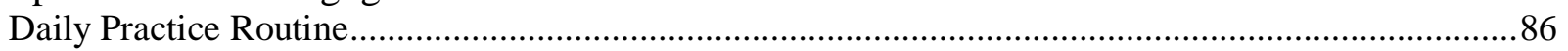

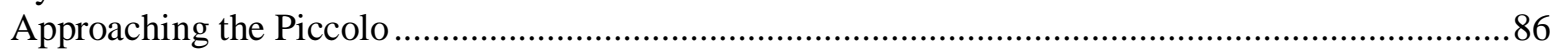

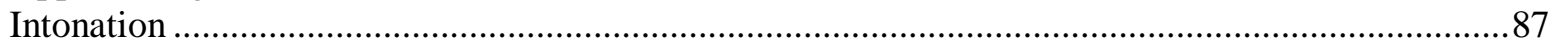

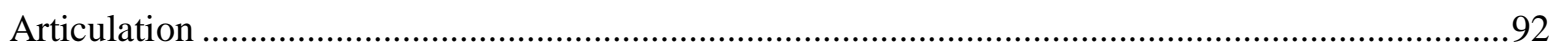

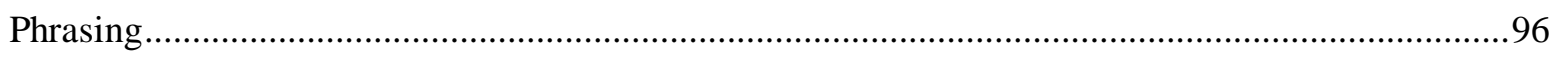

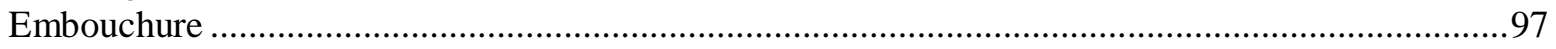

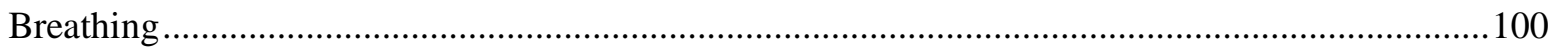

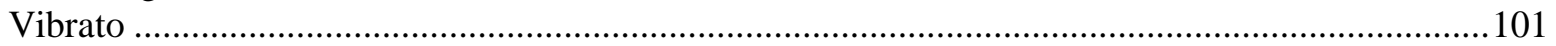

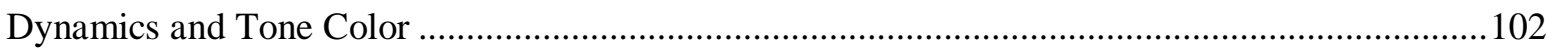

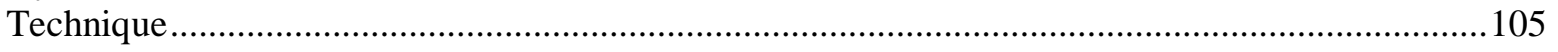

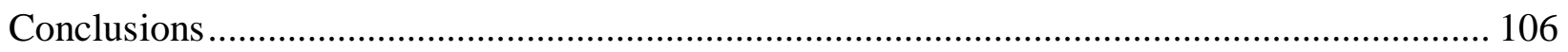

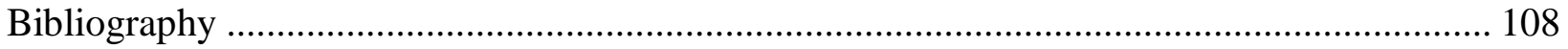

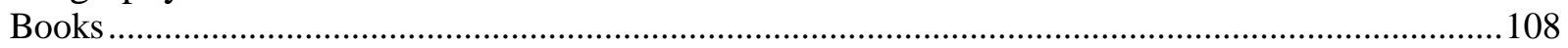

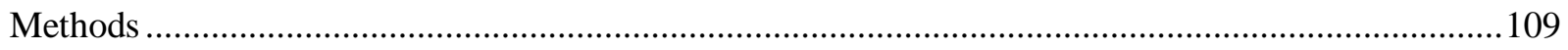

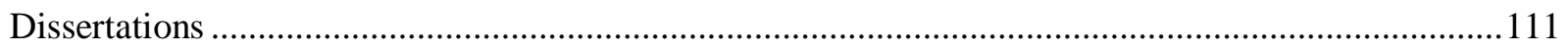

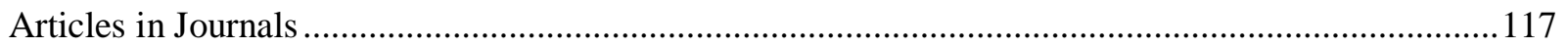




\section{Figures}

Figure 1. Pitch Notation Chart ................................................................................................ vii

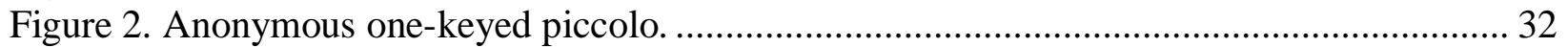

Figure 3. Anonymous English six-key, E-flat military piccolo, circa 1890 ............................ 34

Figure 4. Anonymous German reform piccolo in the style of Schwedler, circa 1890............... 37

Figure 5. Anonymous English piccolo, circa 1870 ......................................................... 38

Figure 6. Thibouville Cabart ring-system piccolo, circa 1878 .............................................. 38

Figure 7. Jean-Louis Tulou, Paris. six-key D-flat Piccolo, Pitch A=435. Photo Michael Lynn .. 40

Figure 8. Boehm-system by Emil Rittershausen, Carl Fischer stencil piccolo, circa 1927......... 41

Figure 9. Carl Fischer silver conical D-flat piccolo, circa 1925 ......................................... 41

Figure 10. Conn Pan American model with ebonite head and silver body, circa 1925 .............. 46

Figure 11. Keefe Brossa F sharp....................................................................................... 49

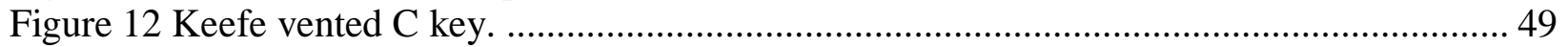

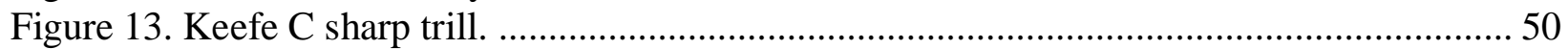

Figure 14. Keefe G\# Trill Mechanism............................................................................. 50

All photos were taken by the author unless otherwise indicated. 
Scientific pitch notation (SPN), also known as American Standard Pitch Notation (ASPN) will be utilized for this document. This system is based on the pitch nomenclature system developed by Hermann Von Helmholtz, known as the "Helmholtz system." This system uses integers rather than tick marks to specify octave designations. It denotes middle $\mathrm{C}$ as $\mathrm{C} 4$ increasing by 1 for each ascending octave and a decrease by 1 for each descending octave. As the piccolo is a transposing instrument, notation will be referenced as "written," rather than “sounding," pitch.

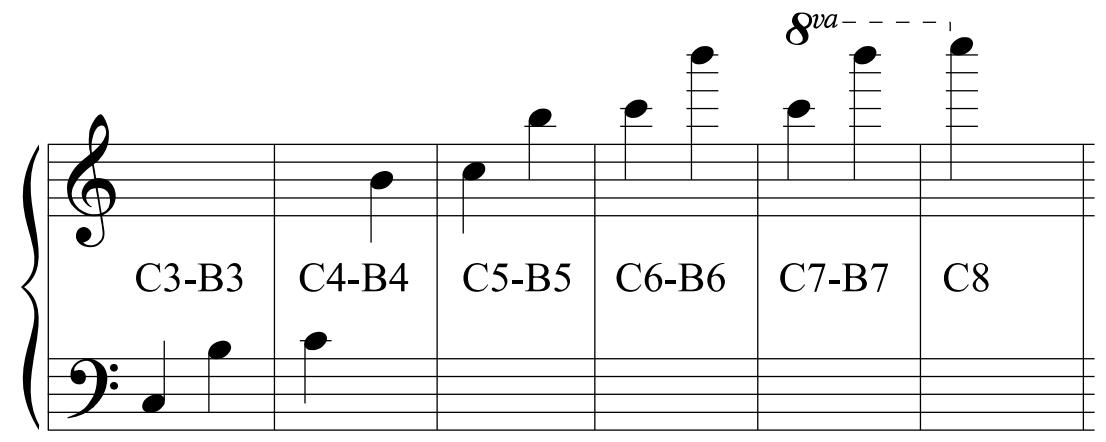

Figure 1. Pitch Notation Chart 


\section{Preface}

\section{Document Intention}

While the flute and the piccolo share the same origins and similar historical developments, they are different instruments requiring different approaches to attain a high level of proficiency. There has always been an expectation that flutists, by default, are also piccolo players. The inherent problem faced is one of insufficient piccolo training and instruction to develop their skills. Many flutists are asked in middle school or high school to play piccolo in the band and for most this becomes an exercise in learning by trial and error. Very few young flutists have access to a private teacher who also teaches the piccolo. It may not be until a student seeks out piccolo study in college with a knowledgeable teacher or in a program that offers piccolo specialization, that they are able to experience even a minimal amount of training on the piccolo.

The purpose of this document is to provide both teachers and students with a reference that includes a broad understanding of the historical use and mechanical development of the piccolo as well as an annotated bibliography of piccolo articles and research. This document compiles peer-reviewed research about the piccolo and focuses on piccolo-specific resources and their potential application in training and developing the modern piccolo player. This writing summarizes and outlines nine method books and available modern (post-1960) in-print resources and provides some guidance on the application of the content in applied instruction. Sources included are those that focus on the piccolo explicitly or contain substantial sections dedicated to the piccolo including but not limited to: method books, fingering charts, dissertations, journal articles, and treatises in English. Sources that are focused primarily on the flute or address the flute and piccolo as the same instrument, for example, "method for flute and piccolo," will be excluded. Non-print online sources such as videos, blogs, and podcasts, as well as other audio 
and video format sources will also be excluded because it is beyond the scope of this document.

Chapter one introduces the topic of piccolo pedagogy and discusses the historical precedent that has been set, leading to the limited number of resources focused on teaching the piccolo. It also identifies the core resource material used for the historical and mechanical development chapters of this document. Chapter two outlines the historical development of the piccolo from bone flute artifacts to the piccolo of the twenty-first century. Chapter three outlines the mechanical development of the piccolo from the simplest (keyless) form to the instruments used in modern performances and connects these developments to Chapter two. Topics covered in the chapter include the addition of keys, material trends, and cutting edge concepts from twenty-first century makers. Chapter four discusses the history of piccolo pedagogy and identifies specific contributions made by William Hebert. Chapter five surveys selected piccolospecific resources and method books as well as reviews the content of each. Chapter six explores the application of the sources surveyed from Chapter five to the areas of intonation, articulation, phrasing, embouchure, breathing, vibrato, dynamics, and tone color as addressed in Chapter four, creating an instructional guide for the application of these sources. 


\section{Chapter One - Introduction}

The origins of the piccolo can be traced back to primitive transverse flutes from prehistoric time that were made with varying numbers of finger holes bored into hollow animal bones. There is evidence, although rare, that transverse flutes were utilized by the Etruscans and Romans dating back to the second century B.C.E. (Before Common Era). There is also evidence of the use of transverse flutes in both sacred and secular rituals in non-western cultures dating back to the ninth century B.C.E. ${ }^{1}$ In the Middle Ages (500-1430) the fife, predecessor to the modern western-piccolo, evolved in Europe as a military instrument for troop movement and ceremonial purposes. It is only during the past three hundred years that the piccolo has developed from its simplest form into the modern instrument of the twenty-first century. During this more recent history, the piccolo has played a significant role in the main symphonic works and has served as a staple in military bands around the world. Composers have recognized the piccolo as an extension of the flute since the mid-eighteenth century, adding over an octave to the top of the orchestra. Only in the last five decades have composers explored the piccolo as both a solo and chamber instrument capable of far more color and nuance than previously thought. Works written for piccolo such as Parable XII (1973) by Vincent Persichetti (1915-1987), Songbirdsongs (1983) by John Luther Adams (b. 1953), Concerto for Piccolo and Orchestra (1996) by Lowell Liebermann (b. 1961), Sonatine (2006) by Jindřich Feld (1925-2007), and Zoe and Xena (2014) by Daniel Dorff (b. 1956) use the piccolo as an orchestral soloist, a chamber instrument, and a duo partner respectively. Each piece has a different character and is scored using the piccolo in a variety of ways emphasizing the potential for color and nuance.

\footnotetext{
${ }^{1}$ Nancy Nourse, "The Piccolo: An Overview of Its History and Instruction” (M.M. thesis, The Crane School of Music, SUNY Potsdam, 1981), 7-8.
} 
The musical and mechanical development of the piccolo followed the same course as the flute although the piccolo arrived much later. This delayed development could be attributed solely to the more prominent role of the flute. As modern composers became more interested in what was once considered an auxiliary instrument of the orchestra, the need for performers who specialize in this instrument grew. The limited concert use of the piccolo in the Renaissance and early Baroque is due in large part to the harshness of the extreme upper register and the weak, colorless haunting quality of the lowest which composers saw as problematic. These factors limited the piccolo to a small role creating a military or storm-like effect. What composers previously considered "defects," have now become qualities that provide modern composers with a wider color palette. ${ }^{2}$ This new specialization and the desires of modern composers inspired the need for better performers and instruments. The twentieth-century piccolo saw the development of new scales which improved intonation. ${ }^{3}$ Multiple improvements in pad design, materials, and advances in the mechanism, such as the addition of auxiliary keys, have brought the piccolo into the modern era and placed it on par with the flute.

These three-hundred years of documented history bring to light the kind of training piccolo players have received. Research suggests from the early eighteenth century until as recently as the mid-twentieth century, players received the same training as their counterparts from the early eighteenth century. This training consisted mostly of trial and error with performers experimenting for themselves while trying to master the smaller version of the transverse flute. Haydn M. Matthews, composer, teacher, and former flutist for the Second Cavalry Band states in a contributed article to the May 1922 issue of The Flutist,

\footnotetext{
${ }^{2}$ Walter Piston, Orchestration (New York: Norton, 1955), 142.

${ }^{3}$ Scale refers to the relationship of pitches determined by the size and placement of tone holes based on a schema or diagram of measurement.
} 
The scarcity of real piccolo players is ... due to the fact that real teachers of the instrument are so rare ... When the only way to master any subject is to go ahead and experiment by oneself, it naturally follows that only mediocre results can be obtained, and it is on account of these struggles, that most of us dislike the little flute. $^{4}$

Most piccolo players received little or no training and were presented with the piccolo while in middle school or high school for use in marching or concert ensemble. This scenario is not limited only to the United States, it occurs around the world. Some students take a liking to the instrument and spend time working to become better players. To further complicate the matter, the common assumption was that if someone could play the flute, they also could play the piccolo because it was just a "small flute." 5 This assumption is still prevalent in the twentyfirst century. Most do not realize that the air support, intonation tendencies, embouchure control, and tonal palette of the piccolo are very different from the concert flute and need to be approached differently. ${ }^{6}$ Additionally, the piccolo is acoustically a very different instrument from the flute. Quality and consistency can vary widely from instrument to instrument as well as from maker to maker.

\section{Related Literature}

In the preliminary research for this document, online databases such as WorldCat, ProQuest Dissertation \& Theses, RILM Abstracts of Musical Literature led to several relevant results by using keywords, "piccolo" and "pedagogy" and "method" or "development." There were a limited number of dissertations about the piccolo, but all were beneficial and provided focused research on the topics of history, mechanical development, pedagogy, and repertoire.

\footnotetext{
${ }^{4}$ Nourse, "The piccolo: an overview," 120.

${ }^{5}$ Cynthia Ellis, "Let's Talk Picc: Urban Myths." Flute Talk 32, no. 7 (March 2013): 40.

${ }^{6}$ Jennifer Bouton Schaub, "Let's Talk Picc: Piccolo and Flute: Similarities and Differences," Flute Talk 33, no. 9 (May/June 2014): 32.
} 
Pan, Flute Talk, and Flutist Quarterly were the primary journals that contained reoccurring articles that focused on the piccolo. Also, information contained in orchestration treatises, excerpt books, and etudes provided supporting facts. All sources are either printed in English or are available in translation, and the literature has been divided into sections for organizational purposes.

\section{Books}

During the examination of literature about the piccolo, only limited references to the instrument are presented because most books focus primarily on the flute limiting their piccolo content to a description of the instrument focusing on the size, octave transposition, tessitura, and lack of a foot joint in comparison to the flute. A few resources include greater detail that extends beyond a simple description. Woodwind Instruments and Their History (1957) by Anthony Baines discusses orchestral use and trends at the beginning of the twentieth century. In The Flute: A Study of its History, Development, and Construction (1979), Philip Bate describes the piccolo as "the smallest flute that we may call standard in the orchestra today." Bate also gives a brief overview of the modern use of the piccolo in the orchestra, military bands, flute bands, and the role of the D-flat and E-flat piccolos. Bate's description is limited to three paragraphs, however, it is more thorough than most. Nancy Toff, The Flute Book: A Complete Guide for Students and Performers (2012), discusses in greater detail the technical aspects including: measurements, materials, makers, and advancements, major excerpts and prominent composers, and the role of the modern piccolo in solo and ensemble works. ${ }^{8}$ The Complete Guide to the

${ }^{7}$ Philip Bate, The Flute: A Study of its History, Development, and Construction (New York: Norton, 1979), 12.

${ }^{8}$ Nancy Toff, The Flute Book: A Complete Guide for Students and Performers (New York: Oxford University Press, 2012) 
Flute and Piccolo (2000), by James Phelan, dedicates an entire chapter to the piccolo and focuses on more technical aspects of the piccolo including idiosyncrasies of construction, maintenance, and repair. ${ }^{9}$

\section{Dissertations}

Theses and dissertations regarding the historical development of the piccolo include Zartouhi Dombourian-Eby's The Piccolo in the Nineteenth Century (1987), Angela R. Heck's The Mechanical Development of the Piccolo (2010), Heather Hall Coleman's The Adoption and Role of the D-Flat Piccolo and Other High Band Flutes in the Nineteenth-Century American Amateur Band (1999), Therese M. Wacker's The Piccolo in the Chamber Music of the Twentieth Century: An Annotated Bibliography of Selected Works (2000), and Nancy Nourse's The Piccolo: An Overview of Its History and Instruction (1981).

The major mechanical developments made to the piccolo occurred in the last two hundred years. Angela R. Heck's The Mechanical Development of the Piccolo (2010) provides a very clear description of the progression and development of various materials and key work designs that would lead to the modern piccolo used in orchestras presently. Dombourian-Eby's

The Piccolo in the Nineteenth Century and Nourse's The Piccolo: An Overview of its History and Instruction contain information regarding mechanical developments.

Dissertations with pedagogical focus and content referenced in this document include:

Emily J. Butterfield's The Professional Life and Pedagogy of Clement Barone (2003), Jennifer Gartley's The Impact of Jan Gippo on Contemporary Piccolo Literature (2009), Emily G. Orr's Teaching the Piccolo: A Survey of Selected College Flute Teachers (2005), Joseph Jacob

\footnotetext{
${ }^{9}$ James Phelan and Lillian Burkart, The Complete Guide to the Flute and Piccolo
} (Massachusetts: Burkart-Phelan, Inc., 2000) 
Roseman's William Hebert: Fundamentals of Playing and Teaching Piccolo (1996), and the document by Nancy Nourse. These sources are of importance because they contain many of the instructional concepts and techniques utilized by influential teachers of the piccolo and provide a clearer understanding of the historical developments around piccolo pedagogy in general.

Technique and Pedagogy Methods

Fingering charts for the piccolo referenced in this document are those found in Ernesto Köhler's Schule zum Selbstunterricht für die Piccolo-Flöte oder Trommel-Pfeife: Praktische Anleitung zur gründlichen Erlernung der Piccolo-Flöte $(1891)^{10}$, Jean-Louis Tulou's Metodo popolare Carlo Andreoni (1957), Steven Tanzer's A Basic Guide to Fingerings for the Piccolo (1990), and The Complete Piccolo: A Comprehensive Guide to Fingerings, Repertoire and History (2007), by Jan Gippo. It is important to note that these fingering resources are among the few currently in print and readily available for purchase. These guides collectively provide charts for one-keyed piccolos, simple-system piccolos, and the modern piccolo. These sources also include additional information of importance and will be referenced as appropriate in this document.

More recent literature shows an increased interest in piccolo specialization with the publication of Andrew Lane's Piccolo Craft: The Teach-Yourself Piccolo Method (2010), Patricia Morris's The Piccolo Study Book (1998), Danielle Eden's Piccolo! Piccolo! A Selection of Essential Studies and Warm-Up Exercises (1994), Trevor Wye and Patricia Morris's A Piccolo Practice Book (1988) and Clement Barone's Learning the Piccolo (1975). These resources are directed mainly towards those flutists with little or no experience on the piccolo.

${ }^{10}$ Ernesto Köhler's Self-instructor for Piccolo: Practical Directions for Thoroughly Learning the Piccolo was first published in 1891 and has been reprinted most recently in 2000. 
These books emphasize the challenges and problematic areas inherent to the piccolo and piccolo repertoire. For those who have a moderate amount of musical training before beginning piccolo, these sources provide clear and concise guidance but would not necessarily be appropriate for beginners lacking musical training.

The addition of Nicola Mazzanti's The Mazzanti Method: Daily Exercises for Piccolo (2014), Jean Louis Beaumadier's, Exercices pour la flûte piccolo (1999), and Eugeniusz Towarnicki's Studium technicki na matym flecie (1980) present piccolo players with exercises focused on the specific challenges that performers face. The authors are virtuosi performers. Journals

Few serial publications on the flute and flute pedagogy existed prior to 1900, and those that did were directed toward the amateur player and focused more on music reviews and scores. The Flutist, a monthly publication out of Asheville, North Carolina and edited by Emil Medicus, made its debut in 1920. It was the first publication specifically addressing the needs of flutists. It was not until the 1970's that publications directed towards professional flutists and teachers were consistently available. As of the date of this document sources currently in print are, Flute Talk, a publication of the Instrumentalist Publishing Co., Flutist Quarterly the publication of the National Flute Association, and Pan, formerly Flute, the publication of the British Flute Society. Flute Talk is the only one of these publications to regularly include articles that feature the piccolo.

\section{Procedure}

Sources specific to the piccolo will be utilized for the purposes of this document. Dissertations are available on historical use and pedagogy, mechanical development, and on specific individual performers, teachers, and composers. These sources contain areas of overlap 
and will be combined into chapters two and three which will discuss historical aspects of the instrument. Items that are inclusive of both flute and piccolo may be mentioned when information is pertinent to the research but only piccolo-specific methods will be included in the methods survey in chapter five and in the pedagogical application of the method books in the final chapter. These inclusive items pertain to construction and music principles common to both instruments. Books, dissertations, and articles with historical and instructional importance to vibrato, embouchure, technique, intonation, and other similar topics will be referenced as necessary and included in the bibliography. The bibliography will serve as a comprehensive resource list for teachers and students and will include those resources relevant to the study and instruction of the piccolo. 
Chapter Two - History

Guide to Historical Resources

This chapter discusses the history and developmental use of the piccolo. The primary resources used by historians to establish the historical development of the piccolo come from instrument manufacturers' catalogs, extant instruments, orchestration treatises, piccolo tutors, and orchestral music. Some of the extant sources describing the piccolo refer to it as a "small flute" likely referencing the relationship to the larger concert flute. These resources are minimal and difficult to acquire but a few have been archived by the Library of Congress in the Dayton C. Miller collection and are available digitally. Many of these sources have been utilized and referenced by the authors of the dissertations included in this document. From 1772 until 1914, there were twenty-two orchestration treatises written that gave a "rather objective" view as to the type of piccolo in use and its capabilities. ${ }^{11}$ There are four dissertations and a master's thesis that cover piccolo history quite well and provide greater details should the reader find the need to explore further any of the information contained in this chapter. The master's thesis written by Nancy Nourse in 1981, is the first research to approach piccolo history in the twentieth century and is cited in most of the subsequent dissertations that cover history. She provides an extremely thorough timeline in which the uses of non-Western, piccolo-like instruments are introduced. Since her thesis was published, there have been a few archaeological discoveries. These have been included below, thus making the information current. The Nourse thesis is not available on ProQuest but can be found in the library holdings of the National Flute Association, in the

\footnotetext{
11 Zartouhi Dombourian-Eby, "A History of the Piccolo," (Flutist Quarterly 16, no. 1, 1991), 15.
} 
Library of Congress in the Dayton C. Miller Collection, and on file at the State University of New York at Potsdam.

\section{History and Usage}

Before the Piccolo

The origins of the piccolo can be traced back to pre-historic times when primitive relatives of flutes (both transverse and vertical) were made from animal bones in which varying numbers of finger holes were placed. In 2008, at Hohle Fels, a stone-age cave in southern Germany, fragments of a flute made from a griffon vulture's wing bone were found. This boneflute consisted of a V-notched mouthpiece and five finger holes and resembled a modern-day pennywhistle. The flute has been carbon dated to at least 35,000 years old but was found among other Aurignacian artifacts placing it closer to 42,000 years old, which coincides with the settlement of modern humans in the area, making it the oldest known instrument ever found. There was some debate over the initial carbon-14 dating of this instrument; however, retesting of the instrument, as well as other surrounding artifacts, provided more consistent results, and the current data has been confirmed. ${ }^{12}$

Flute fragments made from mammoth ivory were also found in nearby Geissenklösterle earlier the same year, and carbon-14 dating places them at least 35,000 years ago. The mammoth-ivory was split in half, hollowed out, carved, and then fit back together with an airtight seal. ${ }^{13}$ This elaborate process, which would have been done with stone tools, negates any

12 "Prehistoric Flutes Date to 42,000 Years Ago, USA Today, May 24, 2012, http://content.usatoday.com/communities/sciencefair/post/2012/05/prehistoric-flutes-foundfrom-42000-year-old-cave/1\#.Vyt-ND-LRA8 [accessed May 5, 2016]

13 "Bone Flute is Oldest Instrument, Study Says," National Geographic News, June 24, 2009, http://news.nationalgeographic.com/news/2009/06/090624-bone-flute-oldest-instrument.html [accessed May 5, 2016] 
questions as to whether the finger-holes were from a carnivore's teeth or from the natural effects of the elements and reveals a much earlier musical tradition than previously thought. These flutes were purposefully made by early man and with such revolutionary designs already apparent. One can only assume that there were previous versions showing the development of these instruments. If they survived, they have yet to be found. Wulf Hein, an experimental archaeologist at Tubingen University, made a replica of this bone-flute and uploaded a video to YouTube of himself playing the instrument, demonstrating the capacity of the ancient instrument to produce a significant number of pitches. ${ }^{14}$ These archaeological finds represent the very humble beginnings of the flute family.

In 1999, archeologists discovered six complete ancient flutes in the Henan province of China at Jiahu, an early Neolithic site. The instruments found were playable and Carbon-14 dating places them at between 7,000 and 9,000 years old. The instruments produced pitches equivalent to the Western major scale. ${ }^{15}$ While these limited artifacts represent the historical beginnings of the flute and piccolo, they do not provide a direct link to the use or development of the modern instrument. They confirm the existence of smaller, flute-like instruments in earlier historical periods. There is additional evidence, although rare, that transverse flutes were utilized by the early Etruscans and Romans, but not the Greeks, according to Howard Mayer Brown, an American musicologist and author of Musical Iconography ${ }^{16}$ This claim is based on images of transverse flutes found on burial urns found in Etruscan tombs dating back to the second century

14 "The Ice-Age Flute that Can Play the Star-Spangled Banner," The Guardian, February 15, 2013, http://www.theguardian.com/music/2013/feb/15/ice-age-flute [accessed May 5, 2016] ${ }^{15}$ U.S. Department of Energy's Brookhaven National Laboratory, "Brookhaven Lab Expert Helps Date Flute Thought to Be Oldest Playable Musical Instrument," September 22, 1999, https://www.bnl.gov/bnlweb/pubaf/pr/1999/bnlpr092299.html [accessed August 27, 2016] ${ }^{16}$ Nancy Nourse, "The Piccolo: An Overview," 7-8. 
B.C.E.

Non-Western Instruments

Records show that non-western cultures have been using small transverse flutes for ceremonial purposes dating back to the ninth century B.C.E. These small flutes might be considered distant relatives of the modern piccolo and demonstrate the cultural importance of the higher voice in non-western cultures. In China, a ten-holed flute available in several sizes, called the $t i-t z u$ is used in the performance of traditional music. The $t i-t z u$ has a hole between the embouchure and first finger-hole where a vibrating membrane of bamboo, paper, or cocoon would be placed producing an effect like that of a kazoo membrane. ${ }^{17}$ New Guinea also has a variety of sizes of ethnic flutes, the smallest of which is reserved for sacred use. The Japanese gagaku, a type of fuye or small flute, is specifically used for national classic music and is associated with gagaku court music. ${ }^{18}$ Another Japanese fuye, the noh-kan, a small transverse flute, is used in Noh theater performances and hayashi ensembles. It is the flute on which Mei (1962) by Kazuo Fukushima (b. 1930), is based. ${ }^{19}$ The East Indian culture also has a classical flute that is very much like the fuye from Japan. These regionally diverse instruments continue to be used in theatrical and ceremonial performances in the twenty-first century as a means of preserving cultural history.

\footnotetext{
17 Ibid.

${ }^{18}$ Ibid.

${ }^{19}$ Mihoko Watanabe, “The Essence of Mei,” Flutist Quarterly 33, no. 3 (Spring, 2008): 16-24.
} 


\section{The Fife}

The fife was developed during the Middle Ages (c. 500-1430) and is an early form of the modern piccolo. The fife was a short cylindrical tube stopped with a cork at one end, often in Bflat or A-flat with six finger holes, one or two sections, and metal bands called ferrules protecting the ends of the sections. Its purpose was martial, to sound commands guiding troop movement and positioning. ${ }^{20}$ In comparison to the piccolo, the bore of the fife was narrower making the instrument louder and shriller, thus easier to be heard on the battlefield. The origin of the fife was the Schweitzerpfeiff or Swiss pipe, introduced by Swiss mercenaries throughout Europe. ${ }^{21}$ The use of the fife and drums had a documented presence on the battlefields of Marignano in $1515 .^{22}$

While the fife is a close relative of the modern piccolo, the similarities of the two instruments seem to diverge during the Baroque period, likely due to the addition of keys to permit more flexibility in more distant key signatures, although there is no clear delineation as to where the fife and piccolo separate. Thoinot Arbeau (pen name of Jehan Tabourot) may be the first to make a distinction between the fife and piccolo. In his Orcheosgraphie (1558) he states, “...We apply the name fife to a small transverse flute with six holes, which, as it has a very narrow bore no bigger than a pistol bullet gives a piercing sound." 23

As the piccolo came to replace the fife in concert settings, players still referred to the piccolo as "fife" out of habit, not unlike many players referring to their instrument as a "horn."

\footnotetext{
20 Therese Wacker, "The Piccolo in the Chamber Music of the Twentieth Century: An Annotated Bibliography of Selected Works," (DMA diss., The Ohio State University, 2000), 6-7.

${ }^{21}$ Ibid., 7.

${ }^{22}$ Nourse, "The Piccolo: An Overview," 26.

${ }^{23}$ Danielle Georgina Eden, "The Piccolo: its History, Solo Repertoire and Usage since 1800 to Modern Day in Western Europe," (DMA diss., University of London, 1999), 10.
} 
The lack of precise nomenclature and the fact that players referred to instruments by generic names contributed to the uncertain and shrouded piccolo history. The fife has a long history and continues to be used apart from the piccolo.

\section{Middle Ages - Renaissance}

It was documented that during the middle ages a six-finger-holed transverse flute was quite popular and was called for in a thirteenth-century trouvère song. ${ }^{24}$ The term "flute" referenced both vertical and transverse instruments and was used interchangeably. Adenet le Roi was one of the first who made a distinction between the vertical and transverse flutes in his writings in 1285 . At the time of this early documentation, instruments of both classes were being made in families or consorts containing many sizes. ${ }^{25}$ Michael Praetorius lists several transverse flutes in his Syntagma Musicum (1615-1619) and is clear to point out that the descant instrument speaks one octave higher than written. Although there is no mention specifically of a smaller flute, this does not mean that it did not exist. There are extant instrument cases which would have contained up to five transverse flutes of varying sizes and would have been used by the same musician, likely to accommodate key, pitch, or voice part as needed. ${ }^{26}$ It is impossible to know for certain the specific instruments utilized in medieval and renaissance music due to the non-specific and inconsistent nomenclature. However, there are indications of flute consorts using wide ranges of instruments. Clear documentation of size and pitch designations is limited to graphic representations in manuscripts thus resulting in a more speculative than definitive early history for the piccolo.

\footnotetext{
${ }^{24}$ Nourse, “The Piccolo: An Overview," 12.

25 Ibid., 13.

${ }^{26}$ Ibid., 14-17.
} 
Musical preferences moved away from homogenous consorts at the beginning of the seventeenth century, and the flute used in the broken consort ${ }^{27}$ was a tenor flute; therefore, it is likely that the smaller transverse flute was limited to use in military music and for entertainment. It is interesting to note that the term "flute" was still ambiguous and predominantly referred to the recorder while the fuller designations "German flute" or "flauto traverso" referred to the transverse flute. Instrument identification was complicated even further by terms like "kleine Flöte, Oktaveflöte, ottavino, and petite flute" describing both similar and completely different instruments. $^{28}$

\section{Baroque Period}

The piccolo first appeared in orchestral scores in the early eighteenth century and one of the earliest documented uses of the piccolo was for an elaborate cadenza in Handel's opera Rinaldo (1711). Passages also appeared in the score in the works Riccardo primo and Water Music. Handel lists flageolet in the original autograph score for Rinaldo but later altered the name to flauto piccolo, in his handwriting. This fact does call into question in whether the instrument was a recorder; however, the written key of G major would suggest otherwise. ${ }^{29}$ The definitive first use of the piccolo in an orchestral score is regularly questioned by scholars and reinvestigated each time new information is uncovered.

It is no surprise that in the beginning of the Baroque period, nomenclature was rather vague and was dependent on the composer and the region. The word piccolo is an Italian adjective that means, "little," and flauto without a modifier referred to a recorder. Flauto piccolo,

27 An early Baroque term defining an ensemble containing more than one family of instruments.

${ }^{28}$ Nourse, "The Piccolo: An Overview," 28-29.

${ }^{29}$ Wacker, "The Piccolo in the Chamber Music of the Twentieth Century: An Annotated Bibliography of Selected Works," 13-14. 
kleine flöte, and flageolet were all terms that could have been applied to several different instruments during the period. In many cases, the only additional information that may identify the instrument is the key signature. The Baroque instrumental parts were written in nontransposing keys that favored the smaller transverse flute over the recorder and flute-à-bec, both of which were transposing instruments that favored flat keys rather than sharps. ${ }^{30}$

Research about compositions that include the piccolo has focused on prominent composers, specifically Vivaldi. There is debate whether the three concerti for flautino utilized the transverse piccolo or if they were intended for sopranino recorders. These solo parts have been extensively studied and compared to the ranges of possible instruments. Dale Higbee's conclusion is that some of the passages as Vivaldi wrote them were impossible on all but the one-keyed transverse piccolo. He references a quote from Michel Corrette's Méthode pour apprendre aisément à jouer de la flûte traversière (1730) that mentions Vivaldi's "enthusiasm for novel effects in music." ${ }^{31}$ Corrette also comments in his writings on the "small transverse octave flutes that give a charming effect in the Tambourins." 32 These remarks represent the first literary reference to the octave transverse flute.

Johann Sebastian Bach (1685-1750) included the piccolo in his Cantata Ihr wedet weinen und heulen, BWV 103 in $1725 .{ }^{33}$ It was the Paris Opera and the works of Jean-Philippe Rameau (1683-1764) that established the "petite flute traversière" as a regular complement to the orchestra although the instrument would not be mentioned in the opera records until 1781 . The

\footnotetext{
${ }^{30}$ Bate, The Flute: A Study of its History, Development, and Construction, 183.

${ }^{31}$ Ibid., 184.

${ }^{32}$ Eden, "The Piccolo: its History, Solo Repertoire and Usage since 1800 to Modern Day in Western Europe," 25-26.

${ }^{33}$ Angela Heck, "The Mechanical Development of the Piccolo" (DMA diss., University of Oklahoma, 2010), 16.
} 
Musée instrumental du Conservatoire national supéieur de musique, located in Paris, has an anonymous French-made ivory one-keyed piccolo dating from 1730-1740 in the archives that supports the references made by Corrette. It is interesting to note that Johann Joachim Quantz (1697-1773) makes no reference to the piccolo but acknowledges flutes in varying sizes in his treatise, On Playing the Flute. ${ }^{34}$ This might simply be that the piccolo was not a standard part of chamber ensembles in the court or simply that Quantz was aware of but not familiar with the instrument. It was during this period that families of flute makers began to emerge. Based on Corrette's statements and documents from inventories, it has been suggested that Thomas Lot (1708-1787) and Jacques-Martin Hotteterre (1674-1763) may have been two of the earliest manufacturers of one-keyed piccolos. These documents date their instruments to c.1711 or possibly earlier. Although it is unclear whether Hotteterre's instruments were piccolos or soprano recorders, there is an extant Lot three-piece boxwood piccolo in a museum in Tokyo, Japan. ${ }^{35}$

\section{Classical Period}

During the Classical period (1750-1825) the piccolo became more prominent, and its widespread use was more readily documented especially in the orchestral rosters. Nancy Nourse's document references sales records for several known flute and piccolo makers who listed the instrument as "piccoli," and "octava flauti" in their inventory lists. ${ }^{36}$ Initially, piccolos rarely appeared in works with tonalities beyond two flats or three sharps due to the difficulty of cross-fingerings and intonation which were challenging to play on the one and four-keyed

\footnotetext{
${ }^{34}$ Nourse, "The Piccolo: An Overview," 36.

${ }^{35}$ Eden, "The Piccolo: its History, Solo Repertoire and Usage since 1800 to Modern Day in Western Europe," 26-34.

${ }^{36}$ Nourse, "The Piccolo: An Overview," 44.
} 
instruments in use at the time. ${ }^{37}$

One composer who used the piccolo regularly for effect was Wolfgang Amadeus Mozart (1756-1791). He did not include piccolos in any of his symphonies but he did use them in his dances and minuets as early as 1770, and included the piccolo in his orchestral scoring of 6 Minuets for Orchestra, K. 104 (K. 61e). Mozart utilized the piccolo for the effect it created, replicating the timbre of traditional dance music of the time. This may be why he included the instrument in his opera, Abduction of the Seraglio, where the piccolo and percussion are reminiscent of Turkish military music. ${ }^{38}$

According to Nourse, a surprising number of composers include the piccolo in their compositions. She notes that Christoph Willibald Gluck (1714-1787) scored two piccolos in Iphigenia Tauride (1779). Haydn also wrote for the piccolo in The Seasons (1798). Ludwig van Beethoven's (1770-1827) first work with piccolo was Musik zu einem Ritterballett (1790), and though it doubles the melody in only a few movements, it is Beethoven who is credited with introducing the piccolo as a regular member of the orchestra. ${ }^{39}$ Beethoven brought the piccolo, as well as the contrabassoon, into the symphony, thus expanding the range and timbre of the orchestra in his Fifth Symphony (1807). Initially, he used the piccolo to double the melody in the fourth movement of the Fifth Symphony, because the doubling produced a more reinforced and projecting timbre. Beethoven continued its use in the remainder of his compositions for more than the initial layered and supportive effect, eventually assigning it solo lines in his Ninth Symphony. ${ }^{40}$ Philip Bate states, “In Beethoven's hands the piccolo may be said to have come to

\footnotetext{
37 Ibid., 13.

38 Ibid., 44.

${ }^{39}$ Zartouhi Dombourian-Eby, "The Piccolo in the Nineteenth Century," (D.M. diss., Northwestern University, 1987), 15-16.

${ }^{40}$ Ibid., 44-45.
} 
orchestral maturity, ready to take its place in the standard symphony orchestra." ${ }^{41}$ Beethoven calls for piccolo in sixteen of his works making use of it to varying degrees and using the preBöehm instrument in its full range from D4 to A6. ${ }^{42}$ Dombourian-Eby's dissertation provides examples of Beethoven's scores and greater detail of the use of piccolo in all of his works.

Carl Maria von Weber (1786-1826) is known for featuring the piccolo during magical or supernatural moments. Der Freischütz (1821) is mentioned in many orchestration treatises due to Weber's scoring for two flutes and two piccolos. In Der Freischütz, the two piccolos represent a "diabolical sneer." Weber was the first to write independent parts for two piccolos although the examples are conservative with regards to range and could have been easily played on a simplesystem piccolo. ${ }^{43}$ Louis Spohr (1784-1859) followed suit with his composition Jessonda (1823), which is the first known orchestral work to use the D-flat piccolo. Both flutists in this opera are required to double on D-flat piccolo. The second flute part switches to C piccolo in three numbers requiring the player to have both the D-flat and $\mathrm{C}$ piccolo available. This is also the first work to call for the first player to double on piccolo. ${ }^{44}$

The piccolo also became a standard instrument in many of Gioacchino Rossini's (17921868) operas. Barber of Seville (1816), The Thievish Magpie (1817), Semiramide (1823), and William Tell (1829) all contain prominent florid solo piccolo lines some of which have become standard on orchestral audition lists. ${ }^{45}$ Rossini made full use of the piccolo's more piercing upper register to add brilliance to the orchestra, especially during tutti sections. Known for challenging solo piccolo passages, many of Rossini's works were written in keys that presented easily for the

${ }^{41}$ Bate, The Flute: A Study of its History, Development, and Construction, 180.

42 Dombourian-Eby, "The Piccolo in the Nineteenth Century," 14-15.

${ }^{43}$ Dombourian-Eby, "The Piccolo in the Nineteenth Century," 49-53.

44 Ibid., 53-54.

${ }^{45}$ Nourse, "The Piccolo: an Overview," 45. 
pre-Böehm piccolo. William Tell is the only Rossini work to be mentioned in orchestration treatises, likely because the second flute is called on to double on piccolo. The piccolo doubles the melody in the storm section, and while there is no solo passage in this work, Rossini does write A6 and B6, neither of which were considered usable notes on the piccolo by tutors and treatises written prior to the $1880 \mathrm{~s} .{ }^{46}$

\section{Romantic Period}

One would be remiss to not focus on the important contributions of Theobald Böehm (1794-1881) to the flute in the beginning of the Romantic period. Böehm completely redesigned the flute key work (1832 and 1847 systems) and by extension, though delayed, the piccolo. While also a composer, Böehm is best known for his contributions to the mechanical development of the flute and those contributions will be reserved for chapter three of this document.

Two notable orchestral composers, Hector Berlioz (1803-1869) and Pyotr Ilych Tchaikovsky (1840-1893), both piccolo players themselves, wrote some of the most challenging and recognizable piccolo lines in the symphonic literature. Berlioz included piccolo in Menuet des Follets in Faust and Tchaikovsky included the piccolo in his ballets. ${ }^{47}$ Both composers played simple system piccolos. Berlioz believed that piccolos were "strangely abused," due to their overuse and used too frequently to add "thrill, pierce, or flash forth." He felt that they were capable of "joyous character," as well as to accentuate "violent and tearing effects." ${ }^{48}$ His opinions regarding the usefulness of the piccolo may explain the significant demands that he

46 Dombourian-Eby, "The Piccolo in the Nineteenth Century," 64-70.

${ }^{47}$ Baines, Woodwind Instruments and their History, 57.

${ }^{48}$ Berlioz, Hector, and Hugh Macdonald. Berlioz's Orchestration Treatise: a Translation and Commentary (Cambridge: Cambridge University Press, 2002), 121. 
placed on the piccolo. The requirements of range and control that Berlioz expected from the piccolo were such that other composers would not attempt such writing for almost fifty years until the likes of Tchaikovsky. It is also evident that Berlioz favored the instrument as he wrote in accessible keys playable on simple-system instruments. Berlioz was the first known composer in the Romantic period to score for two solo piccolos. "Dance of the Sprits," from The Damnation of Faust (1846) and "Evocation," from the same work required three piccolos and followed in the footsteps of Weber's composition written twenty-five years earlier. Frequently, the primary role of the piccolo in the Romantic period was to mimic sounds of nature, representing howling wind or lighting.

Felix Mendelssohn (1809-1847) included piccolo in his work Calm Sea and Prosperous Voyage (1828) and Robert Schumann (1810-1856) included piccolo in both Paradise and the Peri (1843) and Concertstücke for Four Horns (1849). Both composers wrote only a few works that included piccolo parts, which were limited to a few passages at most, and although brief, their presence was important.

The influence of Berlioz was far reaching and the French began utilizing the piccolo in orchestral works like Charles Gounod's (1818-1893) Faust (1859), Léo Delibes'(1836-1891) Coppelia (1870), and Georges Bizet's ( 1838-1875) Carmen (1875). The French often wrote rather florid and challenging music for the piccolo as can be seen in Paul Dukas' (1865-1935) Sorcerer's Apprentice (1897) and Maurice Ravel's (1875-1937) Daphnis and Chloe (1912).

The first passage in a symphonic work that featured the piccolo in an exposed soloist role was Tchaikovsky's Fourth Symphony (1877) which was a full seventy years after the piccolo first appeared in works of Beethoven. ${ }^{49}$ It is this challenging solo that is credited with bringing

${ }^{49}$ Dombourian-Eby, "The Piccolo in the Nineteenth Century," 13. 
the piccolo into the ranks of solo orchestral instruments. One of the many difficulties of this solo is that the fingering combinations on both the simple-system piccolo and the Böehm-system piccolo are quite complex. Another difficulty is the dynamic marking, piano, printed through the exposed solo which is performed with a range of almost two octaves. And finally, the first two movements of the work are tacet for the piccolo. After this extended period of rest, the piccolo must come in on A6, a note that had not been written for piccolo since Berlioz's Symphony Fantastique. These complex variables have made this challenging solo a premiere excerpt on almost every orchestral audition for piccolo. ${ }^{50}$

Another important composer to mention is Antonin Dvořák (1841-1904). Aside from Beethoven's orchestral works, Dvořák’s Symphony No. 9 (1893) is the only other symphony referred to in orchestration treatises that discuss the piccolo. Seven of his nine symphonies utilize the piccolo to some extent, and the second flutist often doubles on piccolo. ${ }^{51}$

Gustav Mahler (1860-1911) placed high demands on the piccolo in his First Symphony (1888) and is credited with the first expressive or lyrical use of the piccolo as a solo instrument in his Second Symphony (1894). In this symphony, the entire flute section of four is called on to play piccolo, which had never been done before. This new independence as a soloist and Mahler's creative usage paved the way for the piccolo as an indispensable orchestral instrument in the twentieth century. ${ }^{52}$ Mahler used two piccolos in each of his symphonies except his Ninth Symphony (1909-10). The use of two piccolos enabled him to produce effects not previously heard in symphonic works. Mahler was a knowledgeable composer and orchestrator and did not limit himself by key when scoring for the piccolo. His works included a large amount of

\footnotetext{
${ }^{50}$ Dombourian-Eby, "The Piccolo in the Nineteenth Century," 159-163.

${ }^{51}$ Ibid., 151-153.

52 Ibid., 13.
} 
chromaticism which posed a challenge for the simple-system piccolo. This chromaticism might suggest that the Böehm-system piccolo was becoming more popular due in large part to the availability of the instruments. Players no longer needed to master a second fingering system and could approach every key equally. Mahler also frequently pushed the ability of the instrument and on more than one occasion scored one or more piccolos up to written C7. Of all the innovative ways in which Mahler employed the piccolo, it is his soft and expressive writing that has become his greatest contribution to symphonic works with piccolo. ${ }^{53}$

While Mahler pushed the envelope by scoring multiple piccolos, challenging the range of the instrument and its capacity for expression, outside of the solo lines the piccolo frequently doubled the flutes and lacked true independence. In contrast, Richard Strauss (1864-1949) approached the piccolo as an entirely independent instrument. Although he wrote fewer actual solos for the piccolo he did compose separate lines for the instrument. In his work Also sprach Zarathustra (1896) the flute section is made up of four players, with the third flute doubling piccolo, while the fourth plays only piccolo. The two piccolos operate outside of the flute section and in varied ways, notably by doubling string chords while the first and second flutes play rather technical chromatic runs. In this work, Strauss focused on the tonal colors and scored the flutes and piccolos in such a way as to bring great expressiveness to the ensemble. His exploration of color was demanding of the instrument since he often required great dynamic control from the piccolo ( $p p p)$ in the higher register. Strauss tended to limit the upper range of the instrument rarely surpassing written A6. ${ }^{54}$

Nikolai Rimsky-Korsakoff (1844-1908) considers "special” instruments in his treatise on

\footnotetext{
${ }^{53}$ Dombourian-Eby, "The Piccolo in the Nineteenth Century," 186-206.

${ }^{54}$ Ibid., 206-217.
} 
orchestration and suggests the following about the piccolo:

The duty of the piccolo... is to extend the range of the ordinary flute...in the high register. The whistling, piercing quality of the piccolo in its highest compass is extraordinarily powerful, but does not lend itself to more moderate shades of expression... The low and middle range of the piccolo...correspond(s) to the same register in the normal flute...but the tone is so much weaker that it is of little service in those regions. ${ }^{55}$

In his work, Scheherazade (1888), Rimsky-Korsakov employs the piccolo in several ways. He uses the piccolo to extend the range of the flutes when called for and to represent the rocking of the boat through the triplet figures, as well as in fanfare passages for brightness and in duo with a second piccolo. He even uses the piccolo on a high trill during a tutti passage as a pedal point. He also makes use of B6 in this work, which is the first time this note had been utilized. ${ }^{56}$ It might be suggested that he either knew someone who could play this note consistently or he wrote the note because of the effect the extreme range provided. This note frightens modern piccolo players using contemporary mechanisms because it is by far the most difficult note for the instrument. Some instruments do not have a usable B6 even using alternate fingerings.

\section{Twentieth Century}

The piccolo's increasing prominence in the orchestra, due in large part to Beethoven and Berlioz, required improvements in pitch and design to meet the needs of players. The greater demands placed on players encouraged piccolo makers to bring the instrument up to the current standards that the flute had already achieved. The twentieth-century piccolo saw many mechanical improvements, but these advancements came after those of the flute. The modern piccolo's development began slowly with many players still performing on the simple system

${ }^{55}$ Nikolay Rimsky-Korsakov, Maksimilian Shtē̌nberg, and Edward Agate. Principles of Orchestration, with Musical Examples Drawn from His Own Works (New York: Dover Publications, 1964), 20.

56 Dombourian-Eby, "The Piccolo in the Nineteenth Century," 167-176. 
instruments even into the 1920s. ${ }^{57}$ This is substantiated by the fact that Ernesto Köhler's (18491907) Schule für Piccolo-Flöte (1900) was provided with a one-keyed and a six-keyed fingering chart insert. ${ }^{58}$ The role of the piccolo in twentieth-century orchestras is such that many of the larger symphonies have full-time piccolo positions, while smaller orchestras have per service players due to budget constraints and size. This new and innovative era for the piccolo allowed composers and players to more widely explore and implement the piccolo as a continued member of the orchestra.

Dimitri Shostakovich (1906-1975) recognized the piccolo as a solo instrument continuing the Russian style of piccolo writing that Tchaikovsky had started. Shostakovich's piccolo lines are just as complex, invigorating, and challenging as his flute lines. Even in his earliest compositions, he makes use of the range and color of the instrument. In his Fifth Symphony (1937) the flute passes the solo to the piccolo allowing it to act as an extension of the flute solo. The range of this solo takes advantage of the lighter quality of the piccolo from written Eb4 to Bb5. Shotakovich's writing for the instrument developed throughout his career giving the piccolo full solos in his Eighth Symphony (1943) and culminating with the highly soloistic piccolo line in his Tenth Symphony (1953).

It is during this period of exploration and innovation that works are written that call for the piccolo to play down to written $\mathrm{C} 4$, two semitones below the range of the standard piccolo in use. Ottorino Respighi (1879-1936) calls for staccato octaves beginning on written C4 in his Fontane di Roma (1915-16). It is interesting to address the issue of the extended low range as Respighi was not the first to call for these notes. Written C4 and C\#4 have appeared in Mahler's

\footnotetext{
${ }^{57}$ Ibid., 9-10.

${ }^{58}$ Ernesto Köhler, Schule für Piccolo-Flöte, (Frankfurt: Zimmermann, 1900), insert.
} 
Second Symphony (1888-94), Englebert Humperdinck's (1854-1921) Hansel and Gretel (1893), even Giuseppe Verdi's (1813-1901) Messa da Requiem (1874). Philip Bate suggests that this occurrence may be due to the "lapse on the part of the composer rather than the availability of a highly unusual instrument." ${ }^{, 59}$ Most of these works seem to have been written within a narrow span of time suggesting that there may have been instruments able to accommodate the extended range. The William S. Haynes Company made a piccolo to C4 for Frank Wadsworth, a member of Sousa's band. John Philip Sousa (1854-1932) had also been known to write C4 for the piccolo. This corroborates the existence of such an instrument. Benjamin Britten (1913-1976) calls for this extended lower range as well in The Young Person's Guide to the Orchestra (1945) and Billy Budd (1951). ${ }^{60}$

The twentieth century gives rise to compositions for wind band. Wind band concerts were a popular form of entertainment at the turn of the century, frequently featuring the piccolo due to its virtuosic facility and ability to project. It is from this popular ensemble that the march form arose and one of the most recognizable marches of all time. The Stars and Stripes Forever was written by John Philip Sousa in 1897 and is marked by one of the most recognizable piccolo solos of all time. Alongside marches, "bird polkas" also became popular with audiences. The virtuosic solos for the piccolo, which were often named for a bird or were related to birds, showed off the technical ability of the player and called for great showmanship. Examples of these solos are, L'oiseau du bois (1887) by Charles Le Thiére (1862-1930), La Roielet (1876) by Eugène Damaré (1840-1919), The Noisy Bird by Louis Balleron (1869-1916), and Will O' The Wisp Polka (1909) by John Summers Cox (1834-1902), a member of Sousa's band. These

${ }^{59}$ Philip Bate, The Flute: A Study of its History, Development, and Construction (London; New York: Norton, 1979), 178.

${ }^{60}$ Nourse, "The Piccolo: an Overview," 55-58. 
piccolo solos provided a source of musical entertainment for the public and promoted the popularity of the piccolo in the United States and abroad. This transition era (1897-1928) is referred to as the "Golden Age" of the piccolo and the solo instrument was used more for entertain as opposed to "aesthetic music-making." 61

This era of concert band popularity paved the way for more serious works for wind band by composers who approached the ensemble in the same way that current orchestral composers do. The piccolo was a mainstay from the beginning of the concert band. Composers like Percy Grainger (1882-1961), Darius Milhaud (1892-1974), Gustav Holst (1874-1934), and Karel Husa (1921-2016) treated the piccolo as an integral part of their ensemble. Holst's First Suite in Eb for Military Band (1909) and his Second Suite in F for Military Band (1911) feature the piccolo prominently both exploring subtlety and nuance of color in the solos as well as the martial quality of the higher register. Husa's Music for Prague, 1968 (1968) features a delicate piccolo solo starting on written E4 and marked pianissimo. These solos highlight some of the most expressive quality and range that the piccolo can capably produce. Folk Song Suite (1924) by Ralph Vaughan-Williams (1872-1958) features the piccolo in a rather exposed and delicate but colorful solo that requires complete tonal and dynamic control in the second movement. These great composers and their works have assured the piccolo a place in the concert band setting in addition to the already established symphony orchestra.

While the "Golden Age," of the piccolo saw the instrument in a virtuosic light, it was treated somewhat like a carnival attraction. Nevertheless, the instrument did receive attention from this period per the orchestral and band repertoire. Another area of interest to some composers at the turn of the century was the piccolo's potential in chamber music. In some

${ }^{61}$ Nourse, "The Piccolo: An Overview," 73-74. 
works, the flutist doubled on piccolo while in others it was an independent instrument. Pierrot Lunaire (1912) by Arnold Schoenberg (1874-1951) was written for voice and a quintet in which the flutist also plays piccolo. Darius Milhaud wrote La cheminée du roi René (1939) and in the "Chasse à Valabre," the flute switches to piccolo for the ornate solo, invoking the feeling of chasing game during a hunt while the "hunting" horn sounds. A popular scoring in chamber music with the piccolo is pairing it with a low instrument as in Elephant and Mücke (c. 1903) by Henri Kling (1842-1918) for piccolo, trombone, and piano. ${ }^{62}$ Kling was also the author of an orchestration book, Modern Orchestration and Instrumentation; or, the Art of Instrumentation (1905), which demonstrates his understanding of the piccolo and its use in compositional practices.

As the piccolo's prominence grew in orchestras and wind bands, and its usefulness as a chamber instrument became apparent, composers began thinking of the instrument and its potential as a solo instrument. Parable XII for Piccolo (1973) by Vincent Persichetti (1915-1987) is a landmark work that served as a gateway for composers to begin seeing the piccolo as a soloist and a starting point for what would become a substantial list of solo repertoires.

\footnotetext{
62 Wacker, "The Piccolo in the Chamber Music of the Twentieth Century: An Annotated Bibliography of Selected Works," 18.
} 


\section{Chapter Three - Mechanical Development}

This chapter will focus on the materials that have been used in the construction of piccolos as well as the piccolo's divergence from the fife through the addition of key work. Selective developments and manufacturers will be discussed in chronological order and figures are provided as examples of varying construction practices using innovative materials and mechanism design. Materials used in construction will be presented, followed by information organized by period.

While science and technology have influenced the design and materials used in piccolo construction, the instrument made of hollowed out bone can still be seen on the distant horizon. As composers' and performers' musical demands developed so did the piccolo, although not without delay in comparison to the flute. The flute has a very clear and concise history of mechanical development with a lineage of rather famous names like Theobald Böehm. The documentation of the piccolo's mechanical development is based more on conjecture citing manufacturing and sales records, performance notes, and on rare occasion, extant instruments.

Chronological Mechanical Development by Period

\section{Medieval Period}

The fife, originating in medieval Europe, is a distant relative of the piccolo and resembles the early piccolo very closely. The separation of the two instruments seems to appear during the early Baroque period although there no definitive documents verify this as stated in the previous chapter. The addition of the D-sharp key and the larger diameter conical bore allowed the wooden piccolo to better adapt to life in the concert hall. The fife had a narrower diameter cylindrical bore that allowed the instrument to maintain a shrill tone making it better suited for military functions. Although there are fifes with the addition of a D-sharp key, the main 
differences between the fife and piccolo are the size and shape of the bore. Additionally, the design of the fife has remained relatively unchanged in contrast to the piccolo.

\section{Baroque Period}

During the Baroque period (1600-1750), the piccolo began to separate from the fife likely due to the need for an instrument usable in concert settings. In this period, both the simple system flute and piccolo had cylindrical head joints with conical bore bodies, and a key to facilitate D-sharp (see figure 3)

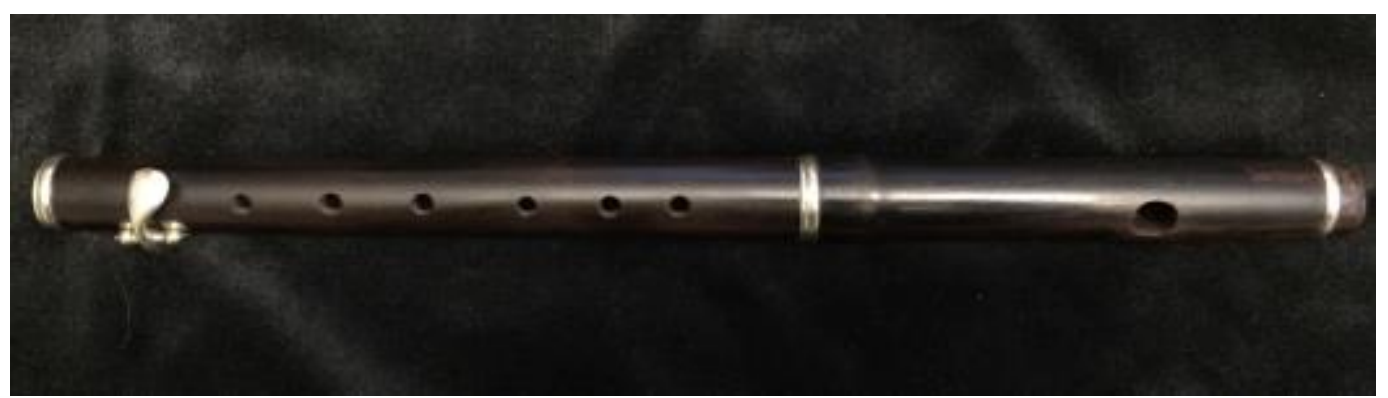

Figure 2. Anonymous one-keyed piccolo.

Credit is given to Jacques-Martin Hotteterre (1605-1690/92) for the addition of a single key, operated by the right-hand fourth finger allowing the instrument access to a full chromatic scale. ${ }^{63}$ Baroque flutes and piccolos were mostly made of ebony, boxwood, glass, and crystal although the latter of those materials was only occasionally used. Flutes and piccolos were often made in three to four sections and had corps de réchange, interchangeable middle joints that allowed the player to accommodate regional pitch variances which ranged from $A=392$ to $\mathrm{A}=440 .{ }^{64}$ Players could adjust to the regional pitch by switching out the center joint and making a small adjustment to the stopper cork in the head joint thus changing the overall length of the tube. As late as 1720, pitch standardization had still not solidified. The development of the

\footnotetext{
${ }^{63}$ Heck, "The Mechanical Development," 14.

64 Ibid., 17.
} 
piccolo is harder to trace since the design was more experimental and fewer piccolos were made than flutes, but the extant examples seem to mimic those characteristics of the flute.

\section{Classical Period}

The two and three-piece, one-keyed piccolos continued to be the most commonly used during the Classical period. The flute of the Classical period evolved further adding additional keys while the piccolo fell behind the flute in development. The most common design for this time was the three-piece instrument although two-piece and four-piece instruments were also in use. In the middle of the eighteenth century, makers began including tuning slides in the head joints. There are examples of piccolos from this time, called miniature flutes, that were made with foot joints and cylindrical bores rather than the traditional conical bore. ${ }^{65}$ While the onekeyed piccolos presented players with more simplified fingerings that they were used to, the instruments lacked the ability to play accurately in more remote keys and soon made way for the four and six-keyed instrument (see figure 4). Simple system or pre-Böehm C piccolos were best suited for keys signatures with one or two sharps, because these keys required no additional key work. The natural scale could be played by removing a finger from a tone hole. The addition of a key for $\mathrm{F}$ and $\mathrm{C}$ would be necessary just to play in the key of $\mathrm{C}$. The problem with the one-key design was that tonalities requiring F-natural, B-flat, and G-sharp required the use of crossfingerings producing notes that were softer, more diffused, and often very sharp or flat. The addition of keys allowed the proper venting of the cross-fingerings and also provided a stronger, more centered tone and more accurate pitch. Players could still use one-keyed fingerings if desired, but the additional keys took time and effort to implement accurately.

${ }^{65}$ Heck, "The Mechanical Development," 23-25. 


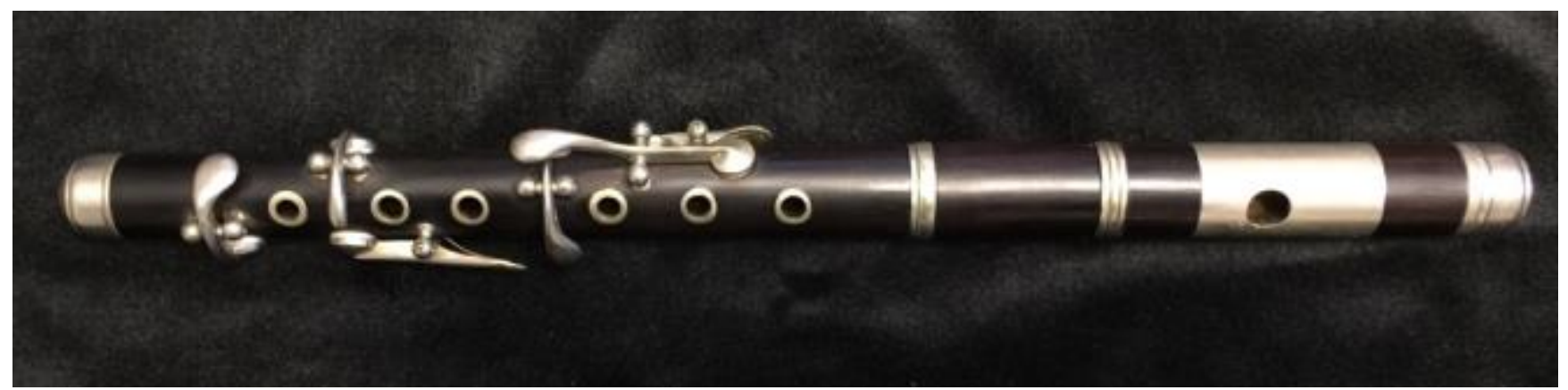

Figure 3. Anonymous English six-key, E-flat military piccolo, circa 1890.

A Prague flutist by the name of Michael Jannusch claimed to be the first to build a piccolo with six-keys in 1824. However, the Dayton C. Miller collection contains an extant sixkeyed ivory piccolo in C, made by Johan Joseph Ziegler (DCM 413) dated as early as 1820$1821{ }^{66}$ The six-keyed piccolo was in use during the time of Ludwig van Beethoven and may have been a ring-keyed Meyer system. It has been suggested that it is due to Beethoven's deafness that he began including the piccolo in his later works. ${ }^{67}$

At the beginning of the eighteenth century, there is evidence that smaller "flutes" pitched in E-flat (D-flat) and F (E-flat), were coming into use, and as early as 1750 there was more demand for the instruments pitched in E-flat (D-flat). ${ }^{68}$ Piccolos were frequently described by the lowest sounding pitch of the instrument. Piccolos pitched in concert $\mathrm{C}$ were labeled as D piccolos just as D-flat piccolos were listed as E-flat. The nomenclature for these higher pitched instruments is often misleading. The most popular of the flat-key piccolos was the D-flat piccolo. These instruments were most commonly used as band piccolos in the nineteenth century while orchestras preferred piccolos in C. Bands, in contrast to orchestras, played in mostly flat keys, requiring the addition of four or five keys to allow the pre-Böehm $\mathrm{C}$ piccolo to play in $\mathrm{B}$-flat and E-flat comfortably. By using a piccolo pitched in D-flat, a half step higher, three flats would

\footnotetext{
${ }^{66}$ Nourse, "The Piccolo: An Overview," 47-48.

${ }^{67}$ Heck, "The Mechanical Development," 26-27.

${ }^{68}$ Bate, The Flute: A Study of its History, Development, and Construction, 195.
} 
transpose to three sharps making the key easier for the player and placing the instrument closer to the natural key of the instrument. The transposing piccolos allowed players to play in more remote keys, though it required the player to have multiple instruments available.

With the introduction of the Böehm system piccolos, remote keys were no longer an issue. Because using difficult cross-fingerings for chromatic pitches was no longer a concern, the D-flat piccolo was replaced by the C piccolo which was already in use in the orchestra. ${ }^{69}$ The early nineteenth century demonstrates what might be the first attempts to correct the pitch and intonation shortcomings and develop the piccolo into a functional orchestral instrument.

\section{Romantic Period}

It was during the Romantic period that the piccolo moved another step forward with the addition of two more keys bringing the total to eight. This period of development also saw greater use of hardwoods, like grenadilla and cocus wood in the construction of piccolos as opposed to the popularity of boxwood in the construction of earlier piccolos. The addition of each new key also meant additional tone holes and posts or plates to support the mechanism. These additional tone holes substantially weakened the body and increased the chances of the wooden body cracking. The hardwoods provided excellent structural strength, more so than boxwood.

In the mid-nineteenth century, the Böehm-system flute became the popular choice for most flutists. While many players adopted the new Böehm-system flute, they continued to play the six-keyed piccolo. It was still rather standard at the turn of the century for performers to use a Böehm system flute and a simple-system piccolo which required knowledge of multiple

${ }^{69}$ Coleman, Heather Hall, "The Adoption and Role of the D-Flat Piccolo and Other High Band Flutes in the Nineteenth-Century American Amateur Band." (D.M.A. diss., The University of Memphis, 1999), 8-9. 
fingering systems. Böehm's Schema ${ }^{70}$ and key work provided flute players with instruments that had a bigger sound and more accurate intonation and allowed players to develop more virtuosic technique. The design and development of the piccolo was challenged mostly due to its size. Bore diameter in relationship to the overall length and tone hole placement left little room for error. Makers were frequently torn between sacrificing tone for pitch. Philip Bate suggests that the delay in piccolo development may be because the flute represented the greater challenge due to the larger distance between tone hole placement while the piccolo remained relatively manageable. ${ }^{71}$

Theobald Boehm would eventually apply his mechanism to the piccolo, and he is recorded as building a piccolo in 1835 . Although it is not clear as to which system was used for the piccolo's mechanism, it was likely his 1832 design that was used. ${ }^{72}$ The Böehm-system was slow to be accepted because many older players felt that the new system would impede them. The new system, however, did allow players to have instruments with matching key work thus eliminating the need for multiple fingering systems. ${ }^{73}$ Although Böehm did not make many piccolos, most used his refined 1847 system maintaining the conical wood body. However, in contrast he felt that the cylindrical bodied flutes were superior in design. There is an extant silver cylindrical-bodied piccolo in a collection at Der Karl Marx Universität in Leipzig believed to be a Böehm-prototype possibly made for Kapellmeister Pott. ${ }^{74}$ Although it utilizes Böehm's body

\footnotetext{
${ }^{70}$ Schema refers to the diagram showing Böehm's mathematical measurements for tone hole size and placement.

${ }^{71}$ Bate, The Flute: A Study of its History, Development, and Construction, 195.

72 Eden, "The Piccolo: its History, Solo Repertoire and Usage since 1800 to Modern Day in Western Europe," 175.

${ }^{73}$ Heck, "The Mechanical Development," 28.

${ }^{74}$ Dombourian-Eby, "The Piccolo in the $19^{\text {th }}$ Century," 376.
} 
design, it does not make use of a full Böehm-system key work. ${ }^{75}$ The firm of Böehm \& Mendler (founded in 1862) produced a cylindrical Böehm-system piccolo in three different material combinations: silver with wood embouchure, wood with silver, wood with German silver. ${ }^{76}$ Many makers would experiment and alter Boehm's original design but not without creating problems. Maximillian Schwedler was a champion of the German reform-system flutes and designed a mechanism that kept the conical bore and cylindrical head joint, a combination that he felt was superior in tonal colors. His mechanism (see figure 5) varied greatly from the Böehm-system and required fingering akin to those of earlier flutes.

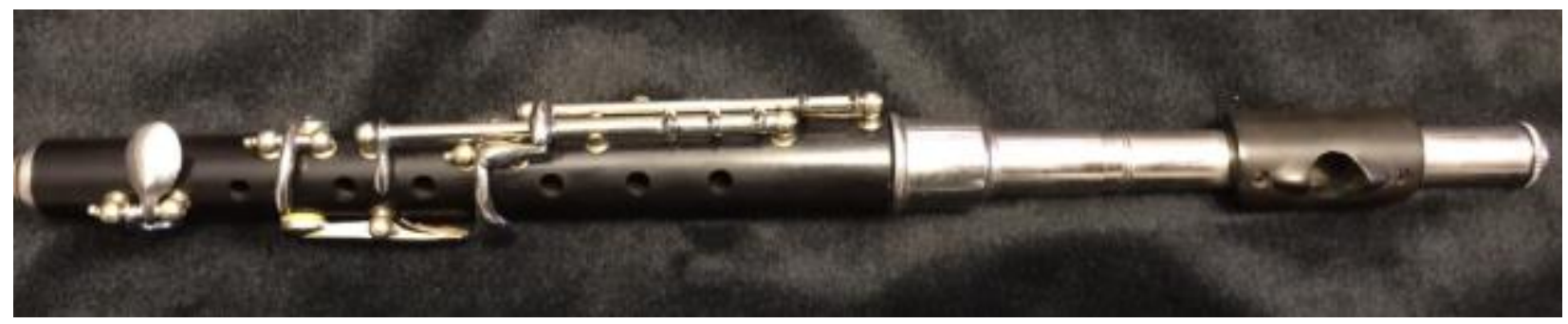

Figure 4. Anonymous German reform piccolo in the style of Schwedler, circa 1890.

However, it was Boehm's work that allowed the piccolo to adapt to the ever-increasing demands of the music. Böehm's mechanism was far superior to any other system at the time.

It is of importance to add that composers in the nineteenth century showed increasing interest in the use of the piccolo as shown in chapter three. Beginning with Beethoven's symphony and leading up to Rossini and Berlioz, there was a steady increase in the use of the piccolo. Following the works of Rossini and Berlioz, there was a sharp decline in writing that included the piccolo. Wagner and Dvořák utilized the piccolo sparingly, but their compositions marked the slow return of the piccolo that peaked in the works of Mahler. This decline in usage

${ }^{75}$ Eden, "The Piccolo: its History, Solo Repertoire and Usage since 1800 to Modern Day in Western Europe," 178.

${ }^{76}$ Ibid., 179. 
could be attributed to the inherent mechanical deficiencies of the simple-system piccolos which limited their ability to play in more remote key signatures called for as chromaticism grew. The Böehm mechanism was not immediately popular, and makers experimented with key work designs that attempted to keep the simple-system fingers while enlarging the tone holes for pitch and tone (see figure 6).

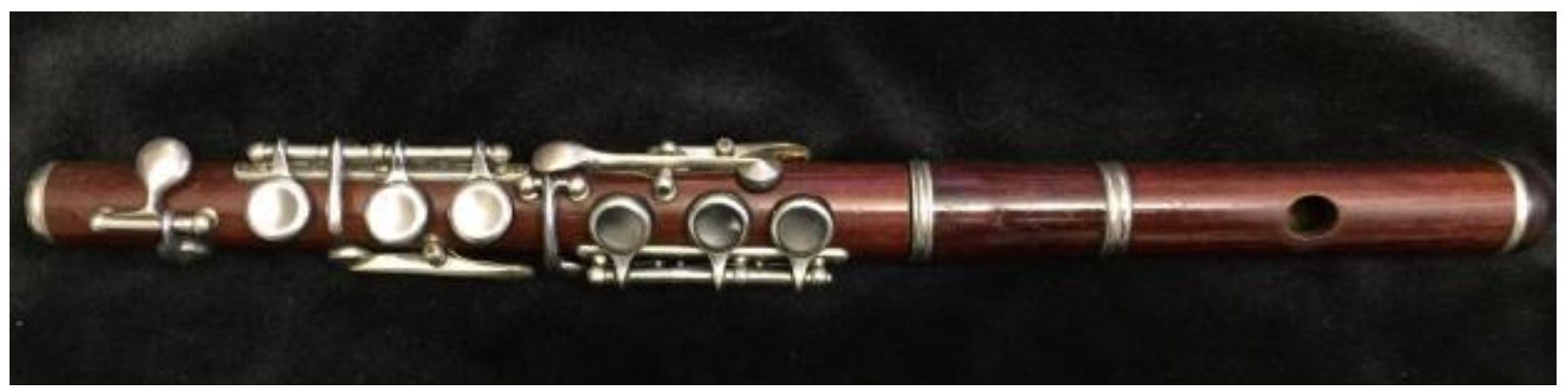

Figure 5. Anonymous English piccolo, circa 1870.

The resurgence of orchestration including piccolo could be due in large part to the introduction and more widespread availability of the Böehm-system piccolo. Early Böehm-system piccolos used ring-keys keeping the open tone holes associated with the simple-system piccolos while also taking advantage of the newer mechanism (see figure 7).

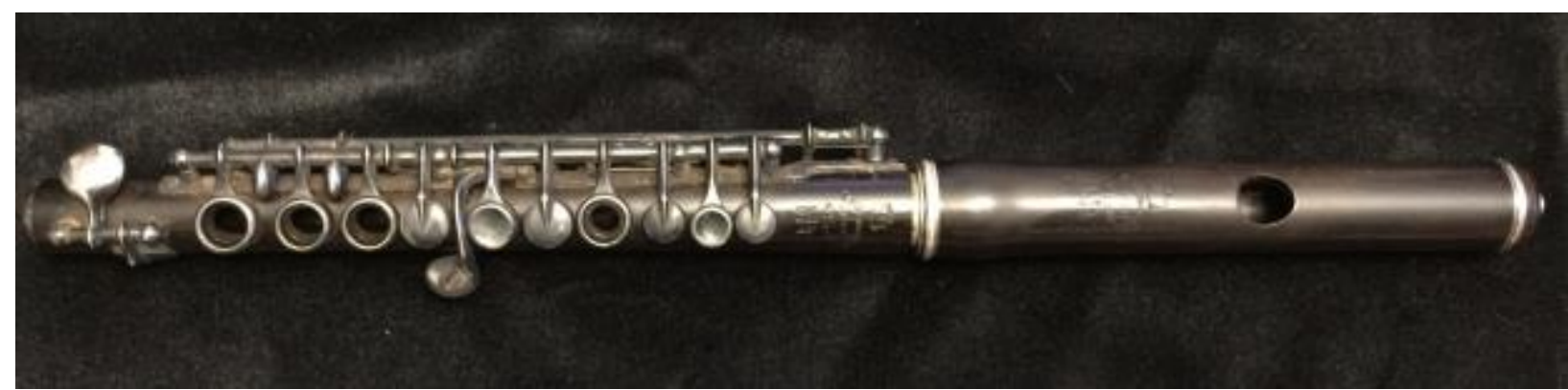

Figure 6. Thibouville Cabart ring-system piccolo, circa 1878.

Taking into consideration the dates of composition and origin, the works of Beethoven, Weber, and Spohr likely premiered on one-keyed piccolos as did Rossini’s Semirimide. However, William Tell was possibly written for a four-keyed piccolo due to the B6, which rarely appears on one-keyed fingering charts. 


\section{Twentieth Century}

The twentieth-century piccolo has seen the development of new scales (tone hole size and placement relationships), multiple improvements in pad materials and design, advances in mechanism structure, and the addition of auxiliary keys. The development of the modern piccolo began slowly as many players still performed on various simple-system instruments even into the 1920s. ${ }^{77}$ The continued use of simple-system instruments is further substantiated by the fact that Ernesto Köhler's Schule für Piccolo-Flöte (1900) was provided with a one-keyed and a sixkeyed fingering chart insert. ${ }^{78}$ The use of one and four-keyed piccolos fell out of favor after the 1920s since the availability of Böehm-system piccolos continued to grow. However, the use of six-keyed piccolos did continue even further into the twentieth century. Metodo popolare per Ottavino, Opus 108 (first publication 1870), was written by Jean Louis Tulou (1786-1865) a Professor at the Paris Conservatoire. The tutor was revised and republished under the title Tulou Metodo Popolare Carlo Andreoni in 1957 and contained a multi-keyed and Böehm-system fingering charts. ${ }^{79}$ The widely available 1957 edition demonstrated that the publishing company was attempting to accommodate both the old and new systems in the new edition. The Böehmsystem was likely not part of the original publication, because Tulou was an instrument maker and opposed to the Böehm-system. An example of a Tulou piccolo (Figure 8) exists in the flute collection of Michael Lynn, Professor of Recorder \& Baroque Flute and Curator of Musical Instruments Emeritus at Oberlin College and Conservatory. This example is a six-key, D-flat

77 Dombourian-Eby, "The Piccolo in the $19^{\text {th }}$ Century," 9-10.

${ }^{78}$ Ern Ernesto Köhler, Schule für Piccolo-Flöte. (Frankfurt: Zimmermann, 1900), insert.

${ }^{79}$ Eden, "The Piccolo: its History, Solo Repertoire and Usage since 1800 to Modern Day in Western Europe," 439. 
piccolo pitched at $\mathrm{A}=435 .^{80}$

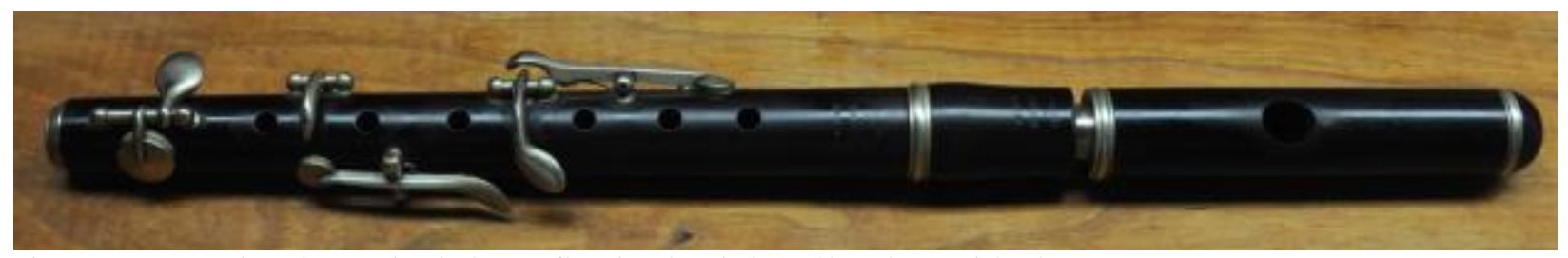

Figure 7. Jean-Louis Tulou, Paris. six-key D-flat Piccolo, Pitch A=435. Photo Michael Lynn

The piccolo received the greatest mechanical advancement at the beginning of the

twentieth-century. Performers and composers were aware of the inconsistency of instruments in use and growing demand encouraged makers to focus on applying the Böehm-system.

Instruments made of gold, silver, German silver, and many types of composite materials appeared in the market due to the growth in experimentation. The early twentieth century also saw a rise in the retail market and distribution of professional instruments. Large music retailers began marketing instruments under their company name although the instruments were made by well-known and respected makers not the retailer. Carl Fischer Music was one such retailer in New York and an importer of professional instruments. The company imported instruments from notable French and German makers and added the Carl Fischer logo, referred to as a stencil, before selling the instrument. Respected flute and piccolo maker, Emil Rittershausen (18521927), was a German maker who was trained by Böehm in the shops of Böehm \& Mendler. ${ }^{81}$ Rittershausen exported to Carl Fischer who added the Fischer stencil (see figure 9).

${ }^{80}$ Michael Lynn, “Tulou, Jean-Louis 6-key piccolo,” http://www.originalflutes.com/frenchflutes/tulou-jean-6-key-piccolo.html [accessed January 30, 2017].

${ }^{81}$ Eden, "The Piccolo: its History, Solo Repertoire and Usage since 1800 to Modern Day in Western Europe," 191-193. 


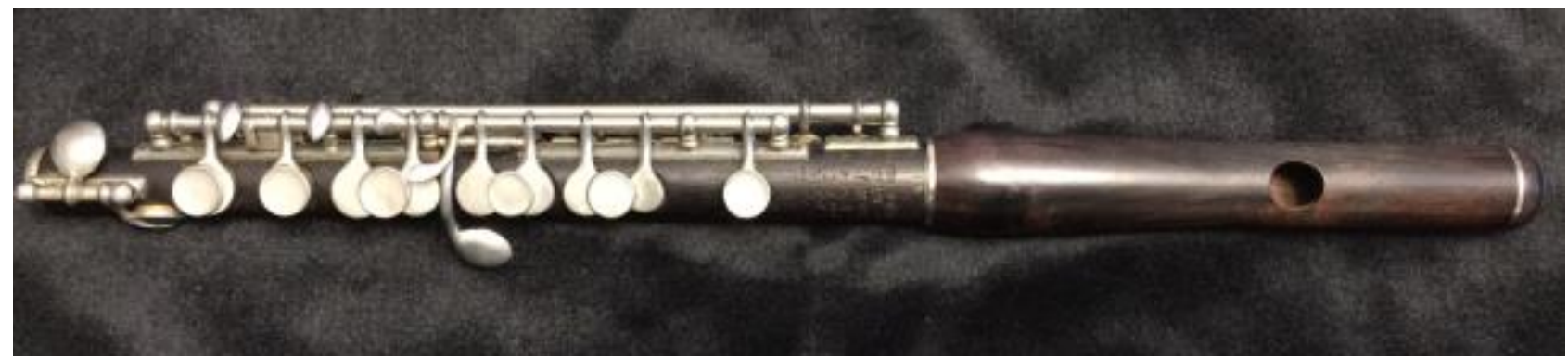

Figure 8. Boehm-system by Emil Rittershausen, Carl Fischer stencil piccolo, circa 1927.

The piccolo varied greatly in both design and materials during the early 1900s. The

William S. Haynes Company reported that 95 percent of piccolos sold in 1930 were silver with a cylindrical bore. Silver was scarce during World War II and metal for military instruments was purchased from private sources. Both Haynes and Verne Q. Powell Flute, Inc. discontinued the production of wood piccolos for a limited time after World War II. ${ }^{82}$ In 1950, both companies discontinued the production of cylindrical bore piccolos completely, continuing to make only conical bore wood and silver piccolos (see figure 10). During the same period, George Bundy

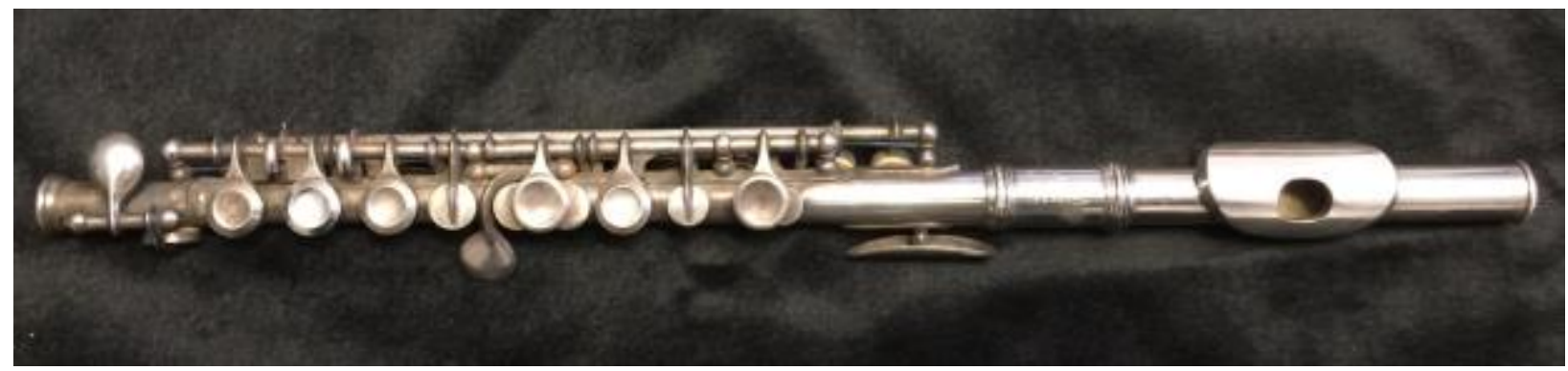

Figure 9. Carl Fischer silver conical D-flat piccolo, circa 1925.

was given the rights to distribute Selmer products in the United States which created more competition. Bundy predicted that the metal cylindrical bore piccolo would be the instrument of the future. ${ }^{83}$ Manufacturers in the early twentieth century were also producing $\mathrm{C}$ piccolos for orchestral playing, Db piccolos for band use, and a few Ab piccolos for symphonic and operatic repertoire that required the instruments to play down to middle C. ${ }^{84}$ Albert Cooper (b. 1924) was

\footnotetext{
${ }^{82}$ Heck, "The Mechanical Development," 80.

${ }^{83}$ Ibid., 81.

${ }^{84}$ Heck, "The Mechanical Development," 88-89.
} 
commissioned by the former principal flute of the London Symphony to build a piccolo to written C4. This commission, due to the upcoming recording of Benjamin Britten's Billy Budd which has a written $\mathrm{C} 4$ for the piccolo, resulted in the production of two cylindrical-bore piccolos. The production of these two piccolos encouraged Albert Cooper to return to his research to develop a new and improved scale for the cylindrical piccolo. ${ }^{85}$ Although the twopiece design made from grenadilla wood has remained the most prevalent for professional players, cylindrical metal piccolos are still manufactured but are predominantly used in school marching band programs. Cylindrical bored piccolos are not favored by most professional players mainly due to balance of scale and tonal qualities.

\section{Twenty-First Century Advancements}

Currently, makers like the Keefe Piccolo Company, Nagahara Flutes, Burkart Flutes and Piccolos, Hammig Piccolos, and Braun Flutes are providing their clients with options allowing them to customize the instrument for their own personal needs. Multiple head joint options, custom padding, alternate mechanism options including extended range to B4 and additional trill keys, as well as choices of materials all allow players to find a combination that works best for them.

\section{Head Joints}

Most of these companies offer several head joint style options. These include regular, heavy-wall, or thin-wall, all of which can affect the resistance and tone color of the head joint. Also, many of these makers offer head joints in gold, silver, grenadilla, kingwood, as well as many of the other exotic and tone woods mentioned previously. In conjunction with these

\footnotetext{
${ }^{85}$ Eden, "The Piccolo: its History, Solo Repertoire and Usage since 1800 to Modern Day in Western Europe," 242-243.
} 
options, they also offer lip plates and riser materials that differ from the head joint tube. Each of these companies offers several standard proprietary embouchure cuts. The option for a "custom" cut is listed on their websites, brochures, and order forms. This process usually involves meeting with the owner or head joint maker to obtain the exact cut desired. Flutists have had access to head joint options for many years either from the maker or by just exchanging their current head joint for one from another company. This means of changing head joints has not been as easy for piccolo players as the bore diameter, and wall thicknesses vary considerably from company to company, far more so than for flute companies.

There are now makers specializing in piccolo head joints. Eldred Spell and Tobias Mancke are two head joint makers of note. Eldred Spell customizes each head joint to the instrument and the player. He requires an appointment and a deposit, and the instrument must be sent to him. He then takes the necessary measurements for the instrument and makes an entirely custom head joint that works only with the instrument that it was made to match. This process can take anywhere from a week to a month or more depending on his backlog of orders. This process is not convenient for an active performer who is unable to part with their instrument for an extended period.

Head joint maker Tobias Mancke takes a different and innovative approach in keeping with the head joint selection process that allows flutists to try a head joint before purchasing. He has designed a system of barrels or adaptors that allow players to choose between any number of his head joints. The barrel adaptor and head joints are size-based and organized by a series of codes. These codes correlate to different piccolo maker's design specifications allowing the player to test and play many of the Mancke head joints without altering the piccolo body in any way. Because of Mancke's approach, a player can purchase several Mancke head joints in 
different materials allowing for more flexibility and a wider tonal palette. One might not want to use the same head joint for a concerto performed in a large hall as that for a solo or chamber performance.

\section{Materials Used in Construction}

Makers have selected many different materials in the construction of their instruments. Some materials are chosen due to availability and cost while others are chosen for ease of manufacturing. Most instrument makers choose a material for its acoustical properties and the overall effect on tone production. Over the centuries makers have developed better and more consistent ways of machining or milling these materials. Piccolos and flutes have been made of various metals, woods, and plastics, glass, crystal, bone, and ivory. The two most common materials for making piccolos are metal and wood. Different metals and woods have varying properties in both appearance and sound that make them more attractive to the maker and the individual performer. The density of the wood, consistency, and properties of the grain, workability, and susceptibility to moisture all contribute to material choice.

The use of metal in the production of piccolos and flutes had previously been limited to the key work, ferrules, and pivot pins once keys were added. Precious metals like gold and silver are favored for their malleability and tonal properties. As these metals are softer and can dent more easily, they require more care. Many student piccolos are made from a brass alloy tube for strength with silver or nickel plating added for aesthetic and tonal enhancement. Silver is more common than gold and is available in numerous alloys. Sterling silver is $92.5 \%$ pure silver with the remaining $7.5 \%$ being copper or nickel and is the most prominent. Some piccolos are coin silver which can be anywhere from $80 \%-90 \%$ pure silver with the remaining $10 \%-20 \%$ being 
copper or nickel. The higher pure silver content adds additional resistance to the instrument resulting in a "darker" and "warmer" sound.

The choice of wood for piccolos has not changed much over the centuries. The use of bone and ivory has fallen out of favor due to the instability of the material. As bone and ivory decay, they tend to shrink and crack. The international regulation of ivory also precludes the use of most ivory sources as the ivory would have been collected from now endangered species. Grenadilla ${ }^{86}$ and Cocus ${ }^{87}$ woods are the primary materials for modern professional level instrument makers although a few offer woods that are more exotic. Verne Q. Powell Flutes, Inc. ${ }^{88}$ offers the option of a piccolo made from Kingw ood. ${ }^{89}$ Tobias Manke offers nine different wood options for his piccolo head joints.

Rosewood - a very dense wood with a rich sound and electric tone. African Olive - smooth, liquid sound with a wooden undertone. Bocote - light and bright.

Pink Ivory - an incredibly dense wood. Full sound.

Kingwood - very easy to play, with a full sound.

Cocobolo - dense, polished wood; like Grenadilla but slightly softer in outline. Cocuswood - a softer, more spread sound.

Mopane - a hard wood with an edge of brilliance in the sound.

Grenadilla - the traditional wood. Full sound with good projection. ${ }^{90}$

${ }^{86}$ African Blackwood is a fine and straight grain wood most often used in turned objects, where it is considered to be among the very finest of all turning woods. When made into clarinet or oboe bodies, the wood is typically processed on metal-working equipment, giving it a reputation as being metal-like in some of its working properties. http://www.wood-database.com/africanblackwood/ (Accessed November 16, 2016)

${ }^{87}$ Commonly known as the Jamaican Rain Tree. Traditionally, Cocuswood has been considered one of the very finest of tonewoods, used extensively for woodwind instruments in the 1800s. The Wood Database http://www.wood-database.com/?s=Cocus [Accessed November 16, 2016] ${ }^{88}$ Powell Flutes, https://powellflutes.com/piccolos/handmade-custom [Accessed November 16, 2016]

${ }^{89}$ Kingwood is among the densest and probably strongest of all the rosewoods. Easily turned and able to be highly polished. The Wood Database, http://www.wood-database.com/kingwood/ [Accessed November 16, 2016]

${ }^{90}$ Carolyn Nussbaum Music Company, https://www.flute4u.com/store/Mancke-PiccoloHeadjoint.html [Accessed November 16, 2016] 
Some companies offer synthetic materials that emulate the tonal qualities of wood but are not affected by moisture or temperature extremes which can cause wood to crack. Ebonite is a hard, rubberized material that looks like dark wood, is easily machined, does not warp or crack, and produces a sweet wood-like tone. Ebonite was first introduced around 1840 and was predominantly used for piccolos due to frequent use outdoors. Ebonite is the name associated with musical instrument manufacturing although the material is more generally known as vulcanized rubber. Conn Instruments made piccolos with a cylindrical metal body and an ebonite head joint combining the new material into a production model (see figure 2)

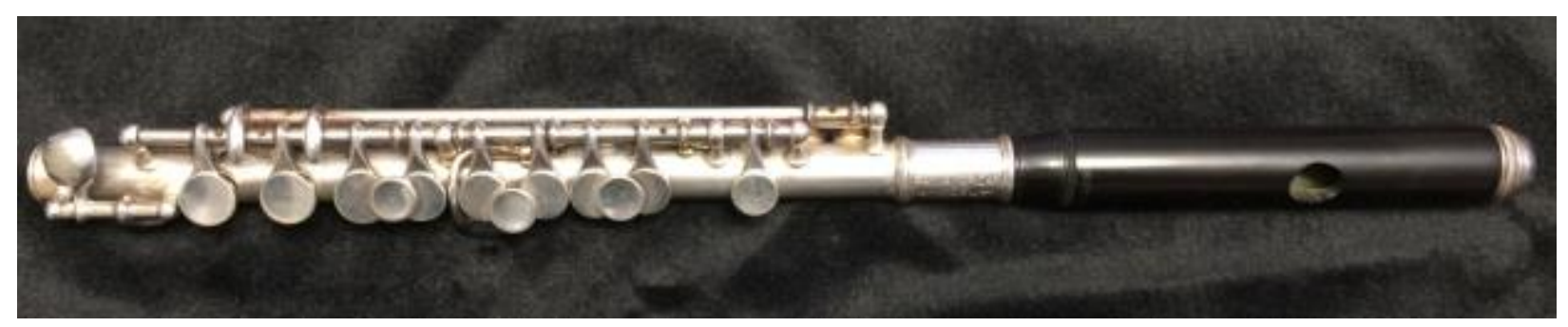

Figure 10. Conn Pan American model with ebonite head and silver body, circa 1925.

\section{Padding Design}

Traditionally, piccolo pads were not dissimilar to flute pads. Leather swatches glued to keys, purse pads, felt pads covered in leather, or pieces of cork, these styles were utilized on simple system flutes. Due to the small keys and key heights, most of which are less than two millimeters, the thickness of the pad was critical in providing proper venting without affecting the pitch or tone. Twentieth-century piccolos rely on bladder covered felts with card backings as found on most models available today. Cork is used by some makers on the waterline keys although some players choose to invest in having the entire instrument corked which tends towards a brighter sound and greater volume.

Another type of pad that has become popular is one designed by David Straubinger. This pad also has a bladder covered felt but includes a plastic stabilizer that replaces the card backing 
of the standard pad. This plastic stabilizer provides a sturdier and more stable pad making it less susceptible to changes due to the weather. Some players experience a greater response in resonance from the instrument. Installing Straubinger pads requires that the key cups must level with the tone holes, because there is no give from the pad surface. The high cost of the pads is prohibitive and requires a great deal of preparatory work to get the mechanism to the highest tolerances necessary for these pads. Several high-end piccolos, like Keefe piccolos, come standard with Straubinger pads.

When comparing Straubinger pads, cork pads, and standard pressed or woven felt pads, players notice that both the response of the piccolo and the tone change. Standard pads feel softer and have more give while the cork and Straubinger pads have none. The sound of a piccolo with cork padding is far brighter than standard pads while the Straubinger pads are somewhere in the middle. Technicians tend to find cork far more challenging and unforgiving than either of the other two pad styles but require the same type of mechanical perfection as the Straubinger pads. Standard felt pads are the most forgiving, far less expensive, and easiest to work with allowing more variation in the mechanical regulation.

\section{Mechanism}

The modern piccolo mechanism has finally caught up to that of the modern flute, and most of the advancement has taken place in the last thirty years. In the mid-twentieth century, Arthur Murray experimented with the Böehm-system seeking to improve it further. In 1948 Murray, soloist in England's Royal Air Force Band made changes to the system that included open G-sharp and D-sharp keys and a touch piece for F-sharp like that of Brossa. Walfrid Kujala, piccolo with the Chicago Symphony, felt that these changes allowed for more flexibility in the 
right hand. These changes were applied to the flute as well. Only fifty Murray flutes and six Murray piccolos were produced by the Armstrong Company in 1972. ${ }^{91}$

In 1992, John Fonville, recording artist and contemporary performance specialist at University of California, San Diego, presented the idea of an open-holed, full quarter-tone piccolo to various flute makers. The holes would be cut through the cork pad allowing the piccolo to produce perfect quarter-tones and would require two additional quarter-tone keys. Eva Kingma, known for her quarter-tone flutes agreed to collaborate with Fonville, and he now performs on a full set of quarter-tone flutes (piccolo, C concert, alto, bass) made by Kigma. ${ }^{92}$

The Lopatin Flute Company owned and run by Leonard Lopatin, former third flute and piccolo with the Metropolitan Opera Orchestra, was started in 1994. Lopatin believed that the concept of square tone holes might provide a sharper edge for venting the air column at each tone hole. His line of flutes made with this design is called SquareOne and he has applied the concept to the piccolo with great success. ${ }^{93}$

Keefe piccolos are made by Jim Keefe and Janet Kinmonth, in Boston, Massachusetts. Jim Keefe began his career building piccolos for Brannen Brothers in 1978 eventually becoming vice president of the company. He is widely known and respected for his innovative head joint and mechanism designs. Janet Kinmonth worked at Brannen Brothers from 1984 until 1999, finishing piccolos and serving as the finishing department manager. The company offers three

${ }^{91}$ Wacker, "The Piccolo in the Chamber Music of the Twentieth Century: An Annotated Bibliography of Selected Works," 12.

92 John Fonville, "Let's Talk Picc: The Open-holed Piccolo.” Flute Talk 15, no. 6 (February 1996): 31-32; UC San Diego Division of Arts and Humanities, "John Fonville,"http://musicweb.ucsd.edu/people/people.php?cmd=fm_music_directory_detail\&query_ Full_Name $=+$ John + Fonville\&query_Active_Status $=$ Faculty $\% 203 \% 20$ Emeritus [accessed

February 10, 2017]

93 The Lopatin Flute Company, "The Lopatin SquareONE Piccolo," http://www.lopatinflutes.com/SquareONE piccolo.htm [accessed February 10, 2017] 
head joint styles as well as custom head joints. In addition, $14 \mathrm{k}$ gold options are available for the rings and sleeves on their head joints. Several innovative key work options are available including, Brossa F-sharp (see figure 11), the vented C key (see figure 12), split E mechanism, a G-sharp trill key, and a C-sharp trill key (see figure 13). The C-sharp trill key functions just as it does on the flute. The mechanism includes an additional tone hole and key between the trill and thumb B-flat tone holes as well as an additional lever near the chromatic B-flat lever. This mechanism has only recently become available likely due to the compact size of the piccolo and the inherent design problems that arise with additional key work in such a compact space.

Figure 11. Keefe Brossa F sharp.
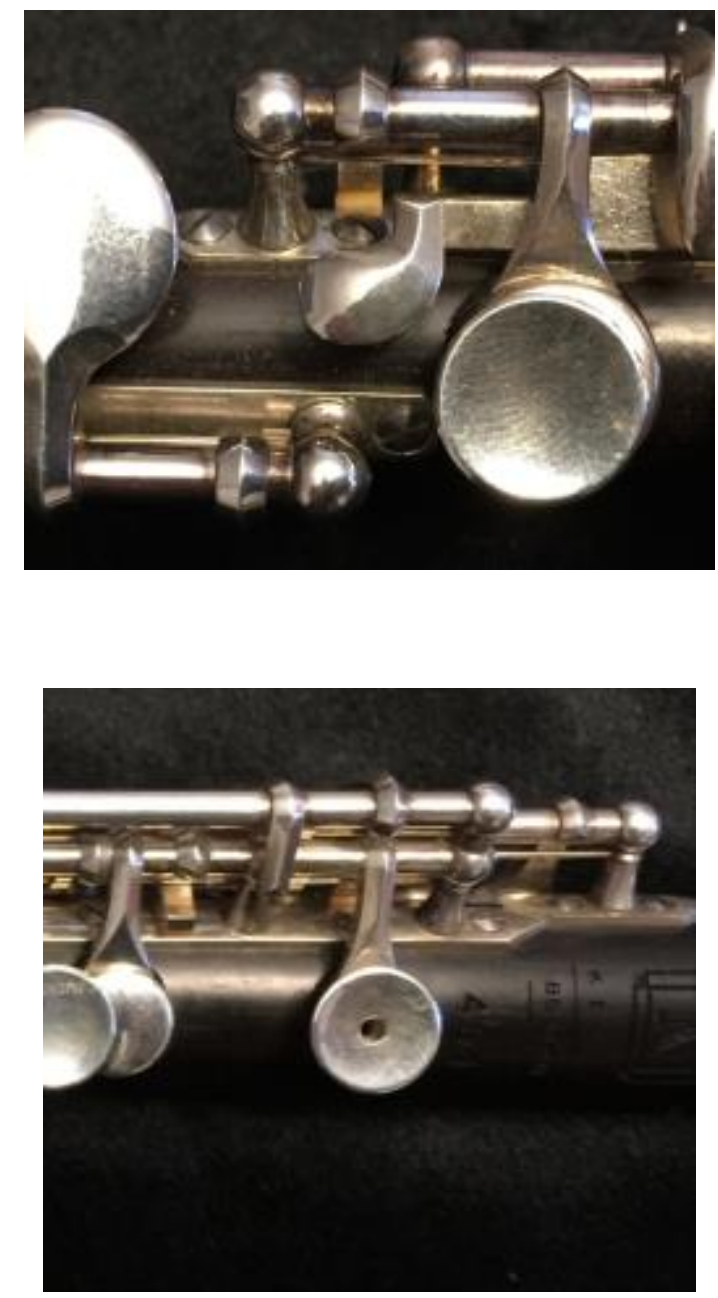

Figure 12 Keefe vented C key. 


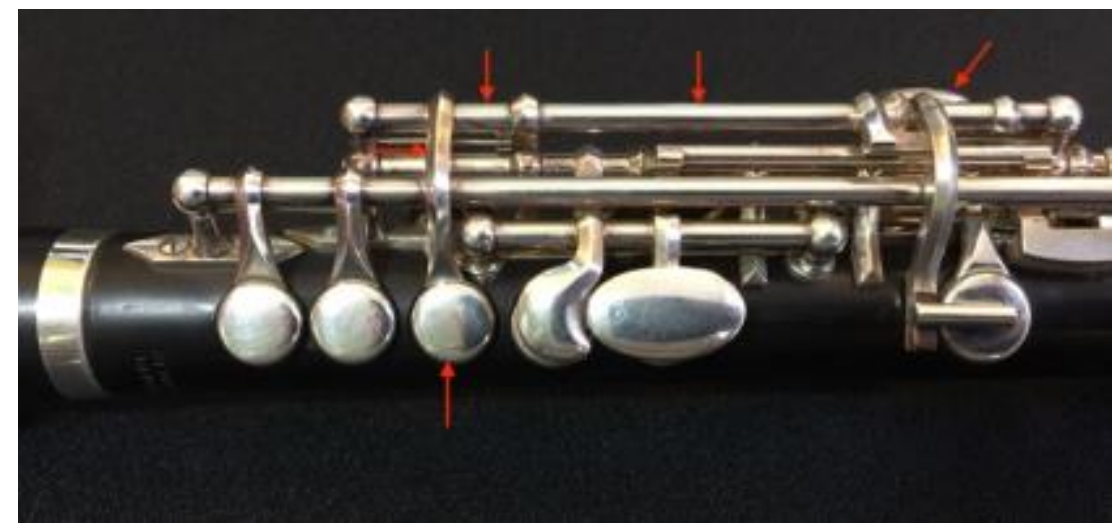

Figure 13. Keefe C sharp trill.

The G-sharp trill key facilitates the trill from G7 to A7, normally an awkward or impossible trill on most piccolos. The mechanism for this trill (see figure 14) includes the addition of a touch piece for the right hand that couples with the C-sharp trill key and allows the player to simultaneously vent the G-sharp and C-sharp trill tone holes with only one finger. ${ }^{94}$

Figure 14. Keefe G\# Trill Mechanism.

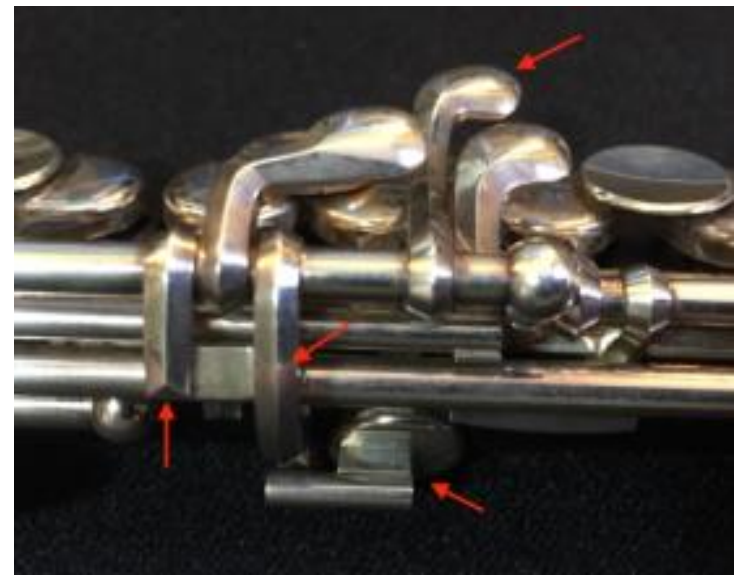

Nagahara Flutes Company has developed the Mini, which is not unlike the historical small flutes but with the benefits of modern technology, mechanisms, and materials, and a range to low B. The Nagahara Mini is produced with a slight taper to the head joint and an enlarged, cylindrical body allowing it to play more like a flute. Nagahara's goal was to create a piccolo

\footnotetext{
${ }^{94}$ Keefe Piccolos, http://www.keefepiccolo.com/index.html?hjoint.html [Accessed November $16,2016]$
} 
that is more in keeping with what they believe to be the original intention for the piccolo, "a miniature flute." Kanichi Nagahara also redesigned the scale which has more than doubled the size of the tone holes. This ventilation allows for more expression possibilities regarding dynamics and tonal colors. The Mini is also capable of producing written B3. Their desire to extend the range has resulted in the development of a patented mechanism, the "B-key touch." This mechanism, while allowing the production of written B3 also keeps the B-key closed when not in use, effectively acting as a gizmo-key or high $\mathrm{C}$ facilitator when engaged to produce the upper register. The company also has a newly designed thumb-key that strengthens the mechanism and elongates the B-natural touch piece. This moves the fulcrum point on the key, thus changing the balance and feel of the key work ${ }^{95}$ Nagahara offers three different styles of head joints and riser designs to suit the needs of players. It should be stated that the brochure reads, "this is not a piccolo." Although the instrument is intended to be used for the piccolo repertoire, Nagahara views this as a "mini-flute," rather than a traditional piccolo.

Anton Braun, a German flute and piccolo maker, has been producing piccolos since 1985 . His instrument was designed with input from flutist Michael Hasel and chief conductor Herbert von Karajan both from the Berliner Philharmonike. Braun redesigned the tone hole placement and size using new calculations to produce a "well-tuned" instrument. His piccolo uses one single C tone hole for the thumb key, known as the "Briccialdi Thumb-key," a design developed by and named for Giulio Briccialdi (1818-1881). Braun states that the recalculations implemented into his design give the instrument excellent intonation and tonal balance and a big focused sound, especially in the low and middle registers. The response is easier, or less resistant, especially in the difficult third octave making the high G-sharp facilitator no longer

${ }^{95}$ Nagahara Flutes, http://www.nagaharaflutes.com/mini [Accessed November 16, 2016] 
necessary. Braun offers a model that he refers to as, "the small flute" that can play a written C4. This model has been available since 2010 and was requested by Rolf Bissinger, a member of the city opera in Frankfurt. At one point, Braun made a cylindrical model piccolo but mentions on his website that the cylindrical model is far inferior to the conical model, and that they no longer include it in production. ${ }^{96}$ The addition of a written $\mathrm{C} 4$ mechanism adds acoustical benefit and accommodates those passages from the orchestral repertoire that include this note for the piccolo in the score. A list of these passages as well as further historical explanation can be found in the June 2011 edition of the Journal of the British Flute Society in an article titled, "The new Anton Braun piccolo to low C," written by Klaus Dapper. ${ }^{97}$

While the Braun and Nagahara companies are promoting instruments capable of playing a written $\mathrm{C} 4$, this is not a new concept. As cited in the previous chapter, piccolos extended to written C4 were extant in the late Romantic period and early twentieth century, and written C4 and C\#4 were called for in works from that period. The Dayton C. Miller collection lists on their checklist of instruments an anonymous piccolo in C (No. 747) and a J.C. Haynes and Company piccolo (No. 182) that were made with the C4 mechanism. The Haynes piccolo was made in 1897 for a member of Sousa's band. ${ }^{98}$

The piccolo of the twenty-first century is a far cry from the instruments used three hundred years ago. More accurate intonation due to enhanced measurements of bore and tone hole size as well as the addition of auxiliary mechanism to aid in pitch and technical facility have raised the standards for construction. These superior instruments have placed the piccolo on par

\footnotetext{
96 Braun Flutes, http://www.braunflutes.com/piccolo_en.htm [Accessed on November 18, 2016]

${ }^{97}$ A link is provided to the article, including historical photos, on the Braun piccolo website.

98 Nourse, “The Piccolo: An Overview," 57.
} 
with its concert flute counterpart and undoubtedly have pushed the envelope for modern compositions. 


\section{Chapter Four - Problematic Pedagogy}

The Problem

This chapter presents challenges faced by piccolo players related to poorly written method books and the lack of piccolo teachers or flute teachers who include piccolo as part of their curriculum. Specific emphasis will be given to the teachings of William Hebert and the seven crucial skill areas of intonation, articulation, phrasing, embouchure, breathing, vibrato, and dynamics and tone color.

Fredrick W. Westphal, author of Guide to Teaching Woodwinds states, "Teaching the woodwind instruments with good results becomes a fairly simple process when the instruments themselves are fully understood and when appropriate techniques, procedures and materials are used in abundant variety. $" 99$ There are twenty-two documented tutors for the piccolo from before 1865 until 1929. ${ }^{100}$ Many of the sources do not contain publication dates; dates had to be inferred based on the tutor's author. Several of the piccolo tutors are excerpts from flute tutors that were then poorly edited for an appropriate piccolo range and then carelessly produced with multitudes of errors and inconsistencies. The publications of the early tutors appear to be motivated only by profit, not pedagogy. ${ }^{101}$ Another prevalent issue with many of the tutors is that there is no indication as to which model of piccolo they were written for, one- or four-keyed. Poorly written piccolo tutors represented the bulk of the pedagogical material for the instruments prior to the twentieth-century. John Krell, former piccolo with the Philadelphia Orchestra and teacher at the Curtis Institute quotes his former teacher, William Kincaid, as saying, "There are

${ }^{99}$ Fredrick F. Westphal, Guide to Teaching Woodwinds, (New York: McGraw-Hill Publications, 1989), 1.

100 Zartouhi Dombourian-Eby, "A History of the Piccolo," (Flutist Quarterly 16, no. 1, 1991), 16.

101 Ibid., 16. 
no piccolo method books as such, and no one really gives piccolo lessons." ${ }^{102}$ Without such protocol, many teachers and players are not convinced of the need for piccolo instruction. Many teachers of flute do not have the experience necessary to assist students with the piccolo idiosyncrasies, and students must learn the piccolo in the traditional "trial by fire."103

While the limited availability of teachers was problematic, so was the lack of reliable and well-written methods. Many of the methods were taken from flute tutors and methods or simplified versions of them. The Schule für Piccoloflöte (c.1898) by Ernesto Köhler is an example. This flute tutor was published as no. 55 in the series while the piccolo tutor was no. 151. The differences between the methods are limited to Köhler addressing a different placement for the piccolo on the lip and the translations in which the tutor was available. While the flute tutor includes instruction on articulation, the piccolo tutor does not. ${ }^{104}$ Another example of an incomplete tutor is Metodo populare per Ottavino Opus 108. As mentioned previously, this was originally a flute tutor which contained a small section for the piccolo. This tutor excerpt would later be republished in 1957 by Riccordi acknowledging the original composer and the new editor in the title.

Emily Orr's doctoral dissertation, Teaching the Piccolo: A Survey of Selected College Flute Teachers (2005) addresses this lack of formal piccolo instruction. Orr surveyed sixty-five flute teachers of undergraduate students at schools accredited by the National Association of Schools of Music (NASM) on their pedagogical approach to the piccolo. Her dissertation summarizes the survey results, revealing the most common pedagogical practices among college

102 John C. Krell, Kincadiana, (Santa Clarita: The National Flute Association, Inc., 1997), 99.

${ }^{103}$ Emily G. Orr, "Teaching the Piccolo: A Survey of Selected College Flute Teachers," (D.M.A. diss., The University of North Carolina at Greensboro, 2005), 2.

${ }^{104}$ Eden, "The Piccolo: its History, Solo Repertoire and Usage since 1800 to Modern Day in Western Europe," 420-423. 
flute teachers. ${ }^{105}$ The survey was divided into: biographical information on the respondents, instruments and pedagogical materials, and pedagogy. Orr provides "descriptive text and tables," and three chapters of responses as received during the survey. ${ }^{106}$ The first question on Orr's survey was, "Was piccolo a required part of any of your own degree work?" This question resulted in a very telling response. Seventy-eight and a half percent of the participants replied to the question with "no." The second question regarding the teaching of piccolo was, "Is piccolo study a required part of your flute curriculum?" Of the teachers who responded, 59\% stated that it was not a required part of their curriculum. These two questions show that there is a continued lack of training on the piccolo. It also leads one to draw the conclusion that a large percentage of teachers who did not study piccolo have students who do not study the piccolo. ${ }^{107}$

Why does history shows a lack of piccolo teachers and reliable methods? The primary factors contributing to this lack are the evolution of the piccolo as an auxiliary instrument to the flute and the delayed mechanical development. The difficulty of the instrument and the challenging and exposed solos may also have deterred some from studying the piccolo. Robert E. Milliard, former flutist with the Minneapolis Symphony, has stated, "many a good flute player who has a fine flute uses an inferior piccolo, perhaps poorly padded or otherwise in bad shape." 108 The demanding solos being written for the piccolo were made even more challenging due the poorly designed and maintained instruments on which they were being played. As the piccolo developed and earned a more prominent role in solo and ensemble compositions, the need arose for competent players.

\footnotetext{
105 Ibid., 3.

106 Ibid., 9.

107 Orr, "Teaching the Piccolo: A Survey of Selected College Flute Teachers," 13-14.

108 Nourse, "The Piccolo: an Overview," 116.
} 
Many flutists have their first experience with the piccolo in high school marching band or concert band where they are handed an instrument and left to figure it out on their own. ${ }^{109}$ Some students seek out those performers who excelled on the piccolo, namely in the orchestra, to receive more specialized training. Trevor Wye suggests that it may be simply the difficulty of the instrument and the fear of the exposed solos which players are called upon to perform that prevent many from playing the piccolo. ${ }^{110}$ The end of the nineteenth century brought about many advancements in the design of the instrument and the repertoire written for piccolo; however, the availability of teachers was limited.

The "trial by fire" method is still the primary route that many piccolo players find themselves taking. Piccolo players that have held positions in major orchestras around the United States like the Los Angeles Philharmonic, the Philadelphia Philharmonic, the Pittsburgh Symphony, and the Saint Louis Symphony, have won auditions despite having never studied with a master piccolo teacher. Players who claim these prime orchestral spots began playing piccolo out of necessity to cover a part in a performance, to win a job, or in high school marching band. These players and their highly-acclaimed positions represent the pinnacle of success attained only through a great deal of hard work. Having a teacher specializing in piccolo would have helped them better prepare for this path. A teacher who specialized in piccolo would have provided them with more guidance when learning the idiosyncrasies of the piccolo and thus, lessened the "trial by fire" aspect.

\footnotetext{
${ }^{109}$ Ibid., 1.

${ }^{110}$ Ibid., 3.
} 


\section{The Pedagogical Perspectives of William Hebert}

A well-known and respected piccolo teacher from the mid-twentieth century, William J. Hebert learned in the "trial by fire" method. He attended Julliard with classmate Samuel Baron, founding member and flutist of the New York Woodwind Quintet and, at age twenty-four, auditioned for the Cleveland Orchestra. He was given no audition list and his preparation consisted of hand-copying the piccolo parts orchestral scores and practicing on his own; his flute teacher would not hear the piccolo in lessons. Hebert won the job and became the tenured solo piccolo for the Cleveland Orchestra from 1947 to his retirement in 1988. He would later serve as flute and piccolo professor at Kent State University and Baldwin-Wallace Conservatory. ${ }^{111}$

William Hebert's concepts of performing and teaching were derived from his own experiences with primary teachers James Pappoutsakis and Arthur Lora, both of whom had very different teaching styles, and neither of whom cared for the piccolo. Hebert felt that his personal teaching style was not best served in the master class setting but rather as a problem-solver working with a student one-on-one. He felt that a balance of explanation and demonstration was highly effective, but that acknowledging the differences in students and addressing them as an individual was the most effective. He believed that it was his responsibility to find a way to articulate what he was doing, and that there was not simply a prescribed method of accomplishing certain musical goals. ${ }^{112}$

William Hebert identified seven specific areas that he believed to be the most crucial skills to master for flute and piccolo players: intonation, articulation, phrasing, embouchure,

\footnotetext{
${ }^{111}$ Roseman, Joseph Jacob, "William Hebert: Fundamentals of Playing and Teaching Piccolo," (D.M. diss., The Florida State University, 1996), 8-11.

112 Roseman, "William Hebert: Fundamentals of Playing and Teaching Piccolo," 6-9.
} 
breathing, vibrato, and dynamics and tone color. ${ }^{113}$ The balance of this chapter will expand on Hebert's view on these seven skills.

\section{Hebert Intonation}

Hebert considered intonation the biggest challenge for a piccolo player as pitch can vary significantly between instruments. The upper register of the piccolo tends to play flat which is the opposite of the upper register on the flute. Hebert recommends placing the piccolo half-way into the lower lip allowing it to act as a cushion for the instrument. The lips act as an octave key and flexibility it is paramount to adjusting pitch while maintaining a characteristic sound. Hebert specifies six techniques to adjust pitch: rolling the piccolo mouthpiece in or out, moving the head upward or downward, moving the jaw inward or outward, placing pressure on the lower lip, alternate fingerings, moving the jaw upward or downward. Hebert also suggests experimentation to figure out what technique is best to use for each situation. In many cases, the repertoire may require the use of several combinations of these methods. Every piccolo player must learn to use alternative fingerings to improve on each of the categories, and some fingerings may not work on every instrument. ${ }^{114}$ Hebert suggests practicing scales and arpeggios to determine the pitch tendencies of an instrument.

\section{Hebert Articulation}

Regarding articulation, Hebert believed that the expressiveness of a given mood could be enhanced simply by connecting or separating the notes. He also felt that the approach to articulation is quite like the flute but that one must be careful not to tongue to heavily. The tonguing on the piccolo should be "light as a feather." Tongue placement and vowel formation

\footnotetext{
113 Ibid., 12.

114 Ibid., 12-15.
} 
are important and one needs to experiment to find what works best. The main difference between the flute and the piccolo is the amount of air pressure behind the articulation. Because the piccolo air pressure is greater, the lips must be firmer to keep from buzzing. This same air pressure used in flute articulation can cause the tongue to propel itself forward and create a much heavier articulation than intended. ${ }^{115}$

Hebert emphasizes the difference between French, German, and American styles of articulation. These differences are based on tongue shape and placement can be attributed to the language and vowel formations. In general, the French say "tu," and the Germans say "du," while the American system of articulation, formulated by William Kincaid, is somewhere in between the softer and harder syllable using a "tcheeh."116 Just as the tongue placement for vowels varies widely across languages, it also varies greatly in articulation.

Hebert states that one should refrain from overplaying in fortissimo or staccatissimo sections and recommends that players ignore the "tissimo." He believes that space between notes in double-tongued, staccato sections should come from the use of clear syllables, but players should avoid playing staccatissimo in these sections. He suggests the use of "that," as the initial syllable with good breath support from the diaphragm behind the tongue. ${ }^{117}$

Another issue prevalent with piccolo articulation is tongue flapping. This percussive sound that occurs when players are double tonguing is a sign that the tongue is moving too far between primary and secondary syllables. Keeping the tongue at a closer distance between the syllables should solve this issue. This percussive sound creates what Hebert terms "garbage" in the sound. He suggests tonguing more lightly, pursing the lips and moving them more forward,

\footnotetext{
115 Roseman, "William Hebert: Fundamentals of Playing and Teaching Piccolo," 16-18.

116 Ibid., 18.

${ }^{117}$ Ibid., 18-19.
} 
as well as exchanging the syllable, "tah," for "dah." Students should practice double tonguing by first playing single tonguing scales between M.M.=72-112 and then switch to double tonguing the same scales between M.M.=96-112. This will create a flexibility in the player's tonguing, preparing the player for the possibility of a conductor taking a different tempo during the performance than in the rehearsal. One additional suggestion is that players practice double tonguing by reversing the primary and secondary syllables, changing "tah-kah," to "kah-tah," thus balancing the syllables and eliminating the possibility of additional accents on the initial attack while also creating more flexibility. ${ }^{118}$

There are instances when Hebert suggests tonguing between the lips which is especially useful for high, soft attacks. Many use this articulation in a series of notes while Hebert prefers only to use it for attacks. Trevor Wye, a British flute pedagogue, describes this as the "dewdrop" stating that it is a necessary articulation for the orchestral player to master. ${ }^{119}$

\section{Hebert Phrasing}

Phrasing is the proper division or separation of the musical line. This includes the length of the phrase and smaller note groupings that belong together. Hebert suggests that students sing the phrase to find the natural shape. He cites the differences between French and German schools of phrasing, preferring a combination of the two. The French tendency is to crescendo when the phrase ascends and decrescendo when the phrase descends, while the German concept is more complex. Germans place the strong beats on one and three in a 4/4 meter. If a phrase or statement were four measures long, the third bar would be the climatic point; thus, measures one and two lead to measure three and then relax on measure four of the phrase. Hebert suggests students

\footnotetext{
118 Roseman, "William Hebert: Fundamentals of Playing and Teaching Piccolo," 19-20. 119 Ibid., 19.
} 
experiment finding a balance between the styles that is most appropriate for the phrase. Players should shape phrases giving different weight to different notes. Give direction to phrases by anticipating musical direction before the notes on the strong beat. He also suggests tapering phrases, making sure not to end the phrase too abruptly but still allow time to take in enough air for the next phrase. ${ }^{120}$

\section{Hebert Embouchure}

With regards to piccolo embouchure, Hebert makes the comparison that the first octave of the piccolo is comparable to the second register of the flute, and the second register of the piccolo is analogous to the third octave of the flute. The differences appear in the extreme high register of the piccolo and the extreme low end of the flute. Hebert approached embouchure with flexibility and did not seek to change a student's embouchure. He felt that if the student was good enough to enter the music program, then their embouchure should be left alone. However, if after several months, a student was still struggling with a technique, he would then explore possible modifications to the embouchure. Due to the smaller size of the piccolo, it should be placed higher on the lower lip to avoid covering the embouchure hole too much. ${ }^{121}$ This position maximizes airflow and gives the best control to the player allowing the lips to remain flexible.

\section{Hebert Breathing}

As an avid believer in the Alexander Technique, Hebert supported the idea that breathing is a whole-body effort. The Alexander Technique focuses on posture and initially on the neck and shoulders where most of a player's tension manifests itself. This tension can affect playing position and inhibit the body's ability to take a deep breath. Deep breathing requires more energy

\footnotetext{
${ }^{120}$ Roseman, "William Hebert: Fundamentals of Playing and Teaching Piccolo," 23-24. 121 Ibid., 24-26.
} 
and effort, and this is where many players fall short. Several smaller breaths can be far more successful especially during a series of connected phrases. Hebert asserts that a "good" breath is difficult to describe without becoming too technical. The challenge is to get the air down to the lower portion of the lungs. There are many ways to convey this idea. Focusing on the solar plexus or abdomen works for most, but Hebert imagined an inner tube around the middle of the body and focused on inflating the tube. He believed that breathing mechanics were similar regardless of the instrument being played, but that the abdominal pressure exerted by the diaphragm in relationship to the embouchure is the differentiation between instruments. The player must find the appropriate breath for the phrase while maintaining necessary support and avoiding tension. ${ }^{122}$

\section{Hebert Vibrato}

Regarding vibrato, Hebert suggests that piccolo vibrato is not unlike flute vibrato except for one difference. He recommends using faster and narrower vibrato as one ascends to the higher registers and prefers using limited, if any, vibrato in the top register. The ear tolerates a slower and wider vibrato on lower frequencies, but pitch fluctuation in the upper registers of the piccolo becomes too intrusive. Vibrato with a wide amplitude could create problems with ensemble tuning, especially in the top octave. Vibrato should be part of the tone and not something additional. Ultimately, it is a matter of taste. Hebert's concept of when to teach vibrato changed over the years. In the beginning, he would only teach vibrato to students who demonstrated a clear, supported tone in all three registers. Later he found that students who had issues with tonal clarity in the higher register benefited from working on vibrato, and the result

122 Roseman, "William Hebert: Fundamentals of Playing and Teaching Piccolo," 27-31. 
was a much clearer tone. ${ }^{123}$ Vibrato work builds on both breath control and placement as well as aids in control and flexibility in the embouchure.

\section{Hebert Dynamics and Tone Color}

Hebert saw dynamics and tone color as two separate entities on the piccolo. He describes dynamics as the volume of air that passes over the embouchure hole. He categorizes tone into three different colors: red, yellow, and blue which can be varied by altering the number of overtones present in the sound thus changing the quality of tone from "edgy" to "hollow." By mixing these primary colors it is possible to get sixty-four possible colors on the flute. However, the piccolo is far more difficult to play in the upper register and thus more limited, making the piccolo far less expressive in the highest notes. Players should strive for complete control over dynamics and intonation in all registers. Unfortunately, dynamics affect pitch on the piccolo far more than on the flute due to the smaller size of the instrument. This makes it far more difficult for players to keep from going flat during a diminuendo. High, sustained pianissimos are one of the greatest challenges piccolo players face. Hebert recommended that the player relax the lips and let the air do most of the work. Keeping the lips pursed forward will help the air stream to maintain the proper angle of attack, preventing the lowering of the pitch, and the relaxed lips will have more control over the pitch as well. It is also important to understand the context of the passage being played. A solo in the higher register of the piccolo marked piano may be played a bit louder if, in the context of the ensemble, the piccolo is being accompanied by more instruments. In this case, the passage will still sound piano. ${ }^{124}$ The instrumentation greatly affects

\footnotetext{
${ }^{123}$ Roseman, "William Hebert: Fundamentals of Playing and Teaching Piccolo," 31-33.

${ }^{124}$ Roseman, "William Hebert: Fundamentals of Playing and Teaching Piccolo," 33-36.
} 
dynamic perspective for the piccolo player, and great care must be taken to adapt written dynamics to those of the ensemble.

Some prominent piccolo teachers continuing the legacy of William Hebert into the twenty-first century are Cynthia Ellis, Walfrid Kujala, Jan Gippo, Mary Stolper, and Trevor Wye. While several current prominent piccolo teachers have studied with a master piccolo teacher, most orchestral players still learn under the "trial by fire" method. These well-known pedagogues have a multitude of different experiences. Each of them has become a proponent of the piccolo, further supporting piccolo specialized training, and each has contributed articles to flute journals on the topic of piccolo pedagogy. Even with this outreach, many students still find themselves standing on a parade field holding a piccolo having never received any instruction on the instrument and only learning by trial and error. 


\section{Chapter Five - Selected Piccolo Resources}

This chapter identifies piccolo resources that students, teachers, and performers will find useful and that are recommended by the author of this document. Results presented in Emily Orr's dissertation are mentioned when applicable. Sources listed as excerpt books for piccolo will be excluded in this section. These resources contain information that addresses the seven Hebert concepts presented in chapter four as well as providing additional informational sources about the piccolo. A short biography of the author of each text is provided. The general content and purposes of each publication are discussed, potential application when pertinent are addressed, and any possible gaps in the information presented. Sources provided are those that this author recommends as core materials for performers and teachers of the piccolo.

\section{The Complete Piccolo}

Jan Gippo was piccolo and flutist of the St. Louis Symphony from 1972-2008. Gippo taught at Webster University from 1980-2010, was on the faculty of the University of MissouriSt. Louis, and presented recitals and master classes throughout the United States and abroad. He is the founder of the Piccolo Committee of the 5,000-plus member National Flute Association and helped raise over $\$ 120,000$ to commission fifteen new works for the instrument. He served on the board of directors for the National Flute Association and was co-chair of the St. Louis Symphony's orchestra committee. Gippo has been an author, contributing editor, and editor-atlarge of Flute Talk Magazine, an Instrumentalist publication. He earned his Bachelor's Degree in Applied Flute from the New England Conservatory of Music and received his Master's Degree 
(Double) in Applied Flute and Wind Ensemble Conducting Literature from the New England Conservatory of Music. ${ }^{125}$

Jan Gippo compiled and edited The Complete Piccolo, A Comprehensive Guide to Fingerings, Repertoire, and History. Contributing authors include Laurie Sokoloff, Therese Wacker, Morgan Williams, and Tammy Sue Kirk. This book contains a comprehensive fingering guide for the piccolo that includes multiple fingerings for each note to help with pitch, tone color, and technical passages. The book begins with an introduction explaining the fingering diagram. The book addresses primary versus traditional fingerings. Primary fingerings focus in order of importance on pitch, blend, and tone. Traditional fingerings are those that have been adapted from the flute but do not account for the acoustical difference between the flute and piccolo. Gippo states that any fingering that is not a "primary" fingering is an "alternate" fingering and should be used to facilitate rapid passages. ${ }^{126}$ Each fingering is annotated, providing information regarding the pitch tendency, and the best use practices for clarity, dynamics, and articulations. It is recommended that each player determines the best fingering for them and their instrument. As every player and instrument is different, the fingerings provided may not work for everyone and every instrument. Fingerings for trills are given in the same manner in the second chapter.

Chapter three presents a concise, but clear, eight-page history of the piccolo adapted from Therese Wacker's doctoral dissertation: "The Piccolo in the Chamber Music of the Twentieth Century: An Annotated Bibliography of Selected Works." The last page of the history is a list of

125 Webster University, “CMS Master Class: St. Louis Symphony Piccolo \& Flutist Jan Gippo,” http://blogs.webster.edu/webstertoday/2013/03/28/cms-master-class-st-louis-symphony-piccoloflutist-jan-gippo/ [accessed February 1, 2017]

${ }^{126}$ Jan Gippo, The Complete Piccolo: A Comprehensive Guide to Fingerings, Repertoire and History. (Bryn Mawr, Pa.: T. Presser, 2007), 8-9. 
end notes which does provide references to additional resources. This chapter is not a complete history of the piccolo but emphasizes the most important points and would serve well for flute students preparing for collegiate examinations at the graduate level. This chapter also provides enough information to act as a desk reference for teachers and students alike. The history presents the areas of "Small Flutes before the Piccolo," "The Fife," "The Early Piccolo and Small Flutes in the Baroque Era," "The Multi-Keyed Piccolo," "The Boehm System," "Other Fingering Systems," "The Piccolo’s Introduction to the Orchestra," "Orchestral Piccolo in the Romantic \& Modern Orchestras," "Piccolo in Concert Band," and "Chamber Music."127

Chapters four and five provide a current (as of 2007) graded list of music available for the piccolo from conventional retailers, resources available directly from the composer, and libraries for new music. Some items may no longer be in print but are included for historical purposes. The authors state that the genre of "flute choir" has been excluded due to the extensive volume of works available. The first page of chapter four provides the description of the included materials as well as a clear guide to the grading scale which uses one to ten, with ten being the most difficult. Included in the introduction is also a "symbols used" section to provide more clarity when referencing specific publishers. Chapter four covers solo and accompanied piccolo repertoire beginning on page thirty-six and concludes with method books on page fifty-four.

Chapter five focuses specifically on the "Golden Age of Piccolo Music," which covers 1865-1935 and those pieces written for players to perform on the "Sunday" band concert circuit. Some of the repertoire does not contain a grade for the piccolo part, and this reflects that the original part has not been found, but that the piece is labeled for piccolo solo. Those pieces listed

127 Gippo, The Complete Piccolo: A Comprehensive Guide to Fingerings, Repertoire and History, 27-34. 
with a grade but no publishing company reflect works where the parts have been found, but the publisher has not been listed. ${ }^{128}$ Both chapters list the works by composer, title, publisher (when available), and grade (when available).

\section{A Basic Guide to Fingerings for the Piccolo}

Stephen Tanzer has performed on piccolo with the New York Philharmonic, the Baltimore Symphony, the Miami Philharmonic, the American Ballet Theatre, and presented and performed at numerous National Flute Association conventions. He has also taught at Temple University and the Philadelphia Musical Academy, and currently teaches at Rowan College. Tanzer's publication has been the only complete fingering resource for piccolo players since it was published in 1990. This resource provides a key chart, basic fingerings, trill fingerings, alternate fingerings, and a complete list of additional notes about the application of some of the fingerings. This resource is concise and useful and provides notes for fingerings that include application at varying dynamic levels, ease of response, and pitch tendencies. In a few of his endnotes, Tanzer cites examples of orchestral repertoire where the fingering might be useful. Some of Tanzer's notes also mention some acoustical basis for the fingerings. This book is a comprehensive fingering resource for piccolo but due to the date of publication, it predates some of the newer mechanisms like the C-sharp trill and those piccolos that extend to written $\mathrm{C} 4$ and B3. Those instruments with additional key work have the potential for additional fingering options with the added mechanisms that this book does not include.

${ }^{128}$ Gippo, The Complete Piccolo: A Comprehensive Guide to Fingerings, Repertoire and History, 55. 


\section{Piccolo! Piccolo! - Book 1}

Dr. Danielle Eden is a graduate of the Royal Academy of Music, the University of London, and the Sydney Conservatorium of Music. Her flute teachers include Sebastian Bell and William Bennet; she studied piccolo under Frank Nolan. Dr. Eden, an Associate of the Royal Academy of Music, has performed with the Sydney Symphony, the Australian Opera and Ballet Orchestra, and the Orana Trio. She serves as flute professor at the Australian Institute of Music and the University of Sydney. ${ }^{129}$

Piccolo! Piccolo! is a complete method for piccolo published in 1994 by Just Flutes in the United Kingdom. Eden begins by suggesting that players should approach the piccolo from the start as a different instrument from the flute. Her explanation for this statement is that the piccolo requires practice, and limiting practice to the flute will not produce the desired progress on the piccolo. She then gives her suggestions as to the application of her method. The sections are divided by different styles of pieces, but it is not necessary for one to work through a section in its entirety before moving to the next section. ${ }^{130}$

Eden provides four warm-up exercises and three scale study suggestions with alternate rhythms and articulations. She has chosen a wide selection of melodies from a broad range of sources. The melodies contain a variety of rhythms, articulations, and tonalities. She provides information about some of the melodies' origins as well as historical information. She includes some Baroque dance styles giving suggestions regarding performance and on what aspects the player should focus. She also includes a few duets which make excellent ensemble studies with

129 Australian Institute of Music, “Dr. Danielle Eden,” http://www.aim.edu.au/teachers/drdanielle-eden [accessed February 12, 2017]

${ }^{130}$ Danielle Eden, Piccolo! Piccolo!: A Selection of Essential Studies and Warm-Up Exercises, (Croydon, Surrey: Just Flutes, 1994), 2. 
a colleague or teacher. The final page of Book 1, a brief introduction to the upper register discusses some of the difficulties inherent in the extremes of the piccolo. She makes points about active air support, performing confidently, and recommends returning to the beginning of Book 1 to play the first exercises up the octave.

\section{Piccolo! Piccolo! - Book 2}

Book 2 is more focused on building technique than Book 1. The second volume again provides suggestions about how best to use the method. Eden starts with a brief introduction focused on extending the register and continues the discussion from Book 1. She includes more intensive and involved warm-up exercises that require more technique than her first volume. While there are a few melodies that encourage the player to implement musicality with technique, she intersperses scale work throughout Book 2, including minor tonalities. Eden also focuses more on chordal studies which include the major, minor, augmented, and both diminished and dominant seventh chords. The etudes that she includes in Book 2 are more rhythmically challenging, lengthier, and include larger leaps to high registers. The studies are progressive and has a section that focuses specifically on written Bb6, B6, and C6, providing recommended fingerings for these notes. There is a very short section at the end of Book 2 that presents two familiar orchestral excerpts: Semiramide by Rossini, and Scherzo from Symphony No. 4 by Tchaikovsky. Eden dedicates the last two pages to some extended techniques and provides a microtone fingering chart for piccolo.

\section{Learning the Piccolo}

Learning the Piccolo: a Treatise on the Subtleties and Problems of Playing the Piccolo in Relation to the Flute by Clement Barone was published in 1975 by Musicprint and in 1996 by 
Little Piper. This resource was shown to be used by $8.3 \%$ of the respondents in the Orr survey. ${ }^{131}$ Barone performed with the La Scala Opera, The Philadelphia Orchestra, the Houston Symphony, and joined the Detroit Symphony in 1958 as the solo piccolo until 1991. He taught at the University of Michigan School of Music and was an Associate Professor at Wayne State University of Music in Detroit, Michigan. Barone includes comments in his preface addressing the piccolo's place in the orchestra and the challenges surrounding it. Barone recommends approaching the piccolo as a small flute, striving for homogeneous sound as one would when playing the regular flute. He disagreed with the idea that playing the piccolo has an adverse effect on one's flute playing, and that one must remember that the piccolo is much smaller than the flute with the adjustments made greatly magnified in comparison. Special attention should be placed on tuning the piccolo as the tendencies are different than those of the flute.

Barone's book, while directed toward the study of the piccolo, primarily includes repertoire written for the flute that he has edited to be played on the piccolo. The primary factor in this concept is that Barone has taken some familiar repertoire and adapted it to the piccolo, making some octave displacements for range requirements. He has given short notes on the intent of each of the exercises that are quite helpful and draw attention to piccolo-specific challenges. Barone's method provides the player with familiar exercises which they have likely studied on the flute, while also allowing the player to focus on the differences that are inherent in the piccolo. The repertoire in Barone's book does not explore extreme ranges on the piccolo, with most ranging from D4 to F6. Only two pieces contain marked 8va and only one extends beyond F6 to B6 although the exercise could be carried out without the additional complexities of the octave transposition.

${ }^{131}$ Orr, "Teaching the Piccolo: A Survey of Selected College Flute Teachers," 17. 
The chosen repertoire is representative of Clement Barone's teachings of musicality and nuance and has been selected to elicit the same sense of line from piccolo players while addressing, at least partially, the idiosyncratic problems inherent in the piccolo. This book, while presenting the player with beautiful, traditional studies for the player, does not supply detailed remarks for the player. This resource would be an excellent book for use by an accomplished flute player who is exploring and working on the piccolo for those times when they are expected to double. The repertoire contained in the book does not include any extended technique nor does it force the player to explore the top register outside of one example in a scaler passage. This book also does not address fingerings or provide a fingering chart of potentially useful piccolo fingerings. This book would best be suited as supplemental material for an intermediate or advanced player whose primary focus is not the piccolo. Also, high school or college players who might be called upon to play piccolo in an ensemble might find this book useful for musicality and tonal studies.

\section{The Piccolo Study Book}

Patricia Morris studied on an open scholarship with Geoffrey Gilbert at the Royal Manchester College of Music. Her career began in the Royal Liverpool Philharmonic, where she specialized in playing the piccolo. She performs as the Principal Piccolo with the BBC Symphony Orchestra. Morris has a strong commitment to and enjoyment of teaching. As well as being a professor at the Academy, she gives masterclasses at various conservatories and courses around Europe. She currently teaches piccolo at the Royal Northern College of Music. ${ }^{132}$

\footnotetext{
132 Royal Academy of Music, "Patricia Morris," https://www.ram.ac.uk/about-us/staff/patriciamorris [accessed February 17, 2017]
} 
The Piccolo Study Book by Patricia Morris is a collection of studies, warm-up exercises, and technical information. Morris groups her studies into categories that deal with specific technical areas that include, warming up, flexibility, articulation, fingering, ornaments, and a section she calls "grandiose." She includes a page for special fingerings. Morris recommends adding thirty to forty minutes of additional dedicated piccolo practice to a daily routine in order for a performer to feel secure about playing the piccolo with the same control and expressive quality as their flute. She also states that the piccolo is an orchestral instrument and the practice schedule and routine should reflect the techniques required in demanding orchestral repertoire. Morris' book utilizes some standard works for flute as Barone did, but she states that some of the studies have been transposed and that she has altered the dynamics and articulations in others.

Morris provides three exercises and one excerpt in her warm-up section as well as makes recommendations from the standard flute repertoire that players are likely to own and encourages players to utilize these pieces when beginning their warm up. She also cites orchestral repertoire as examples of how the warm up exercises will benefit the player. She emphasizes using reasonable breath and establishing a point of reference for tuning. The importance of placing the head joint in the position where the instrument is most in tune before beginning the warm up session is paramount to the success of establishing a consistent center of pitch throughout the warm-up session.

In Section 1 - Sound and Flexibility, Morris has arranged the exercises in progressive order, again using exercises from notable composers. She gives insight on the intention of the exercises and what the performer should aim to accomplish, again referencing orchestral repertoire where these techniques will benefit the performer. This connection of the studies and 
how they benefit the orchestral repertoire allows the performer to reference the excerpt quickly and transfer the technique from the practice session to the performance.

Section 2 - Articulation is focused on approaching different styles of articulation on the piccolo and how they can differ from the flute. She also suggests regularly practicing flutter tonguing as it does appear regularly in modern orchestral repertoire. She directs the performer as to which articulations to use on each exercise. Exercises progressively become more challenging as she layers dynamic direction over the already suggested articulation. Morris also addresses the difficulty of triple-tonguing and makes suggestions regarding syllables and how to apply them to the exercise that she has chosen. Her repertoire choices are clearly suited to her recommended strategies, and the performer should see the correlation to the orchestral repertoire that she cites for each example.

Section 3 - Fingering addresses more of the balancing issues that come from the size and placement of the piccolo and is far less about specific fingerings. The chosen exercises do require the player to focus on hand position and balance. Morris does provide an exercise that focuses on the use of the B-flat fingerings but this is the extent of the actual "fingering" suggestions. Her point about balance is well made and grossly underrated by most players. As the piccolo does not sit deeply into the chin like the flute, balance can potentially become an issue for some players. Morris' selected exercises do exemplify this problem in such a way that they become apparent to the player, and they are then able to address the issue.

Section 4 - Ornamentation, is quite simply an exercise for trills. There is a short explanation as to how the ornament should be applied but no other ornamentation is addressed. Also, there is only one exercise in this section, and while it does present a compact exercise for the subject matter, it does not provide much more in the way of musicality or other ornaments. 
Section 5 - Grandiose Studies contains two exercises that allow the player to explore the musical shapes and lyrical lines of the work. The techniques from the previous sections can clearly be applied, and the player will see immediately how the previous exercises culminate with these choices. This section is rather short in comparison to the thoroughness of the preceding sections, but one might suspect that a player may choose to approach the orchestral repertoire that Patricia Morris references in her exercises using a book of excerpts.

The final section, "Special Fingerings," provides some alternative fingerings for pitch and timbre changes with references to instruments that may have a split E mechanism. The printed fingerings are limited and can be found in both fingering sources previously discussed in this document.

\section{Exercises pour la flute piccolo}

This method book is available in several languages and is part of the French Flutists Propose collection published by Gérard Billaudot. Jean-Louis Beaumadier, the author of this book, is the solo piccolo in the Orchestre National de France and was a student of Jean-Pierre Rampal and Alain Marion in Paris. Beaumadier's thorough introduction notes that colleagues around the world have commented that there were no method books written for the piccolo. Beaumadier's hope was that his book might help those flute players who are interested in the piccolo and will become a small contribution to the already "vast literature" for flute. His recommendation that it is "intended for students who can already play the flute correctly." He adds that this publication represents his thoughts about playing the piccolo based on his experience, and that the fundamental idea of this book is to consider the piccolo as an "instrument in its own right."133

${ }^{133}$ Jean-Louis Beaumaudier, Exercices pour la flûte piccolo (Paris: G. Billaudot, 1999), 6. 
In this method, Beaumaudier approaches the areas of regularity of sound, articulation, technique, intonation and articulation in the high register, intonation with two piccolos, rapid trills and quick passages, and concludes with a final section of his "tips." This book represents one of only a few recent contributions to the study of the piccolo which addresses the instrument separately from the flute by focusing on piccolo-specific problems.

Beaumaudier's section on intonation centers on focusing a flexible embouchure while also developing fluid technique, utilizing essential technical passages and vocalizes that might be familiar to more accomplished flute players. He emphasizes that the vocalizes help the player to "take pleasure," in finding their sound while working on the embouchure and intonation. In each exercise, he recommends beginning slowly and to making sure that even and consistent support is used. He also states that the importance of low register tonal work is indispensable and functions as a "prelude," to working on articulation.

In Beaumaudier's chapter for articulation, he provides a step-by-step instruction for approaching articulation beginning with the diaphragm. His instructions introduce the primary syllable of "tu," and the secondary syllable of "ku." He emphasizes the importance of supporting both syllables while keeping the throat open while maintaining a balance between the syllables. His exercises continue with the vocalize approach, but he includes orchestral excerpts when appropriate as well as solo repertoire with which to apply his articulation exercises. Important to note is that he specifically addresses articulation in the top register and introduces the staccato articulation which is frequently too short on the piccolo. He also provides excerpts from the orchestral repertoire for examples of double and triple tonguing, citing times when alternate syllables may be necessary to increase the lightness and speed of the articulation. 
His section on technique is much shorter than the previous section, and his exercises are focused on traditionally difficult finger passages on the piccolo due to the size of the instrument, balance, and mechanism. There is a limited focus on technique in this book and Beaumaudier intended this book for "those that can already play the flute correctly." "134 Flute and piccolo have similar technical challenges and the author has limited the area of focus to only those that are specifically challenging to the piccolo like articulation and lip flexibility. He includes a limited, but helpful, overview of slurring pianissimo passages in the top register. The concepts of slurring in the top register are similar between the flute and piccolo, although the piccolo is more challenging. His selected excerpts are again from the orchestral repertoire and quite appropriate for applicable practice.

\section{The Mazzanti Method}

Nicola Mazzanti serves as Solo Piccolo of the Maggio Musicale Fiorentino Orchestra, a position he has held since 1988. As a soloist, he has performed with orchestras such as "I Pomeriggi Musicali” of Milan, the Malta Philharmonic Orchestra, the Florence Symphony Orchestra and Akronos of Prato. He has taught piccolo at the Hochschule in Luzern and at the Conservatorio della Svizzera Italiana in Lugano (Switzerland) as well as the Conservatorio "Verdi" in Milano. His website is a regular destination for dedicated piccolo players. His book "The Mazzanti Method" for piccolo, published in 2014 by Theodore Presser, has been welcomed as a milestone in the teaching of this instrument. ${ }^{135}$

Mazzanti's method begins with an introduction in which he discusses his methodology and motivation for creating this resource. He then discusses briefly how best to

\footnotetext{
${ }^{134}$ Jean-Louis Beaumaudier, Exercices pour la flûte piccolo (Paris: G. Billaudot, 1999), 6. ${ }^{135}$ Nicola Mazzanti, http://www.piccoloflute.it/p.asp?p=biografia\&l=en [accessed February 9, 2017]
} 
apply his method to "maximize your skills and potential." 136 The method is divided into three sections: Sound, Scales, and Arpeggios, and Melodies, Operas, Lieder.

In Part I: Sound, Mazzanti lists three checkpoints to remember: Support, Larynx, and Embouchure. He dedicates several pages of exercises to each of the three checkpoints while introducing other topics such as intonation and dynamics. He also briefly mentions the importance of each of the checkpoints and offers suggestions as to how best focus on the checkpoint in the provided exercises. Beginning on page fifty-eight, he introduces exercises that involve singing and playing as a method to address and apply all three checkpoints. Singing while playing is considered an extended technique on the flute. Robert Dick includes similar exercises in his book, The Other Flute; however, this is the first application to piccolo study in print of which the author is aware.

In Part II: Scales and Arpeggios, Mazzanti applies the use of two different types of scales: limited interval and full range. Limited interval scales are those that terminate at a fifth or octave, while full range scales use the entire range of the instrument within a set pattern such as a major or natural minor scale. He states that "When the interval of a fifth is not exceeded, adapting the lips is normally not needed..." ${ }^{137}$ Mazzanti does recommend that once one is comfortable with the full range of the piccolo, a player should focus on scales that cover the entire range of the piccolo such as in Marcel Moyse's Exercise Journaliers. However, for the piccolo, he does have specific recommendations when using these exercises. Mazzanti includes numerous diatonic and chromatic scale and arpeggio exercises that comprehensively address the technical needs of the player.

${ }^{136}$ Mazzanti, The Mazzanti Method: Daily Exercises for Piccolo, 3.

${ }^{137}$ Ibid., 67. 
In Part III: Melodies, Operas, Lieder, Mazzanti includes famous simple melodies for daily study. He believes that working on a melody allows one to utilize the skills learned in the previous studies and apply them into a stronger musical intention. He urges the player to focus dynamics, sounds, intonation, and vibrato, and challenges that playing slowly with expression and good intonation on the piccolo is far more difficult than technical passages. His final suggestions for this section are to exaggerate dynamics and then transpose the melody by half steps until the entire range of the instrument has been covered. ${ }^{138}$

\section{The Study of Technique in Small Flute Playing}

Eugeniusz Towarniki was a graduate of the Conservatory of Music in Lvóv and studied with Marcel Moyse in Paris. He served as Professor at the Conservatory in Lvóv prior to World War II. He also served in the Polish Army and after becoming a prisoner of the Nazi Concentration Camps, returned home to become principal flutist with the Radio and Television Symphony Orchestra in Kraków. He also served as a teacher of flute in the State College of Music Kraków. He is the author of the most famous Polish school of study for flute and piccolo. ${ }^{139}$ His method book for piccolo, Studium Techniki na matym flecie, was first published in 1968 with notes in Polish, German, and Russian. His book begins with an introduction and short history of the piccolo, citing works in which it was first used. He also briefly discusses the inherent differences of playing piccolo, addressing tonal and technical difficulties.

${ }^{138}$ Mazzanti, The Mazzanti Method: Daily Exercises for Piccolo, 131.

${ }^{139}$ Lukasz Dlugosz, "Polish Flutists," Die Deutsche Gesellschaft für Floete e.V., https://floete.net/publications/flutists-worldwide/polish-flutists/?L=1 [accessed November 22, 2016]. 
After the introduction, a series of studies in each key, starting in $\mathrm{C}$ major, are presented to address technique, articulation, and ensemble work utilizing a duo or trio. Each major key is followed by the relative minor key and similar material in the new key. The key exercises extend the entire range of the instrument from written D4 up to C7. Following the studies in all keys, Towarniki provides orchestral excerpts interspersed with exercises, and solo compositions, some of which have piano accompaniment. Some of the orchestral excerpts included are from obcure works and hard to find. The book includes one-hundred and ninety-one exercises in total. Two inserts are provided, one, a basic fingering chart and the other a trill fingering chart, both of which are for the Böehm-system piccolos.

\section{A Piccolo Practice Book}

Authors Trevor Wye and Patricia Morris (mentioned previously), are well-respected flute and piccolo pedagogues, are internationally acclaimed. Trevor Wye is Professor and Head of the Flute Department of the Royal Northern College of Music, and his teachers included Geoffrey Gilbert and Marcel Moyse. This book was named by $43.7 \%$ of the respondents in the Orr survey, making it the most popular piccolo resource of those who participated in the survey. The Wye/Morris book, first published in 1988, is designed to help flutists carry their playing techniques over to the piccolo through a guided and organized approach to various aspects of performance technique. The prose is presented in a vernacular and inviting way along with comments, not unlike those one might hear in a lesson with a teacher. The comments are both thoughtful and mindful of the student. Included are numerous orchestral excerpts and this book could be used as a supplemental resource for piccolo orchestral excerpt study. This publication is divided into sections on tone and intonation, articulation, top register studies, special fingerings, recognizable orchestral piccolo solos, harmonic fingerings, duets, and suggested practice 
routines. The authors do state that they assume those using this book are acceptably accomplished at the flute. For those who are not prepared for the level necessary to continue study in this book, the authors refer to Trevor Wye's series Practice Bookfor the Flute, Volumes 1-6, published by Novello, as a good place to start. These volumes are also available in an omnibus addition.

Wye and Morris predominantly use orchestral excerpts for their method. Although, there are a few exceptions which include exercises taken from fundamental flute studies. The use of orchestral excerpts defines this source as a method for more accomplished flutists. The level of difficulty of the examples would prevent flutists early in their studies from using the book without great challenge. The authors provide short notes for many of the exercises, guiding the player through the pitfalls of the excerpt. The section on tone addresses changes in dynamics as well as tonal color and vibrato. The chapter treats tone as a variable product depending on the excerpt performed and relies highly on the proficiency of the player to make the necessary adjustments. They do mention the technical aspect of cork placement in the head joint affecting the piccolo tone and pitch in contrast to that of the flute. They make the recommendation to check the pitch of the written A6 as well as the octaves to find the optimal placement.

Wye and Morris state that "articulation exercises are tone exercises" and that articulation is useless if the tone is not good. The chapter on articulation continues with the presentation of additional orchestral excerpts that exemplify varying styles of articulation. This section covers single, double, and triple-tonguing, as well as the author's recommendations for tongue placement, by practicing with alternate syllables. They have chosen to include flutter tonguing in this chapter and have provided examples of repertoire which applies the technique. 
In their chapter on the top register, Wye and Morris suggest supporting mezzo forte and approaching the top using scales to work from mid-range up to the extremes. They provide top register examples using orchestral excerpts and suggest proceeding through them, "on your first good day." ${ }^{140}$ In the final chapter, Wye and Morris provide a short list of excerpts that are most likely to appear on orchestral auditions and make recommendations as to other sources that contain material for further orchestral study. ${ }^{141}$ This publication contains a multitude of orchestral excerpts for piccolo, some of which are only available through rental. The included excerpts are varied and represent a wide scope of study covering many periods and composers.

\section{Piccolo Craft}

Piccolo Craft: The Teach-Yourself Piccolo Method was written in 2008 by Andrew Lane, is now in its fourth edition and is available through Just Flutes in the United Kingdom. Andrew Lane has been the principal piccolo and flutist in the City of Birmingham Symphony Orchestra for thirty-three years. He studied at the Royal Academy of Music, played as guest flute, piccolo and alto flute in concerts and recordings with the BBC Symphony, Royal Philharmonic, Royal Liverpool Philharmonic, BBC Philharmonic, Welsh National Opera, Birmingham Royal Ballet, Mid-Wales Opera, London Philharmonic, Philharmonia, and the Orquesta Sinfónica de Tenerife, Spain. Lane teaches piccolo at Royal Welsh College of Music and Drama and runs an annual series of piccolo workshops at Birmingham Conservatoire. His interest in flute construction has lead him to assist flute-maker William Simmons design innovative mechanisms for the flute and piccolo. $^{142}$

140 Trevor Wye and Patricia Morris, A Piccolo Practice Book, (London: Novello, 1988), 84.

${ }^{141}$ Ibid., 197-208.

142 Royal Welsh College of Music and Drama, "Andrew Lane," http://www.rwcmd.ac.uk/other/biography/woodwind/andrew_lane.aspx [accessed February 3, 2017 
Lane states in the forward that this book was written as a guide for the "proficient" flutist to be able to teach themselves piccolo. This book contains vast amounts of information about many different aspects of piccolo playing, many of which, the other sources do not address. Lane includes a few musical examples, but they are minimal. The main draw of this resource is the broad approach to the instrument. Lane begins with his recommendations on purchasing a piccolo, what to consider when looking, and how to choose a piccolo. The book then proceeds to address the standard topics related to piccolo and flute playing like breath support, intonation, and tone and shares some short exercises for these areas. The charm of this notable resource is that the prose comes across as if one were having a conversation with a friend. The writing is welcoming and contains humor while remaining on topic and succinct with the instruction. Lane's explanations are clear and knowledgeable, providing just the right amount of information and addressing those questions one might have wanted to ask but were afraid. This book provides suggested alternative fingerings for problematic passages, and Lane provides a list of the orchestral repertoire that is most challenging and which appears most often in auditions.

Lane's technical knowledge is apparent, and when discussing different mechanisms, both old and new, he includes photos of flutes and piccolos for clarity. Out of all resources included in this document, Lane's book contains the clearest and most precise section on mechanisms and serves to clarify any confusion as to what a key is, what it does, why it is helpful to have, and how best to use it.

One area that Lane addresses that the other sources do not is the area of performance psychology. He discusses professional behavior such as never playing someone else's solo as a warm-up, warming up backstage without annoying colleagues, referring to the distress one might feel prior to performing an exceptionally challenging solo. His approach to the psychological 
hurdles that performers face is sincere, open, and honest. Lane has written on the page what many performers have thought to themselves and delivers those comfortable as well as uncomfortable questions with humor and directness. He applies his real-world experience to his book. While not full of comprehensive warm-up exercises or etudes, Lane's book is full of his personal experiences and helpful suggestions. It makes an excellent starting point for self-study. 


\section{Chapter Six - A Pedagogical Guide}

This chapter is meant to serve as a practice and teaching guide for students, teachers, and performers with a focus on the seven aspects of William Hebert's teachings and based on the author's experiences from practicing, playing, and performing. Advanced players may find some helpful references, suggestions, and new ideas regarding the use of some of the sources. Hebert's fundamental skills listed in chapter four serve as the focus and organization of this chapter. Understanding basic concepts and using common sense when practicing is basic to the application of these suggested resources. When in doubt, the author suggests experimenting cognitively and approaching the difficult techniques from a fresh perspective. There is no substitute for dedicated practice and the methodical development of new skills over time.

Daily Practice Routine Approaching the Piccolo

It is imperative that the piccolo is included in a regular and daily practice routine. While the instrument is similar in many ways to the flute, it is in fact by design, a different instrument. Players new to the instrument might approach piccolo study in the same manner as one would the flute. Hebert recommends placing the piccolo higher on the lower lip as opposed to lower on the lip for the flute. This initial approach is an excellent way to begin basic sound production and to work on technique, but the desired results would likely plateau after a short amount of time. Once a reasonable comfort level is achieved on the piccolo, and this can vary from player to player, the dedicated piccolo practice must begin for players to become proficient. It must be noted that, at least in his teachings, this author has found that allowing those new to the instrument to experiment and experience the instrument before more focused study has had greater results over the long term. If the piccolo feels awkward to the player, the player will 
focus on this aspect and find difficulties working on other more technical points. A short period of experimentation and adjustment to the new instrument reaps more rewards and allows the player to become comfortable and focus.

Since the piccolo is much smaller than the flute, it is also important to consider hand position when beginning. The smaller size might be beneficial to a smaller player while a larger player may feel collapsed or tense in the right shoulder as they bring their arms closer to the body to support the instrument. This large change in hand position when switching from the flute to the piccolo can become a source of unnecessary neck and shoulder tension. Players and teachers should seek to find a naturally comfortable playing position that supports both good posture and hand position. This process can take some time and should be a main point of focus during the experimentation phase when beginning the piccolo. If at any point, just as in flute playing, the player experiences tension, pain, or discomfort, they should take a short break. As in long practice sessions, it is important to take regular short breaks. Muscles have memory and allowing tension and discomfort to continue during practice will build this tension into the playing, creating larger physical and mental issues in the future. Players and teachers should be vigilant about awareness of tension and at first manifestation address the issue. Many times, it is as simple as taking a few minutes to stretch, and other times it may require far more internalized time to find the source. The use of Alexander Technique and yoga have benefitted many players who experience playing tension. Remember that loose muscles vibrate, tight muscles do not.

Intonation

Under the basic elements of piccolo playing, William Hebert places intonation first on his list of focus points. Intonation is a major area of concern for players and ensemble directors. The differences between flute and piccolo intonation can become a challenge for players as the pitch 
tendencies are opposite. Due to its small size, the piccolo leaves little margin for error when it comes to pitch, and tendencies vary widely from instrument to instrument. In general, the upper register of the piccolo is flat whereas the flute tends to be sharp. Pitch tendencies can also vary greatly from instrument to instrument due to quality, age, and condition. Hebert recommends the use of scales and arpeggios to help determine pitch tendencies of an instrument and many teachers would suggest creating a chart to identify the pitch tendencies inherent to a player and their instrument. This is a standard practice. However, it should be done only after a period of experimentation. Players must have a reasonable comfort level with an instrument before attempting to create this chart. Players must have both good breath support and tone production, or the chart may be skewed and of no assistance. It is the recommendation of this author that the chart is made once the player feels moderately comfortable with the instrument, playing position, and is capable of good tone production. Another chart can be created weeks or months later if so desired, and the results may be very different from the earlier chart.

The use of long tones, scales, and arpeggios are standard to instrumental studies and should be incorporated into regular piccolo practice as well. Players should work regularly with a tuner, beginning each day with long tones. The following exercises are meant to allow the player to multitask by warming up while using slow, controlled intonation exercises. Start by setting the tuner, or metronome to a sustained pedal tone, sounding a G4 or A4, which is a comfortable range with which to begin. The player should then play the same note as the sustained pedal with a full, round, and supported sound. Listen carefully for fullness of tone first, and then for pitch discrepancies. No vibrato should be used during this exercise. The note should be held for eight to ten counts and when the player is content with the tone, they may make the necessary adjustments to the head joint to better be in tune with the pedal tone. This exercise can be 
repeated as many times as needed to establish a baseline tuning for the instrument and the following series of intonation exercises. The following exercises should be performed slurred, at mezzo forte, and without vibrato.

After the long-tone exercise and the head joint has been adjusted to a baseline position, the player should move onto tuning scales. These scales are meant to focus on intonation, not on the development of technique. Although they are slow, they will aid in the development of technique especially when playing less familiar scales. These scales should be played in one octave only and slurred. The second and third octaves should not be used for this exercise at this point. The player should set the tuner to a new pedal tone, on $\mathrm{D} 4$, and begin their scale on written D4. Beginning with major scales is recommended, although for this exercise the minor scales may also be used. The player should choose the scale that best serves their needs. The slower speed of these scales will allow the player to work on any scale that they find particularly difficult or that may need additional attention. The scale should be played at the quarter-note equaling $60-80$ beats per minute but may be adjusted to the needs of the player so long as the exercise does not exceed the tempo suggestion. Remember that there is no rush to play through these exercises. They are for warming up and working on intonation, not technique. The player should begin on the tonic, listening carefully to each note and the interval created against the pedal tone. The author prefers to begin on written D4 and move up one semitone as for each repetition.

This exercise is also an excellent way to incorporate aural skills into a practice session by playing, then singing the chosen scale in solfege. Becoming familiar and comfortable with the intervals, overtones, and difference tones created by this exercise will later help the player in ensemble tuning. If needed, both major and minor scales (two octaves) can be found in Piccolo! 
Piccolo! Book 2 on pages 10-14. Two-octave scales can be addressed during the technique portion of the practice session, but it is important to remember that scales for this exercise should be one octave and begin in the lowest register of the piccolo. The player should play this exercise in at least two keys before moving on to the next exercise. Additional scales and repetitions may be included as needed at the discretion of the player.

Following the tuning scales, the player should move on to chord studies or arpeggios. Again, just as in the previous exercise, this exercise should start in the lower octave of the piccolo and should not extend beyond one octave. For this exercise, it is recommended that the player should incorporate all forms of the arpeggio to include: major and minor triads, diminished and augmented triads, and all forms of the arpeggios that include the seventh. Which arpeggios are chosen is again up to the needs of the player but at least major and minor arpeggios should be performed. The author prefers to work through these exercises by tonic and recommends that the arpeggios coordinate with the tonic pitch from the previous exercise thus making the intonation work tonic based. The player should again choose the pedal tone on the tuner or metronome that correlates with the previous exercises using the suggested range between D4 and G4. They should then, begin the arpeggio by playing the quarter-note at $60-80$ beats per minute while listening to the created intervals of the third, fifth, and the octave. Again, the overtones and difference tones created will help the player with ensemble tuning. If desired, the player may use a tuner to check each note for pitch as they play them although the pedal tone may interfere with the tuner's microphone giving a false reading. The author recommends the use of a contact pickup microphone or the use headphones. Using the contact pickup microphone or only one earpiece will prevent the tuner's microphone from picking up the sustained pedal tone. The Mazzanti Method contains printed exercises that include simple and broken 
arpeggiations on pages 102-128. Once this series of intonation exercises have been completed, the player can repeat the entire cycle up the octave.

As mentioned in chapter four, Hebert suggests applying six different techniques to adjust pitch on the piccolo. Most of these techniques are not applicable to fast technical passages but may aid in adjusting the pitch of long, sustained or melodic passages. Rolling the head joint in or out is not a new concept and was used to adjust pitch in the Baroque period on the traverso, but this technique requires moving the head joint to alter the angle of the airstream in relationship to the embouchure and should be avoided if possible. Raising and lower the head and jaw movements are also useful for making more extreme changes, but due to the potential for tension in the neck and the development of bad habits, this method should also be avoided. One exception might be the final sustained note in a passage. Lifting the head and moving the jaw slightly forward will prevent the pitch from going flat as the note is tapered approaching the final release, especially at softer dynamics. Hebert also suggests the use of alternate fingers, referred to as "primary" versus "standard" fingerings in The Complete Piccolo. Alternate fingerings will not take the place of good intonation practices and the performer's ear, but they are meant to improve intonation of particularly bad notes, help with blend in ensembles, and facilitate difficult passages. The suggested exercises in this section provide an excellent opportunity to begin learning and implementing alternative fingerings as they take time to master. These slow tempos and fundamental technical exercises provide the perfect place to find out which fingerings work on a given instrument and which fingerings do not. Hebert affirms that it takes "experimentation and intelligence" to apply different techniques for intonation, and knowing which techniques will work and when to use them is a skill that must be developed. ${ }^{143}$

${ }^{143}$ Roseman, "William Hebert: Fundamentals of Playing and Teaching Piccolo," 14-15. 


\section{Articulation}

Articulation on the piccolo can be quite a challenge due to the small size of the instrument. Using the same type or placement of articulation on the piccolo as on the flute will result in a very aggressive and noisy articulation, what Hebert referred to as "garbage." All movement involved in articulation has the possibility of disrupting the much smaller airstream. This disruption can range from causing an odd noise, or "chirp," or if the airstream is disrupted for too long, the sound can stop completely. Although the instrument is much smaller, flaws in articulation are amplified to the point of being grotesque and obscene. Players must focus attention on maintaining the correct level of support while minimizing the tongue movements and placing those movements further forward in the mouth. Approaching articulation in layers will make sure that all variables are in check, the airstream, the embouchure, and the tongue. Trying to control too many of these variables at one time is counterproductive. By stripping away the layers and focusing on applying them one at a time, we are better able to assess where the problems lie and correct them more quickly.

The first aspect to address with articulation is the air stream. The piccolo requires a much smaller volume of air than the flute, but it is also under greater pressure and moving faster than the flute. To establish a proper airstream, the player should choose an exercise that contains a consistent rhythm. Exercise 12 by Böehm on page 24-25 or exercise 13 by Soussmann on page 26-27 in The Piccolo Study Book are good examples. First, the player should perform three or four systems of the exercise without using the tongue for articulation. Perform the exercise at a comfortable tempo, slower is better, using a "huh," or "hah," syllable rather than the tongue. These breath attacks will make sure that the air column is properly supported and moving at the correct speed for the notes to speak while also helping to focus the embouchure for the note. This 
exercise can be challenging, or at least frustrating for the player because the breath attacks can cause the "chirping," sound. This sound is no more than a clear sign that the airstream is too strong for the note and has caused an overtone to respond rather than the written note. While frustrating, this exercise makes certain that the air column is appropriate for the note before adding another layer.

Step two in the articulation exercise is to make sure that the air column and embouchure are working together. Saying "paa" with a short, diaphragmatic breath engages the core muscles and gets the air column moving into the oral cavity. However, this does not create the necessary vowel for a proper embouchure. After saying "paa" a few times, gradually shift the syllable to "poo-hoo" and then to "pwhoo." This will keep the diaphragm involved as the embouchure is formed. Take this new syllable and apply it to a system or two of the exercise. Going slowly, "poo" through the exercise, making sure to utilize the full air column for each note. As this articulation cycle progresses, the player may return to any of the previous layers of the cycle to reestablish the proper form. This articulation may be used for very soft, pianissimo attacks and can come in handy, so this articulation should be practiced daily.

The next step is to repeat the exercise using a "tu" or "du" syllable but as Hebert suggests, ignore the staccato markings. When adding the tongue for the first time to the exercise, try to recreate the column of air used in the preliminary performance and focus on the physicality of the previous "poo," exercise. Focus on even, consistent, and legato articulations. Short articulations are counterproductive in this early stage of the exercise. Pay close attention to the tip of the tongue, its placement and movement. The movements should be small and light, avoiding extraneous noise and tension in the tongue and throat. Most importantly, experiment with the placement and movement. Although human anatomy is the same for everyone, the 
smaller variables make everyone different. Record yourself and listen to it for cleanliness and consistency and try not to focus on tone. Small recording devices tend to be overpowered by the higher register of the piccolo, so listen just to the evenness of the articulation. Once the legato articulation is even and consistent the exercise can be performed faster keeping in mind to ignore the staccato markings and focus only on the playing the legato articulation at the new tempo. Most will find that as the tempo increases, the articulation becomes shorter out of necessity. The main purpose of the legato articulation, as opposed to the staccato that is marked, is to make sure that there is tone present in the articulation and that the notes don't just become a series of pitched percussive attacks. Once the exercise is at the final tempo using the legato-focused articulation, then judgments can be made as to whether the articulation should be more detached. The faster the exercises goes the lighter the articulation. The smaller and lighter articulation on the piccolo can be quite disconcerting to some as it can feel as if one is barely working to articulate a very active passage.

Double tonguing is often seen as even more challenging, but it should make fast and highly articulate passages easier. The greatest downfall of these passages is that the primary syllable and the secondary syllable, "du" and "gu" are uneven and out of sync with the fingers. One method to combat this disassociation is by repeating the exercise but this time using the primary and secondary syllables. Depending on the individual, "du" and "gu," or "tu" and "ku." Avoid using "ta" and "ka," or "da" and "ga," as these move the tongue further back in the mouth which is less efficient and noisier on the piccolo. On the first attempt at double tonguing the exercise, utilize the syllables in the "du" and "gu," in that order. In the second attempt, use only the secondary syllable, "ga." On the third attempt, reverse the primary and secondary syllables, “gu-du." By placing emphasis on the secondary syllable which utilizes the thicker part of the 
tongue, a balance between syllables can be reached. Following this last phase of the cycle, return to the beginning of the exercise and increase the speed using the first articulation sequence of “du-gu." The balance, control, and speed will be noticeably improved for a short period of time before returning to the more awkward and uneven state. This exercise is most effective in building endurance and speed. Once this exercise and the concepts have been mastered, the player can easily implement the repetitive, slower practice into orchestral and solo repertoire. This practice will aid in the learning process as the repetition and multitasking aspect allow the player to build familiarity with a new piece while at the same time build their fundamental skills. It is important that these exercises are practiced slowly and with utmost care. Time and repetition will produce the best results and players should avoid faster tempos until they are ready to do so. In the beginning, repertoire for the articulation cycle should be limited to etudes of rhythmically consistent subdivisions. Once the exercise is completed, players may choose to move to repertoire containing more variations of articulation styles and greater range. Players may also increase tempo. Hebert recommends practicing single and double-tonging exercises at overlapping speeds. Practice single tonguing sixteenth notes from 72-112 beats per minute and then practice double tonguing of the sixteenth note from 96-112 beats per minute. As Hebert states, this overlap of articulation will prepare performers for those moments when conductors take one tempo in rehearsal and another in concert. Conductors are notorious for this and it always seems to occur during the most challenging and exposed solo. If a player is not prepared, they might be in trouble. ${ }^{144}$

Hebert suggested that differences between national styles of playing were based on vowel production in the language and discussed the variations between French, German, and American

${ }^{144}$ Roseman, "William Hebert: Fundamentals of Playing and Teaching Piccolo," 20. 
styles in his teachings. ${ }^{145}$ The variations of the vowels can profoundly affect the outcome of the articulation and players should experiment to find what works best for their playing and best conveys the stylistic intention of the repertoire.

\section{Phrasing}

Recognizing the natural rise and fall of a musical line contributes to the performance as much as the use of a variety of stylistic articulations and appropriate dynamic contrasts. For some, this comes naturally but for others, it must be practiced, explored and cultivated. One of the best methods to work on phrasing is to utilize recognizable melodies. Hebert recommended having students sing through phrases to help them identify shape and placement of rise and fall. The combination of the two ideas, singing and recognizable melodies, points towards a performance medium, opera, that does both regularly. Vocalists spend countless hours honing breath and pitch control and focusing on applying their practice into spinning beautiful phrases. The use of vocally-oriented repertoire to learn the concepts of phrasing would only make sense when applying Hebert's concept. The final section of The Mazzanti Method (pages 131-140) contains multiple pages of opera and lieder melodies for the player to work through. The repertoire that Mazzanti has chosen to include in his method provides a limited range (D4 to D6) which does not require the player to venture into the upper register where tension and good tone production might become problematic. The player should use the short melodies as exercise to apply the other skills that they have learned while also attempting to follow the printed dynamic and stylistic markings in the solo. Initially, playing the printed stylistic markings and following the breath marks while using a good sound and playing in tune will be the end goal. As the student develops each of the skills, they should begin trying to play with different tone colors,

145 Roseman, "William Hebert: Fundamentals of Playing and Teaching Piccolo," 18-19. 
gradients of vibrato or no vibrato, and identify notes and groups of notes that are of greater importance. Each solo should be played many times and can be revisited at any point. Each time, the player should make more of the stylistic markings while adding additional nuances or taking away some of those previously used. As the player grows, so should the interpretation.

\section{Embouchure}

The piccolo embouchure should be firm to support the high-pressure air, never tight or pinched. The air column is far more supported than on the flute and the piccolo requires far less air, however, the air is under greater pressure which causes most players to tighten up the embouchure to make the aperture smaller. In some cases, players will tighten the embouchure thereby compressing the airstream to compensate for the lack of support. This may work for a short time, but eventually the embouchure will get tired and the lips will give out causing them to buzz which is a clear sign that the support is lacking and that the embouchure is too tight. Once the point of lip buzzing is reached, it is best to take a break so as not to injure the embouchure. At this point, the lips are too weak to continue, but players may continue working in the lower register only, if necessary.

Building the piccolo embouchure is a great deal like training for a marathon. Time and regular training will build the strength and endurance necessary to be successful. The placement of the piccolo both vertically and laterally may be slightly different for each player. Because of its smaller size, the piccolo should be placed higher on the lip than the flute. Exact placement will depend greatly on the player's lip shape and size as well as the instrument. Some instruments have lip plates some do not, and this can alter the comfortable placement for each player. The higher placement may feel odd at first, but it is necessary to line up the airstream most effectively. For those players with slight variations in lip contour, setting the piccolo 
slightly off center may help to produce a clearer and more consistent sound. This again requires some experimentation in or to find the optimal placement for the individual.

One of the best tools for instrument and embouchure training is a mirror. If a player is struggling with finding the best placement, they should first use the mirror to assess their embouchure without the instrument. The player should notice any variations in lip contour, shape of the lips, etc. Next, place the piccolo in playing position, form an embouchure and play a written G4. Again, notice the contour of the lips and shape of the embouchure. Look closely at the aperture or opening where the air is passing over the piccolo. Also, notice any odd tension or embouchure "quirks" that may appear. Relax for a moment and then repeat the exercise. Look for any wrinkles around the embouchure or "scrunched" skin as these may be a sign of unnecessary tension. Remember, the piccolo embouchure is firm, never tight.

The piccolo embouchure needs to be firm enough to contain the high-pressure air column necessary to support the notes, but it also needs to be flexible enough to make minor pitch adjustments, add nuance, and allow the player to control note tapers. If the embouchure is too tight, then flexibility does not exist. In the previous section on articulation, the "pwhoo" exercise was introduced. The exercise will help the player find the balance between the higher air pressure and the flexible control over the embouchure. When working through the embouchure cycle, do not use the tongue. Arpeggios provide a perfect balance of embouchure work and technical skills. Scales, while always necessary in technical study, do not allow the player to become aware of embouchure changes due to the smaller intervals between the notes. Arpeggios contain larger intervals making the player aware of the points where the embouchure is changing as the registers shift. Exercise 119 in Towarniki's Studium Techniki is excellent for this work. This exercise and those that follow are arpeggios and will help build strength and endurance. 
Players may choose to use memorized arpeggios if they prefer. Begin on the lowest note of the arpeggio using the "pwhoo" articulation from the earlier articulation cycle. Use this articulation for each note, taking a short breath or inhale before the next note. Even rhythm and metronomic time is not important at this step of the exercise. This articulate, inhale, articulate, inhale repetition may feel a bit like hyperventilating and players could become dizzy, so be sure to go slow. Only perform the first arpeggio and repeat it two or three times, then rest. Again, this exercise uses the idea of layering. Players may find that as they ascend the arpeggio they feel a tendency to tighten the embouchure as the notes become harder to produce. This is normal although players should not begin to pinch in the upper register. The player should remain on the first arpeggio until they are able to produce the upper notes with minimal to no tension using the "pwhoo" articulation.

Once satisfied with the "pwhoo" articulation, the player may then proceed to slur the entire measure using one breath. It is important that the player not articulate the upper notes as they become more difficult as this defeats the purpose of the exercise. If the upper register notes do not speak, "chirp," or drop to a lower partial, return to the "pwhoo" articulation before attempting the full measure slur again. Once able to slur the entire measure with clean and uninterrupted sound, the player may choose to alter the articulations. While working on embouchure strength and flexibility, use articulation groupings of notes of three or more at a time. Articulation groupings of slur two, tongue two and fully articulated groupings allow the player to use the tongue to produce the note rather than the air and correct embouchure placement. Using the tongue during this exercise is "cheating." The support of the air column and the control of the airstream are what the player should rely on to keep the embouchure in a relaxed and flexible state. As players become more skilled and can maintain the flexibility in the 
embouchure, studies with broken arpeggios will further strengthen endurance and increase the flexibility.

An exercise in The Mazzanti Method (page 66) utilizes harmonics. This is a relatively newer concept on piccolo and this is the only piccolo method book to include the idea. This exercise requires the player to use first-octave fingerings and overblow to attain notes higher in the overtone series. This requires good control and solid breath support. The exercise has been included in the embouchure section because to select the correct harmonic, the embouchure must be set correctly. This exercise will help the player to develop embouchure precision and strength otherwise the wrong note will speak. The harmonics often require a bit more support than the properly vented fingering so the player will also be working on breath support. The use of harmonic exercises will also benefit intonation work. By comparing the harmonic fingering with the properly vented fingering, the player can make pitch adjustments.

\section{Breathing}

The breath is the life force of the instrument, regardless of what instrument you are playing. Breathing is a natural and automatic act, however, when an instrument is involved, the breath must then be introduced to a foreign body in effect creating a second function for the breath. A breath should be constant enough to sustain a series of notes without pitch fluctuation. There also must be enough air to play through the phrase, or a phrase appropriate breath. Also, there needs to be enough air above and beyond the absolute minimum volume for the phrase to allow the player to control dynamics and nuances in the tone like vibrato. Vocalists are masters of breath management and control and utilizing some of their methods makes pedagogical sense.

The first step is to find the diaphragm and this can be accomplished through the laughing exercise. The player should take a breath as they would normally and while exhaling, vocalize, 
"ha, ha, ha." The player will notice, when paying close attention to the abdominal wall, that this forced laughter is motivated by a muscle at the base of the rib cage. This muscle is the diaphragm. The diaphragm separates the thoracic cavity and the abdominal cavity and is part of the breathing apparatus. Take note that the next time the player laughs so hard their "stomach" hurts, this soreness is, in fact, the diaphragm. Piccolo Craft has a section titled "Diaphragm Doings," (pages 25-33), which explains the breathing process.

When inhaling to play the piccolo, the lungs must be fully engaged and allowed to expand. The rib cage must also expand to allow the lungs to reach full capacity when needed. The lower abdomen must also be permitted to expand to make room for the inflating lungs. The diaphragm gently pushes the internal organs of the abdomen ever so slightly to make room for the lungs. If the player carries too much tension in the abdominal wall or shoulders, this tension will prevent the necessary expansion and hinder the potential capacity of the lungs. The throat should also be allowed to open and relax when inhaling, providing a clear path for the breath to access the lungs.

While a full capacity breath should be practiced, especially for moments where needed, like several phrases in the Concerto by Liebermann, the full capacity breath is not always necessary. Hebert recommends taking additional smaller breaths when possible which he marks with a check mark. ${ }^{146}$

\section{Vibrato}

The method of producing vibrato on the piccolo is identical to that of the flute with one exception. As a basic rule, the amplitude of the vibrato must narrow as the player enters the higher registers. The ear does not tolerate wide vibrato in the higher frequencies. First, a wider

\footnotetext{
${ }^{146}$ Roseman, "William Hebert: Fundamentals of Playing and Teaching Piccolo," 30.
} 
vibrato in the upper register is problematic in that the pitch fluctuations are too great, causing the pitch center of the played note to become unclear. This can present a tuning catastrophe in an ensemble setting. Second, the fluctuations in the airstream responsible for the vibrato are too disruptive to the already small airstream required to produce the upper register notes. Attempting to use a wide vibrato in the upper register can disrupt the airstream enough that the notes will cease to respond. The frequency of the vibrato should also increase as the player ascends. The faster vibrato will create a shimmering effect in the upper register while the slower vibrato will cause the tone to sound unstable. Many players, Hebert included, use no vibrato whatsoever in the extreme upper range of the piccolo. ${ }^{147}$ Vibrato should always be part of the tone and the player's ear should dictate the quality of vibrato used.

Vibrato can be taught on piccolo in the same manner that it is taught on flute so long as the player is aware and in control of the amplitude as mentioned above. Learning to breath pulse quarter notes, eighth notes, and triplets at varying speeds is the basic concept for learning vibrato, and it should be treated as a separate entity from the tone completely. Players must learn to control their vibrato to utilize vibrato tastefully, especially on piccolo. Vibrato exercises can benefit players by encouraging better support as well as assisting the player in breath control and portioning breath throughout phrasing.

\section{Dynamics and Tone Color}

Tone color and dynamics can be rather challenging on the piccolo, again due to its small size. Developing a tonal palette on the piccolo is more about nuance and creativity. Tone color is also very dependent on the space itself as in most cases the player's perception of the sound is in large part based on the room. Controlling the subtleties of the embouchure, air stream, aperture,

${ }^{147}$ Roseman, "William Hebert: Fundamentals of Playing and Teaching Piccolo," 31. 
and vibrato all contribute in some way to the perception of sound. Just as on flute, the shape of the aperture, speed, and direction of the air, as well as vowel formation in the oral cavity all affect the tone produced. Players should consider words to describe the sounds qualities that they wish to explore. It is helpful to begin with very general and contrasting definitions like "dark versus bright," "sweet versus edgy," or maybe "rich versus transparent." The player needs to establish a vocabulary for dynamics and tone color because aesthetics of tone can be very personal. Establishing these contrasts will allow the player to identify traits that they assign to those specific tone colors and be better able to replicate them. By varying shades on the scale between the extremes, the player will able to create more subtlety and blended colors as they develop their skills.

The Mazzanti Method approaches tone production using three "checkpoints," support, larynx, and embouchure. ${ }^{148}$ Support and embouchure have been addressed previously in this chapter. Mazzanti discusses the larynx and oral cavity (page 34) and their role in resonance and air speed. Piccolo players tend to tighten the throat which constricts the air flow, and the compression, rather than speed up the air stream, slows it down. He provides a series of simple low note studies (pages 34-40), allowing the player to focus on relaxing the throat and lowering the larynx thereby eliminating throat and neck tension. These studies encompass only the first octave on the piccolo, written $\mathrm{D} 4-\mathrm{Db} 5$, which requires the slowest and most open airstream to produce. This exercise should be used interspersed throughout a practice session as a method to release throat and neck tension. This allows the player to rest the embouchure after working in the higher registers, stretching as one might after a workout in the gym.

${ }^{148}$ Mazzanti, The Mazzanti Method: Daily Exercises for Piccolo, 4. 
Another exercise that Mazzanti provides (pages 58-66) in The Mazzanti Method, applies all three of his check points into one exercise and is somewhat different from what most players have used for improving tone previously. These exercises require the player to sing a pedal tone while playing short, three measure passage over the top. This exercise is difficult, especially in the beginning but the benefits to tone production are worth the challenge. These exercises require the larynx to remain low and stable, the support to remain firm, and the embouchure to remain flexible. If anyone of these factors is out of sync, the exercise will become even more challenging to play.

The first step is to establish a singing tone with the voice simultaneously with the tone production on the piccolo. Place the piccolo in playing position while fingering the first note of the exercise (D4). Begin by humming the first note of the exercise at a mezzo forte dynamic with the lips closed. Gradually move the lips forward to form a piccolo embouchure but do not let the air escape, continue humming. Next, slowly open the aperture and allow air to escape using the embouchure to direct the air into the piccolo as one would when playing. The player will notice a drop in the internal air pressure and will need to increase the support to maintain the correct airspeed required for the piccolo to speak. Continue humming while increasing the airspeed until the piccolo sounds the first note of the exercise. This preliminary exercise should be repeated until the player can play and sing the unison note on demand. Once this is possible, the player can then proceed to work on the first measure of the exercise (page 58).

Playing and singing is a very challenging combination for most players, especially early on. Mazzanti's exercise moves up by a semitone on each system. This exercise begins on written D4 and continues up to written C6 covering the full range of the piccolo. Players new to singing and playing should only focus on the first measure of each line and limit their practice to only the 
first two pages initially. Performing this exercise in the upper register is far more difficult and requires excellent control over the airstream, breath support, and oral cavity. Attempting to move into the higher registers too soon can create additional tension and possible injury to the embouchure and vocal chords. Players should pay close attention to the vocal production being careful to sing the note, and not scream as is the tendency when the exercise goes into the upper register. The sensation of screaming or elevated vocal pressure is a sign that tension is building in the vocal folds and neck, and that the player should return to the lower register, or take a short break. Monitoring this exercise is important so as not create more tension or localized tension as this is detrimental to the player and the tone. As stated before, slow and methodical practice as well and being mindful of discomfort will go a long way. This combination of skills can take some time to master, but the tonal benefits are well worth the effort.

\section{Technique}

While not on Hebert's list of seven, technique is a necessity for discussion. In general, the piccolo functions the same as the flute. The smaller size does place the keys closer to the tone holes and many players find that this allows them to play the piccolo with more facility than the concert flute. One must spend time practicing, becoming accustomed to the variations between the flute and piccolo, most of which have been addressed in this document. Most of the resources reviewed in Chapter Five of this document contain additional exercises for technique, and players should not find a need to search elsewhere to work on facility. Players seeking to use additional studies that are more familiar and common to the flute repertoire should feel free to do so. However, when using studies not chosen for the piccolo, the player must use common sense and knowledge and take into consideration the differences between flute and piccolo, specifically range. 
Many of the reviewed sources contain standard orchestral excerpts that also include performance notes by the authors. These include suggested fingerings, helpful hints for articulation and pitch, or just a friendly warning about challenges within the excerpt. The excerpts do vary from resource to resource although there is some overlap. There are also many additional resources for orchestral excerpts that were not covered because they fall outside of the scope of this document. These sources may also provide information that is of importance to the player as well and should be explored.

\section{Conclusions}

The piccolo no longer simply functions as an auxiliary instrument in the orchestra and has found its way into the concert hall, the world of chamber music, and the solo recital hall. Composers are beginning to approach the instrument as an equal member of the flute family, exploring its potential for expression in their works. While the flute has the luxury of possessing a long line of well-known pedagogues, the piccolo is just beginning to surface as an instrument of interest for study. There have rarely been teachers who specialize in the piccolo prior to the 1900s, although the instrument has been present in ensembles as far back as the 1600s. There is clearly a need for piccolo-specific instruction and the method books to support the instruction. The beginning of twentieth century saw an increase in the number of resources for piccolo players due in large part to the popularity inspired by the "Golden Age." These early resources lacked consistency but are important as markers in the historical development of the piccolo. The modern, twenty-first century additions to the area of piccolo pedagogy present a wealth of information from many leading piccolo players, and although no single source provides a comprehensive methodology, each of the resources has value. The author of each presents their purpose clearly and effectively, but a complete piccolo resource has yet to be written. The 
sources presented by this author represent those that provide the most comprehensive collaborative knowledge regarding the piccolo. Along with the extended bibliography of additional pedagogical sources, it is the hope of this author to provide piccolo players with a more comprehensive and complete source of information for reference by piccolo players. 


\section{Bibliography}

Books

Adler, Samuel. The Study of Orchestration. New York: W.W. Norton, 2002.

Berlioz, Hector, and Hugh Macdonald. Berlioz's Orchestration Treatise: A Translation and Commentary. Cambridge: Cambridge University Press, 2002.

Bate, Philip. The Flute: A Study of its History, Development, and Construction. London; New York: E. Benn, 1979.

Baines, Anthony. Woodwind Instruments and Their History. New York: W.W. Norton, 1957.

Forsyth, Cecil. Orchestration. London: Macmillan and Co., Limited, 1935.

Gippo, Jan., Therese Wacker, Morgan Williams, Tammy Sue Kirk, Laurie Sokoloff. The Complete Piccolo: A Comprehensive Guide to Fingerings, Repertoire and History. Bryn Mawr, Pa.: T. Presser, 2007.

Miller, Dayton C. List of Works Relating to the Flute in the Library of Dayton C. Miller with Annotations. Cleveland, OH: Privately Published, 1922.

National Flute Association (U.S.). The Flutist's Handbook: A Pedagogy Anthology. Volume 2. Santa Clarita, Calif.: The National Flute Association, 2012.

- The Flutist's Handbook: A Pedagogy Anthology. Santa Clarita, CA: National Flute Association, 2006.

Phelan, James., Lillian Burkart. The Complete Guide to the Flute and Piccolo. Shirley, Massachusetts: Burkart-Phelan, Inc., 2000.

Piston, Walter. Orchestration. New York: Norton, 1955.

Rimsky-Korsakov, Nikolay, Maksimilian Shteĭnberg, and Edward Agate. Principles of Orchestration, with Musical Examples Drawn from His Own Works. New York: Dover Publications, 1964.

Tanzer, Stephen. A Basic Guide to Fingerings for the Piccolo. Bala Cynwyd, PA: Sopranino Press, 1990.

Toff, Nancy. The Flute Book: A Complete Guide for Students and Performers. New York, NY: Oxford University Press, 2012.

Widor, Charles-Marie, and Edward F. E. Suddard. The Technique of the Modern Orchestra; A Manual of Practical Instrumentation. London: J. Williams, limited, 1906. 
Methods

The Piccolo: With Exercises and Solos Specially Written and Selected. London: Boosey and Hawkes, 1904.

Arx, Daniel von. Anfänger-Schule für Piccolo-Flöte. Zürich: Hug, 1970.

Barone, Clement. Learning the Piccolo: (a Treatise on the Subtleties and Problems of Playing the Piccolo in Relation to the Flute). New York, N.Y.: Musicprint, 1975.

Beaumadier, Jean Louis. Exercices pour la flûte Piccolo. Paris: G. Billaudot, 1999.

De Ville, Paul. The Eclipse Self Instructor for Piccolo. New York: Carl Fischer, 1905.

Eden, Danielle. Piccolo! Piccolo!: A Selection of Essential Studies and Warm-Up Exercises. Book 2. Coulsdon, Surrey: Just Flutes, 1996.

. Piccolo! Piccolo!: A Selection of Studies and Warm-Up Exercises. Book 1. Croydon, Surrey: Just Flutes, 1994.

Fair, Rex Elton. Piccolo Method. Chicago: M.M. Cole, 1937.

Gippo, Jan, Frank Brockett, John S. Cox, T. Green, Charles Le Thière, and Samuel Woodworth. The Golden Age of the Virtuoso Piccolo. Volume 1. North Carolina: Alry Publications, 2012.

Köhler, Ernesto. Schule zum Selbstunterricht für die Piccolo-Flöte oder Trommel-Pfeife: praktische Anleitung zur gründlichen Erlernung der Piccolo-Flöte - Self-instructor for piccolo: practical directions for thoroughly learning the piccolo. Leipzig: Zimmermann, 1891.

Lane, Andrew. Piccolo Craft: The Teach-Yourself Piccolo Method. Fourth ed. Birmingham: Paper and Print, 2010.

Langey, Otto. Practical Tutor for the Piccolo: In the Simple and the Boehm Systems. London: Boosey \& Hawkes, 1900.

Levine, Carin and Christina and Mitropoulos-Bott. The Techniques of Flute Playing II, Piccolo, Alto, and Bass Flute. Vol. II. New York: Bärenreiter, 2004.

Provides instruction (piccolo, alto, and bass flutes) on types of flutes, extended techniques, percussive effects, vibrato, air sounds, circular breathing, trills, glissando, microtonality, flute and electronics, graphic notation, appendices for special fingers.

—. The Techniques of Flute Playing. Vol. I. New York: Bärenreiter, 2002.

Provides instruction (for flute only) on types of flutes, extended technique, percussive 
effects, vibrato, air sounds, circular breathing, trills, glissando, microtonality, flute and electronics, graphic notation.

Mazzanti, Nicola. The Mazzanti Method: Daily Exercises for Piccolo. King Of Prussia: Theodore Presser Co., 2014.

Mencarelli, Pier Luigi and Reginald Smith Brindle. Metodo per Flauto. Milano: Edizioni Suvini Zerboni, 1975.

Morris, Patricia. The Piccolo Study Book. London: Novello, 1998.

Pepper, J. W. Self Instuctor for the Piccolo. Philidelphia: J. W. Pepper, 1879.

Piazza, Italo. Metodo Popolare per Flauto. New York: Ricordi, 1954.

Poole, Fred H. Flute Tutor for B-Flat Flute, F Flute, E-Flat Flute \& Piccolo, with Scales, Exercises \& Selection of Popular Marches. London: H. Potter, 1900.

Towarnicki, Eugeniusz. Studium Technicki Na Małym Flecie. Kraków: Polskie Wydawn. Muzyczne, 1980.

Tulou, Jean-Louis. Metodo Popolare Carlo Andreoni. New York: Ricordi, 1957.

Tulou, Jean-Louis, Beaumadier, Jean-Louis.,. 140 Petits exercices et études: Pour 1 Ou 2 piccolos. Paris: G. Billaudot, 2004.

Winner, Septimus. Eureka Method for the Piccolo. Boston: Oliver Ditson, 1900.

Wye, Trevor and Patricia Morris. A Piccolo Practice Book. London: Novello, 1988. 


\section{Dissertations}

Butterfield, Emily J. "The Professional Life and Pedagogy of Clement Barone." D.M.A., The Ohio State University, 2003 ProQuest Dissertations \& Theses Full Text https://searchproquest-com.www.libproxy.wvu.edu/docview/305317736? accountid=2837; (accessed April 15, 2016).

Orchestral musician and teacher Clement Barone (1921- ), played piccolo in the Detroit Symphony Orchestra and the Houston Symphony Orchestra for over forty years. A native of Philadelphia, Barone plays an open g-sharp system, which he learned from his first teacher, his flutist-father Clemente Barone. Subsequent teachers included Joseph La Monaca, Frank Versaci, Fernando Morrone, and the eminent William Kincaid, who recommended Barone... During his thirty-two-year career in Detroit... aspects of Barone's flute and piccolo pedagogy, formed from his premise that the flute "should imitate the human singing voice in style and quality of lyricism." Additional chapters include an account of lessons with William Kincaid, a discussion of Barone's publication, Learning the Piccolo: A Treatise on the Subtleties and Problems of Playing the Piccolo in Relation to the Flute (1975), and Barone's perception of changes in orchestral procedures as they impact the professional orchestral musician. [ProQuest document ID 305317736].

Coleman, Heather Hall. "The Adoption and Role of the D-Flat Piccolo and Other High Band Flutes in the Nineteenth-Century American Amateur Band." D.M.A., The University of Memphis, 1999 ProQuest Dissertations \& Theses Full Text https://search-proquestcom.www.libproxy.wvu.edu/docview/304569574?accountid=2837; (accessed April 15, 2016).

The orchestral piccolo in $\mathrm{C}$ has been relatively well documented in the scholarly literature; but the D-flat piccolo and other high-band flutes (those flutes not in C) in American amateur bands of the nineteenth century have never been investigated... This document examines the emergence and gradual adoption of the D-flat piccolo and other high-band flutes in the American amateur band tradition in the nineteenth century. The nature and role of these instruments is studied with the aid of original instruments from the Dayton C. Miller Collection at the Library of Congress, photographs and other materials from the Hazen collection of band ephemera at the Smithsonian institution, instrument and music catalogs from a variety of sources, and a systematic analysis of five chronologically representative band repertoires containing piccolo parts: William Webb's Second Set of Military Divertimentos (c. 1820); the manuscript books of Benjamin H. Grierson's band (1840s); the Port Royal part books from the 7th New Hampshire band currently at the Library of Congress (1861-2); a selection of music from the Library of Congress's Music for the Nation collection (1870s); and Herbert L. Clarke's Imperial Band Book (1890). [ProQuest document ID 304569574]. 
Dennis, Jeannine Marie. "The Life and Music of Lowell Liebermann with an Emphasis on His Music for the Flute and the Piccolo." D.M.A., University of Cincinnati, 1999 ProQuest Dissertations \& Theses Full Text https://search-proquestcom.www.libproxy.wvu.edu/docview/304511635?accountid=2837; (accessed April 15, 2016).

Lowell Liebermann is an increasingly popular composer who is now being covered in the media. He is an outstanding composer, not only for the flute, but also for his main instrument, the piano. In addition, he has composed music for many other instruments, including the violin, 'cello, piano, and orchestra, as well as chorus and vocal solo... the intent of this thesis is to provide valuable information about his music and his background that can be passed on to students, performers, and to others who are interested in Liebermann and his compositions...The focus of this thesis is the flute and piccolo music of this composer, with sections covering his life, general characteristics, and musical style. It also includes an historical overview of his flute and piccolo music, a discussion of Liebermann's importance to the repertoire for flute and Piccolo, and an extensive performance guide for the Sonata for Flute and Piano, the Soliloquy, and the Concerto for Piccolo and Orchestra. Finally, the first two appendices will include a complete catalogue of his works and the recordings of his music through August 1999. [ProQuest document ID 304511635].

Dombourian-Eby, Zartouhi. "The Piccolo in the Nineteenth Century." D.M., Northwestern University, 1987 ProQuest Dissertations \& Theses Full Text https://search-proquestcom.www.libproxy.wvu.edu/docview/303594571?accountid=2837; (accessed April 15, 2016).

The piccolo gained extensively in musical prominence in the course of the nineteenth century...the piccolo evolved slowly during the nineteenth century from a one-keyed into a Boehm system instrument. This study traces the use and development of the piccolo by examining orchestration treatises, method books, music, and other primary sources from 1772 to $1930 \ldots$.. Organization of Document. Introduction; I. The Role of the Symphonic Piccolo in the Music of the Nineteenth Century - Introduction and Music to 1856; II. Music from 1873 to 1908; III. Orchestration Treatises from 1772 to 1914; IV. Tutors from the Nineteenth Century to 1930; V. Flute Makers' Catalogues and Price Lists/Instrument Collections; Conclusion; Appendix. Short Biographies of Nineteenth- and Early TwentiethCentury Flute Players Who Specialized on Piccolo; Selected Bibliography. [ProQuest document ID 303594571].

Eden, Danielle Georgina. "The Piccolo: its History, Solo Repertoire and Usage since 1800 to Modern Day in Western Europe.” University of London, 1999 EThOS e-theses online service http://ethos.bl.uk/OrderDetails.do?uin=uk.bl.ethos.341892; (accessed January 14, 2017). 
Fletcher, Allison Marie Flores. "Ten Orchestral Excerpts for Piccolo: An Historical and Stylistic Analysis." D.M.A., The University of North Carolina at Greensboro, 2008 ProQuest Dissertations \& Theses Full Text https://search-proquestcom.www.libproxy.wvu.edu/docview/304534296?accountid=2837; (accessed April 15, 2016).

As a member of the orchestra, the piccoloist performs in many capacities as both a section player and soloist...The excerpts discussed are from the following works and movements: Rossini's opera overtures (La Gazza Ladra and Semiramide), Beethoven (Symphony No. 9, Finale, Alla Marcia ), Berlioz (La Damnation de Faust ), Tchaikovsky (Symphony No. 4, III. Scherzo), Ravel (Ma mère l'oye, III. Laideronnette, Impératrice des pagodes), Stravinsky (Firebird Suite, 1919 version, "Variation de l'oiseau de feu"), Prokofiev (Lieutenant Kijé Suite, I. The Birth of Kijé, IV. Troïka), Shostakovich (Symphony No. 8, II. Allegretto), and Bartók (Concerto for Orchestra, III. Elegia)...Aspects of each excerpt examined included intonation tendencies, rhythmic difficulties, technical challenges, dynamics, articulation, and timbre. Solutions and practice suggestions are proposed for the challenges presented for each of the excerpts. Each chapter concludes with a summary including the solo piccolo part with notated instructions. The result is a useful reference for teachers, students, and piccoloists preparing for auditions. [ProQuest document ID 304534296].

Gartley, Jennifer. "The Impact of Jan Gippo on Contemporary Piccolo Literature." DMA, University of Illinois at Urbana-Champaign, 2009.

Glaser, Christie. "The "Liebermann Piccolo Concerto" and its Stylistic Elements." M.M., California State University, Long Beach, 2014 ProQuest Dissertations \& Theses Full Text https://search-proquest-com.www.libproxy.wvu.edu/docview/1550893055?accountid=2837; (accessed April 15, 2016).

The Liebermann Piccolo Concerto is a three-movement piece that is twenty minutes in length. This work displays virtuosic capabilities of the piccolo not commonly explored by composers. Typically, the piccolo has been viewed as an auxiliary instrument in ensembles to make a specific melodic line more easily heard above the group in contrast to the more typical soloistic role of the flute. Lowell Liebermann's goal in composing this piccolo concerto was to highlight the musical qualities of the instrument beyond its loud and highpitched capabilities. This project report explores the unique stylistic aspects of Liebermann's piece and how it differs from previous writing for piccolo. [ProQuest document ID 1550893055].

Heck, Angela R. "The Mechanical Development of the Piccolo." D.M.A., The University of Oklahoma, 2010 ProQuest Dissertations \& Theses Full Text https://search-proquestcom.www.libproxy.wvu.edu/docview/741546128? accountid=2837; (accessed April 15, 2016).

The purpose of this document is to explore the mechanical development of the piccolo in relation to the flute. Although there have been several studies conducted about the mechanical development of the flute, the piccolo has never received this special attention 
and deserves to have its story told... Each chapter of this document examines the mechanical improvements in terms of the tube and materials, the head joint, and the mechanism during each stylistic period. With careful examination of the physical properties of each instrument, the reasons for these changes will become clear. The following chapters will include pertinent information regarding the similarities and differences between the piccolo and the flute, the role and importance of families of flute makers, as well as shed light on reasons why composers became interested in scoring for these small flutes. [ProQuest document ID 741546128].

Jelle, Lisa A. "The Flute and Piccolo Music of Martin Amlin: An Introduction, Discussion, and Analysis of the Sonata for Flute and Piano; "Trio Sonatina" for Flute, Clarinet, and Piano; and Sonata for Piccolo and Piano." D.M.A., Rice University, 2000 ProQuest Dissertations \& Theses Full Text https://search-proquestcom.www.libproxy.wvu.edu/docview/304621447? accountid=2837; (accessed April 15, 2016).

The compositional style of music for flute and piccolo by Martin Amlin is examined through formal and harmonic analyses and through interviews with the composer and the musicians most closely associated with the works...Amlin's compositional style as represented in these pieces may be described as combining characteristic twentieth-century American driving rhythms and perpetual motion, symmetry on multiple levels, and a unique blend of French use of color and phrasing...All three pieces exhibit use of the full range of the instruments, a quality that both Buyse and Dombourian-Eby mentioned as appealing to them. Yet, as in the style of the best sonatas of the repertoire, the parts are balanced; lines interweave, rise, and fall in a balanced whole. As more flutists become aware of the quality of these works, they will become a strong and vibrant staple of the body of flute and piccolo literature. [ProQuest document ID 304621447].

Nourse, Nancy. "The Piccolo: An Overview of its History and Instruction." M.M., The State University of New York, Crane School of Music, 1981.

Orr, Emily G. "Teaching the Piccolo: A Survey of Selected College Flute Teachers." D.M.A., The University of North Carolina at Greensboro, 2005 ProQuest Dissertations \& Theses Full Text https://search-proquestcom.www.libproxy.wvu.edu/docview/305395219?accountid=2837; (accessed April 15, 2016).

The piccolo is an auxiliary member of the flute family. A diversity of opinion exists among college flute teachers as to the importance and method of piccolo study as part of a flute curriculum. This author conducted a study to outline some current pedagogical trends among college flute teachers. This document presents information gathered via electronic survey from college flute instructors at schools accredited by the National Association of Schools of Music. The survey questions pertained to background information of respondents, studio size, studio requirements, instruments and pedagogical material, and pedagogy. Sixty-five teachers responded to the survey, and the results are published in this document. [ProQuest document ID 305395219]. 
Roseman, Joseph Jacob. "William Hebert: Fundamentals of Playing and Teaching Piccolo." D.M., The Florida State University, 1996 ProQuest Dissertations \& Theses Full Text https://search-proquest-com.www.libproxy.wvu.edu/docview/304296120?accountid=2837; (accessed April 15, 2016).

William J. Hebert... was piccoloist of the Cleveland Orchestra from 1947 until 1988. A dedicated professional, Hebert has distinguished himself throughout his lifetime, first during his student days in Boston and New York, then as piccoloist of the Cleveland Orchestra and as a prominent teacher... This treatise is an attempt to describe William Hebert's conceptions of the fundamentals of playing and teaching the piccolo. It is hoped that this treatise, written in collaboration with Hebert, will illuminate his career and his approach to teaching... The discussion of Hebert and his teaching methods has been divided into sections on his life, basic elements of playing, orchestral piccolo repertoire, and pedagogical aspects of teaching. An attempt has also been made to compare Hebert's methodology to descriptions of other methods available in published sources in order to point out areas of differences and similarities. Although the sections of this treatise which present William Hebert's playing and teaching concepts are of principal interest, additional benefits emerged from having the opportunity to discuss Hebert's philosophies about music making and reminiscences about his career. [ProQuest document ID 304296120].

Sealy-Miller, Kristi. "An Annotated Guide to Gary Schocker's Music for Flute and Piccolo." D.M., The Florida State University, 2013 ProQuest Dissertations \& Theses Full Text https://search-proquest-com.www.libproxy.wvu.edu/docview/1411850668?accountid=2837; (accessed April 15, 2016).

The purpose of this treatise is to provide a comprehensive annotated bibliography of Gary Schocker's works for flute and piccolo. The pieces in this document include solo works for flute, piccolo, alto flute and bass flute, both accompanied and unaccompanied. This resource is meant to be utilized by private flute instructors, college professors, professional flutists and flute students searching for performance repertoire by Gary Schocker... This document contains a biographical overview of Gary Schocker's life, from his early childhood to the present day. Information taken from personal interviews, articles and his personal biography is included to help flutists have a better knowledge of his background, thus creating a deeper understanding of his music...The primary areas of focus are the rubric, a description of the four distinct levels of difficulty and the annotations themselves. After reading the rubric thoroughly, inquirers can determine their appropriate level and browse through the listing of pieces organized by level or the alphabetical guide to determine what pieces are appropriate for them. In order to facilitate research on Schocker's works other than those that are annotated, there is a complete listing of all of Gary Schocker's works for the flute, including unpublished works and chamber music, in the appendices section. The other appendices include a personal interview with Gary Schocker, discography and background information on selected works. [ProQuest document ID 1411850668].

Teng, Kuo-Jen. "The Role of the Piccolo in Beethoven's Orchestration." D.M.A., University of North Texas, 2011 ProQuest Dissertations \& Theses Full Text https://search-proquest- 
com.www.libproxy.wvu.edu/docview/1041239386?accountid=2837; (accessed April 15, 2016).

This dissertation discusses the role of the piccolo in Beethoven's orchestration in his symphonic works. These include the Fifth Symphony, the Sixth Symphony, the Egmont Overture and the Ninth Symphony. The document includes the history of piccolo's development since the ninth century B.C. until the modern Boehm piccolo. The author provides comparative observation through Beethoven's orchestration techniques such as the range covered, instrumental pairing, balance, and melodic organization of each symphony works. In addition to discussing development of the piccolo in orchestration, this study compares the piccolo's usage through motives (e.g. the "Ode to Joy" theme), harmonic analysis; range; balance; and melodic organization. Appendix A provides of tables that summarize piccolo's harmonic function of works discussed to help the reader comprehend the piccolo function at a glance. This dissertation includes observations of performers, theorists and musicians; and these guides provide the reader with better understanding of the piccolo's place in Beethoven's orchestration. By following the observations, piccolo players will bring a deeper musical and technical understanding to individual performances. [ProQuest document ID 1041239386].

Wacker, Therese M. "The Piccolo in the Chamber Music of the Twentieth Century: An Annotated Bibliography of Selected Works." D.M.A., The Ohio State University, 2000 ProQuest Dissertations \& Theses Full Text https://search-proquestcom.www.libproxy.wvu.edu/docview/304610138?accountid=2837; (accessed April 15, 2016).

The popularity of the piccolo has continued to grow throughout the twentieth century, with much solo and chamber music being written specifically for this instrument. However, the cataloguing of works specifically for the piccolo has not kept up with its emerging importance. Although there are various lists of repertoire available, most deal more specifically with the flute literature, and if the piccolo is included, it is secondary and the list is incomplete... This annotated bibliography is an attempt to catalogue the chamber music of the twentieth century that contains piccolo...Preceding the annotated section is a short history of the development of the piccolo and its use as an ensemble instrument. Because of the lack of historical information available for the eighteenth century there is a discrepancy as to what instrument was used in certain literature. This paper is not meant to settle these differences, but to show how the piccolo is one instrument which may be used in these works. [ProQuest document ID 304610138].

Weigel, Jane Marie,. "An Annotated Performer's Guide with Revised Full Scores of the Piccolo Solos and Duets in the John Philip Sousa Library at the University of Illinois." D.M.A. Research Project, University of Illinois at Urbana-Champaign, 1999. 


\section{Articles in Journals}

Beard, Christine Erlander. "Let's Talk Picc: Starting Students on Piccolo: Develop a Beautiful Tone through Proper Embouchure." Flute Talk (November, 2013): 32. [discusses the basics of helping students to become comfortable on the instrument through the use of mirrors, centering tone, and embouchure development]

. "Piccolo Discography, Part I." Flute Talk 25, no. 8 (April, 2006): 32.

—. "Piccolo Discography, Part II." Flute Talk 25, no. 9(May/June, 2006): 32.

Borst Jones, Katherine. "Let's Talk Picc: Piccolo Tuning." Flute Talk 35, no. 4 (December, 2015): 40. [compares intonation tendencies between conical and cylindrical bore instruments as well as making necessary adjustments to the stopper cork to correct intonation issues]

Bouton Schaub, Jennifer. "Let's Talk Picc: Piccolo Articulation." Flute Talk 34, no. 5 (January, 2015): 32. [discusses various styles of articulation on the piccolo and challenges associated with articulation on the instrument]

. "Let's Talk Picc: Exploring Tone Color on the Piccolo." Flute Talk 34, no. 3

(November, 2014): 32. [discusses the challenges when working to expand the tonal color palette]

. "Let's Talk Picc: How to Choose a Piccolo Player for Band and Orchestra." Flute Talk 34, no. 1 (September, 2014): 32. [discusses the role of the piccolo, piccolo personality, development of airstream and embouchure, transposition, technique, and instruement construction]

. "Let's Talk Picc: Piccolo and Flute: Similarities and Differences." Flute Talk 33, no. 9 (May/June, 2014): 32. [compares the flute and piccolo with regards to technique, construction, scale, tone production, vibrato, and endurance]

Cadwell, Jennifer. "Let's Talk Picc: Most Requested Piccolo Excerpts." Flute Talk 22 (January, 2003): 32. [lists the top twelve requested orchestral excerpts on auditions]

Coltman, John W. "Some Observations on the Piccolo." Flutist Quarterly 16, no. 1 (Winter, 1991): 17-18.

Dapper, Klaus. "The New Anton Braun Piccolo to Low C." Flute: The Journal of the British Flute Society 30, no. 2 (June, 2011): 31-3. [describes a new instrument that can play a low C in the orchestral repertoire that requires it]

Dombourian-Eby, Zartouhi. "A History of the Piccolo." Flutist Quarterly 16, no. 1 (Winter, 1991): 13-16. 
Ellis, Cynthia. "Let's Talk Picc: The Excerpt List." Flute Talk 34, no. 7 (March, 2015): 48. [lists frequently requested orchestral excerpts with specific focus on Shostakovich excerpts for piccolo]

. "Let's Talk Picc: The Piccolo's Role." Flute Talk 35, no. 3 (November, 2015): 40. [discusses the challenges associated with common orchestrations used by composers such as doubling pitched percussion, doubling strings, doubling brass, and doubling woodwinds]

. "Let's Talk Picc: Vibrato." Flute Talk 34, no. 8 (April, 2015): 32. [compares vibrato similarities on flute and piccolo, piccolo specific vibrato pitfalls as well as artistic application of vibrato on piccolo]

- . "Let's Talk Picc: Embouchure Tips for Flexibility and Endurance." Flute Talk 33, no. 8 (April, 2014): 32. [basics of embouchure placement and shape, flexibility, and endurance]

. "Let's Talk Picc: Shhh...Time to Play Softly." Flute Talk 33, no. 7 (March, 2014): 40. [embouchure, air column, and fingers to develop playing at softer dynamics]

_ . "Let's Talk Picc: Fingerings and Hand Position." Flute Talk 32, no. 10 (July/August, 2013): 32. [addresses knowing and using alternate fingerings, trill fingers, and hand placement for balance and comfort]

__. "Let's Talk Picc: Urban Myths." Flute Talk 32, no. 7 (March, 2013): 40. [discusses anecdotal ideas about the piccolo such as piccolo ruining flute embouchure, oiling the piccolo, temperature and wooden piccolos, use of ear plugs, swabbing the piccolo]

_. "Let's Talk Picc: Dedication and Artistry, an Interview with Legendary Piccolo Player and Teacher William Hebert." Flute Talk 31, no. 9 (May/June, 2012): 10-15. [Ellis discusses William Hebert's career and life experiences as a performer and teacher and his thoughts on the role of the piccolo player, doubling, and teaching piccolo]

. "Let's Talk Picc: Etudes for Piccolo Practice." Flute Talk 31, no. 10 (July/August, 2012): 40. [discusses and compares piccolo specific etude books, Morris, Towarnicki, Wye]

_. "Let's Talk Picc: Piccolo Q \& A." Flute Talk 31, no. 8 (April, 2012): 32. [focuses on beginning piccolo and when students should begin playing piccolo, how to choose a player in school bands, objectives for older students, what flutists should know to be successful, alignment, tuning, choosing a piccolo for different venues, and how long to practice piccolo]

. "Let's Talk Picc: Piccolo Tone and Vibrato Tips." Flute Talk 32, no. 3(November, 2012): 32. [discusses concepts of a good embouchure, free flowing airstream, physical alignment, and application of vibrato]

. "Let's Talk Picc: Hearing Protection." Flute Talk 30, no. 7 (March, 2011): 40. [discusses the health benefits supporting the use of hearing protection while playing the piccolo] 
. "Let's Talk Picc: Programming for a Recital." Flute Talk 33, no. 2 (October, 2011): 32.

[Ellis discusses choosing repertoire for a piccolo recital and suggests considerations include, theme, length of piece, and speaking to the audience]

. "Let's Talk Picc: Purchasing a Piccolo." Flute Talk 30, no. 6 (February, 2011): 32. [aspects to consider when purchasing a piccolo such as price, materials, head joint style, bore, and key mechanism]

. "Let's Talk Picc: Thoughts on Piccolo Intonation." Flute Talk 30, no 8 (April, 2011): 32. [approaches to working on piccolo intonation focusing on embouchure placement, head joint alignment, pitch tendencies, use of alternate fingerings, and tuning in ensembles]

. "Let's Talk Picc: 30 Minutes for 30 Days." Flute Talk 30, no. 2 (October, 2010): 32. [importance of consistent daily piccolo practice addressing four key areas: air, embouchure, hands, alternate fingerings]

. "Let's Talk Picc: Questions and Answers." Flute Talk 29, no. 10 (July/August, 2010): 48. [answers questions asked by students about playing softly, alternate fingerings, how woods effect the tonal quality, how the crown effects tonal quality, oiling wood, using ear plugs]

—. "Let's Talk Picc: Breath Control on Piccolo." Flute Talk 28, no. 5 (January, 2009): 32. [piccolo position on the lips, use of phrase specific breath, and the need for stronger support and a faster air column]

_. "Let's Talk Picc: 10 Tricky Piccolo Trills." Flute Talk 27, no. 8 (April, 2008): 32. [provides suggestions on the most often encountered but difficult trills]

—. "Let's Talk Picc: Developing Nuanced Articulation." Flute Talk 48, no. 4 (December, 2008): 32. [importance of tongue placement in piccolo articulation due to the smaller size of the instrument]

—. "Let's Talk Picc: All about Grenadilla." Flute Talk 24 (May/June, 2005): 20. [characteristics of grenadilla wood in comparison to other types of wood used in the manufacturing of piccolos]

Fonville, John. "Let's Talk Picc: Open-holed Piccolo.” Flute Talk 15, no. 6 (February, 1996): 32, 31. [discusses the collaborative creation of a quarter-tone piccolo, the potential uses, repertoire written for the piccolo]

Foster, Robert. "The Stars and Stripes Forever." Flute Talk 24 (July/August, 2005): 40. [origins of the march in 1897 and the path to becoming the nation's march in 1983 as well as the new march form it introduced] 
George, Patricia, ed. "Let's Talk Picc: Q \& A with Jennifer Gunn." Flute Talk 35, no. 6 (February, 2016): 32. [personal practices regarding head joint alignment, caring for wooden piccolos, alternate fingerings, warm-ups, tuning, vibrato and tone, and suggested orchestral excerpts]

_. "Let's Talk Picc: Q \& A with Walfrid Kujala." Flute Talk 35, no. 8 (April, 2016): 32. [personal practices regarding head joint alignment, caring for wooden piccolos, alternate fingerings, warm-up, tuning, vibrato and tone, and suggested orchestral excerpts]

-. "Let's Talk Picc: Q \& A with Greg Milliren." Flute Talk 35, no. 7 (March, 2016): 48. [personal practices regarding head joint alignment, caring for wooden piccolos, alternate fingerings, warm-up, tuning, vibrato and tone, and suggested orchestral excerpts]

Gippo, Jan. "Let's Talk Picc: Delightful New Compositions." Flute Talk 29, no. 8 (April, 2010): 32. [the piccolo's place as a solo instrument and nine new works for the piccolo] -. "Let's Talk Picc: Piccolo Pieces from the Past Thirty Years." Flute Talk 30, no. 1 (September, 2010): 40. [lists repertoire that Gippo considers best representative of the last thirty years]

-. "Let's Talk Picc: Alternate Piccolo Fingerings." Flute Talk 24 (September, 2004): 20. [provides a concise chart for most used piccolo alternate fingerings]

—_. "Let's Talk Picc: Many Piccolos to Choose from." Flute Talk 22 (April, 2003): 32. [discusses important points when looking to purchasing a new piccolo]

- "Let's Talk Picc: Serious Piccolo Study Begins when Students Reach 8th Grade." Flute Talk 21 (March, 2002): 32.

. "A Flute Talk Classic: Special Piccolo Fingerings." Flute Talk 20 (November, 2000): 18-19.

—. "Let's Talk Picc: Piccolo Playing Hints." Flute Talk 18 (January, 1999): 32.

—. "Let's Talk Picc: The Piccolo, Then and Now." Flute Talk 18 (December, 1998): 31-32.

—_. "Let's Talk Picc: Piccolo Misconceptions." Flute Talk 16 (January, 1997): 31-32.

. "Let's Talk Picc: Selecting a Piccolo." Flute Talk 15 (April, 1996): 31-32.

Gonzalez, Jr, Abraham. "Let's Talk Picc: The 2007 International Piccolo Symposium." Flute Talk 27, no. 9 (May/June, 2008): 32. [first all piccolo symposium with guest artists Nicola Mazzanti, Lois Herbine, and Christine Beard] 
Halpin, Jessica. "Career Advice from the Orchestral Flute Section." Flutist Quarterly 31, no. 3 (Spring, 2006): 38-41. [insights of an orchestral flutist about starting an orchestral career, preparation for the audition, details of the audition process; description of the job of most orchestral flutists]

Helcher Yost, Regina. "Let's Talk Picc: Perfect Intonation on the Piccolo." Flute Talk 30, no. 10 (July/August, 2014): 40. [intonation challenges and tuning on the piccolo]

Helcher, Regina. "Let's Talk Picc: Advice from the Pros on Piccolo Auditions." Flute Talk 18 (September, 1998): 32.

Johnson, Rebecca. "The Mazzanti Method: Daily Exercises for Piccolo Nicola Mazzanti." Flutist Quarterly 40, no. 4 (Summer, 2015): 94.

Kirk, Tammy. "Let's Talk Picc: Piccolo Performances." Flute Talk 19 (November, 1999): 32. . "Let's Talk Picc: Selected Piccolo Solos." Flute Talk 16 (July/August, 1997): 34. [includes a concise list of suggested graded repertoire]

Laird, Joy Thomas,. "Piccolo Repertoire Currently Available." The Flutist Quarterly XVI, no. 1 (Winter, 1991): 23-37.

Lauwers, Anke. "The Road (almost) Not Taken." Flutist Quarterly 36, no. 2 (Winter, 2011): 367. [personal narrative which explores the author's experience of winning the 2010 National Flute Association piccolo solo competition]

Milliren, Gregory. "Let's Talk Picc: Piccolo Cross-Training Benefits for Your Flute Playing." Flute Talk 35, no. 2 (October, 2015): 42. [benefits of piccolo practice on flute playing with regards to topics of tension, embouchure, resonance and support, articulation, soft playing, intonation]

Morris, Pat. "Which Came First?" Flute 31, no. 1 (March, 2012): 44-5. [assesses whether repertoire defines the instrument used to play music or vice versa and includes a brief history of the development of the piccolo in comparison with the flute]

Morris, Patricia. "Warblings from a High Flyer." Pan: The Flute Magazine 23, no. 3 (September, 2004): 22-7. [discussion of Romantic repertoire for the piccolo]

Munster, Peter van, "Repertoire Catalogue: Piccolo, Alto Flute, Bass flute-Including Ca. 900 Works for Flute Choir or Flute Orchestra." Fontes Artis Musicae 53, no. 1 (January-March, 2006): 38-.

Nourse, Nancy. "What is a Piccolo?" Flute 31, no. 2 (June, 2012): 20-3. [discusses the definition of the piccolo, as defined by multiple source] 
Nourse, Nancy. "The Piccolo: Examining the Footnotes." Flutist Quarterly 11, no. 2 (Spring, 1990): 47-49.

Raphael, Nan. "Let's Talk Picc: Pacing Your Practice." Flute Talk 34, no. 2 (October, 2014): 40. [suggests a daily routine for flexibility and endurance with suggestions for performance preparation]

Rees, Carla. "Matjaž Debeljak." Pan: The Flute Magazine 27, no. 2 (June, 2008): 16-7. [interview with Matjaž Debeljak, a Slovenian piccolo player]

Rees, Robert. "Patricia Morris." Pan: The Flute Magazine 27, no. 2 (June, 2008): 28-. [interview discussing a presentation for British Flute Society (BFS) convention, about playing piccolo in an orchestra and the adjustments of transferring flute technique to piccolo]

Roberto, Richard. "Let's Talk Picc: Remastered Piccolo Solos." Flute Talk 17 (January, 1998): 32. [the Golden Age of the piccolo (1897-1928) and the popular solos that have been rerecorded]

Rudolph, Kathleen. "Spotlight on Woodwinds: The High(Er) Life: Transforming Good Flutists into Fearless Piccolo Players." Canadian Winds: The Journal of the Canadian Band Association 7, no. 2 (2009): 79-80. [tips and resources for teachers transitioning their students to the piccolo with a focus on choosing the right student, selecting the right instrument, teaching the embouchure and other basics, giving the first lessons, and choosing music]

Stanhope, Paul. "Writing a New Piccolo Concerto: A Composer's Notebook." Pan: The Journal of the British Flute Society 34, no. 1 (March, 2015): 28-31. [author's experience of writing a piccolo concerto for Melbourne Symphony Orchestra (MSO)]

Taylor, Laurence. "Approach to the Piccolo: Part I." Instrumentalist 9 (December, 1955): 24-25.

—. "Approach to the Piccolo: Part II." Instrumentalist 10 (January, 1956): 25-26.

—. "Approach to the Piccolo: Part III." Instrumentalist 10 (February, 1956): 26-27.

Trübcher, Roz. "Choosing a Professional Piccolo." Pan: The Journal of the British Flute Society 34, no. 1 (March, 2015): 32-4. [author's views on how to choose a professional piccolo, buying first piccolo, selection of instruments, views of Matjaz Debeljak, on tone and intonation]

Verhoyen, Peter. "Let's Talk Picc: On Playing Piccolo." Flute Talk 33, no. 4 (December, 2013): 32. [practicing to develop embouchure, vibrato, articulation, and technique]

Watanabe, Mihoko. “The Essence of Mei." Flutist's Quarterly 33, no. 3 (Spring, 2008): 16-24. [discusses the noh-kan flute in Japanese culture] 
White, Joanna Cowan. "Walfrid Kujala, Orchestral "Untangler"." Flutist Quarterly 31, no. 1 (Fall, 2005): 56-60. [his formative influences to his career, his style of teaching, also offers information on his published books about the essentials of studying flute and piccolo]

Williams, Morgan. "Let's Talk Picc: Piccolo Trill Fingerings." Flute Talk 17 (December, 1997): 32. [comprehensive trill fingering chart as well as some of the functionality of the fingerings] 